\title{
Extração de conhecimento de Redes Neurais Artificiais
}

\author{
Edmar Martineli \\ Orientação: \\ $\operatorname{Prof}^{\underline{0}} \operatorname{Dr}^{\mathfrak{o}}$ André Carlos Ponce de Leon Ferreira de Carvalho
}

Dissertação apresentada ao Instituto de Ciências Matemáticas e de Computação - USP, como parte dos requisitos para a obtenção do título de Mestre em Ciências - Área de Ciências de Computação e Matemática Computacional.

USP - São Carlos

Julho de 1999 
A Deus, pela oportunidade, aos meus pais, Gervásio e Tarcila, pelo incentivo e apoio, às minhas irmãs, Edna e Edilene, pela compreensão, e especialmente à minha esposa, Silvia, por me acompanhar e dar forças durante os momentos mais difíceis. 


\section{Agradecimentos}

Ao Professor André pela excelente orientação, ajuda, amizade e incentivo em todos os momentos, contribuindo de maneira decisiva para a realização deste trabalho.

Às Professoras Solange e Calolina, membros do grupo de Inteligência Computacional, que contribuíram com suas críticas e ajuda em algumas das fases do meu trabalho.

Ao colega Hélio Diniz pela colaboração na realização de vários experimentos e redação de alguns tópicos desta dissertação.

À todos os professores e funcionários do ICMC que de algum modo colaboraram com meus estudos realizados neste instituto. trabalho.

À CAPES pelo apoio financeiro fornecido durante parte do desenvolvimento deste

Principalmente à sociedade brasileira que contribui diretamente com o ensino e a pesquisa em universidades públicas através do pagamento de impostos. 


\section{Sumário}

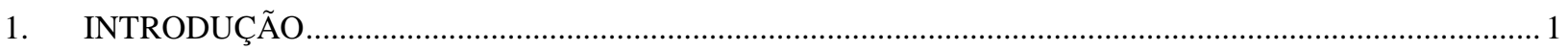

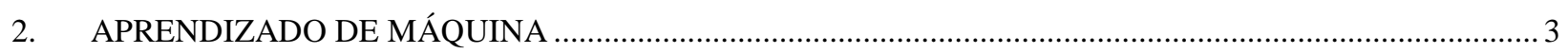

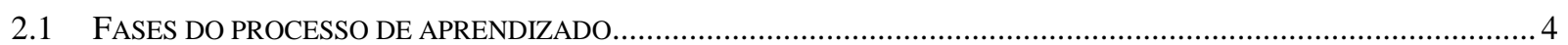

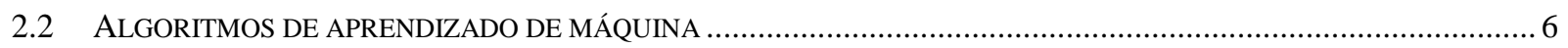

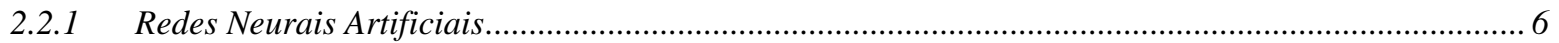

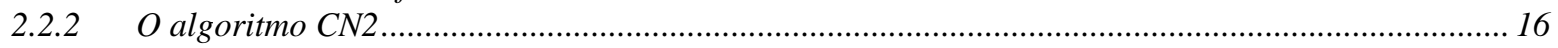

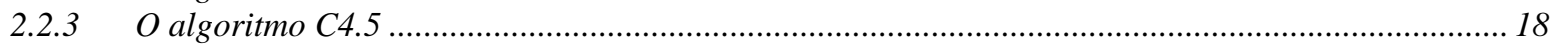

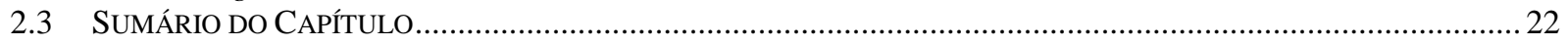

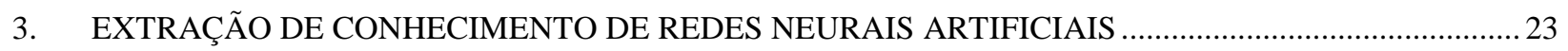

3.1 ClASSIFICAÇÃO DE ALGORITMOS DE EXTRAÇÃO DE CONHECIMENTO DE RNAS ...........................................24

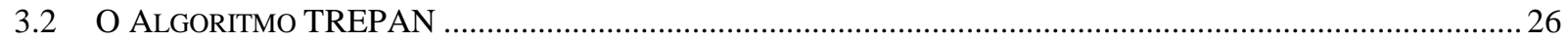

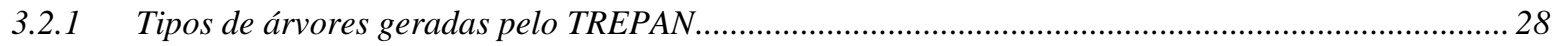

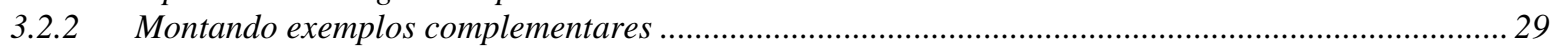

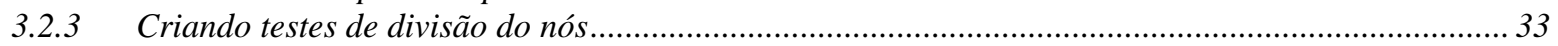

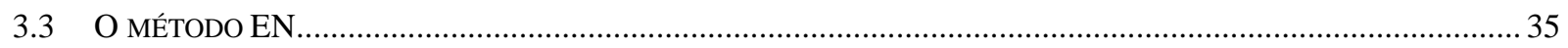

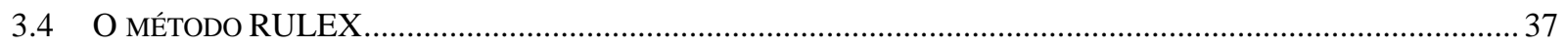

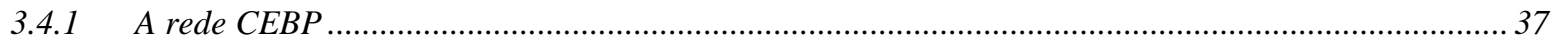

3.4.2 Fixando respostas localmente em cada unidade ............................................................................. 39

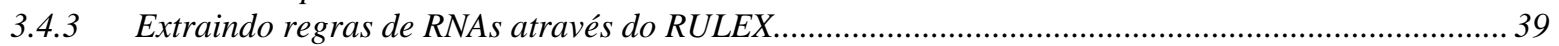

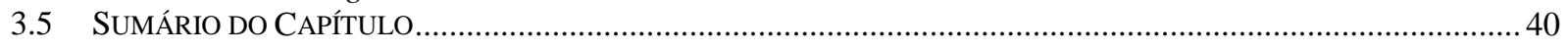

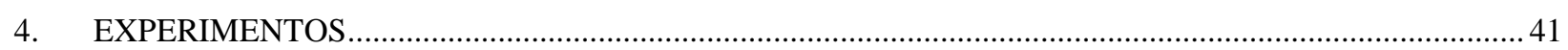

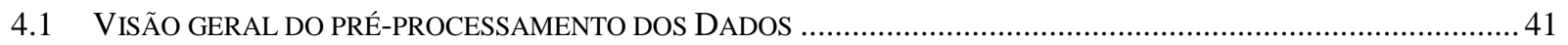

4.1.1 Pré-processamento dos dados para as RNAs .................................................................................. 41

4.1.2 Pré-processamento dos dados para o CN2 e C4.5 ........................................................................ 43

4.1.3 Divisão do conjunto de dados ........................................................................................................ 43

4.1.4 Pré-processamento dos dados para o algoritmo TREPAN ........................................................... 45

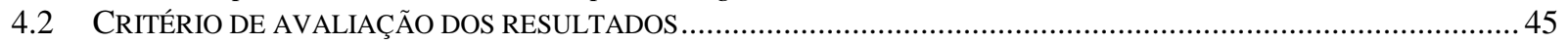

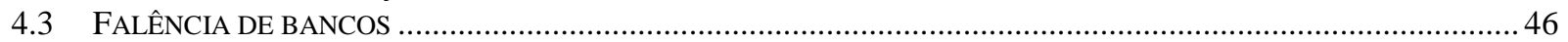

4.3.1 Divisão dos conjuntos de dados e acréscimo de dados com ruído................................................... 49

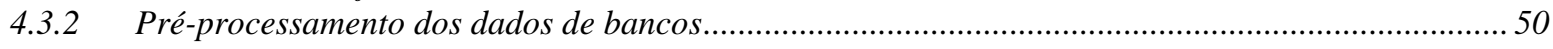

4.3.3 Resultados dos Experimentos.......................................................................................... 51

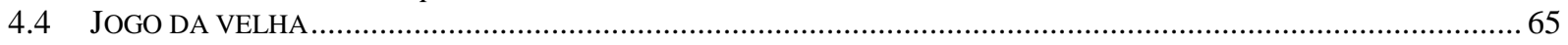

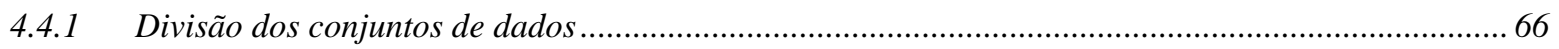

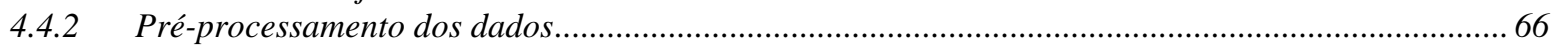

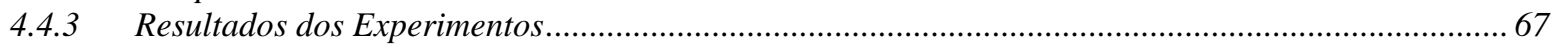

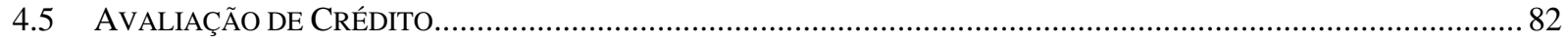

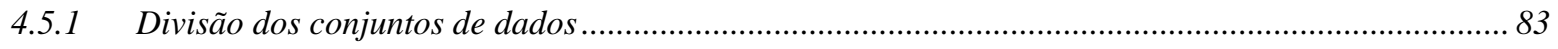

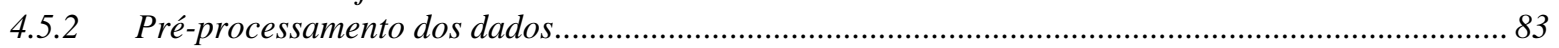

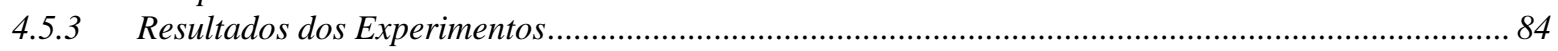

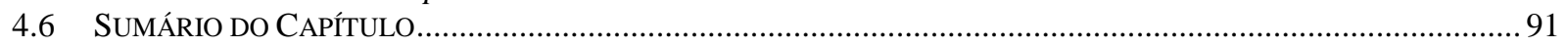

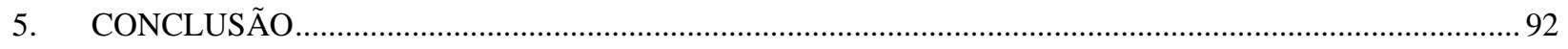

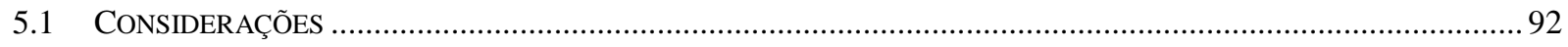

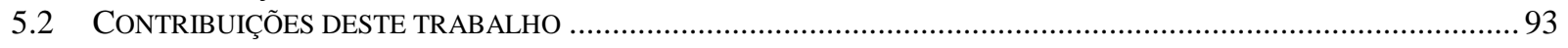

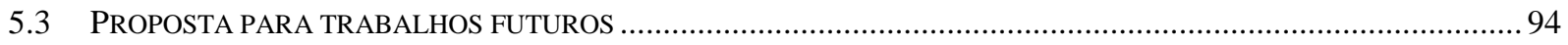

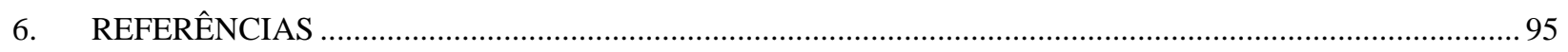

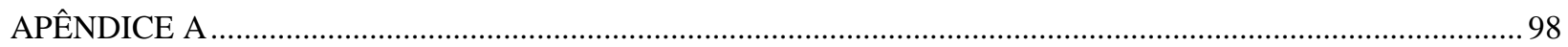




\section{Lista de Figuras}

Figura 1: Processo de aprendizado simplificado................................................................ 4

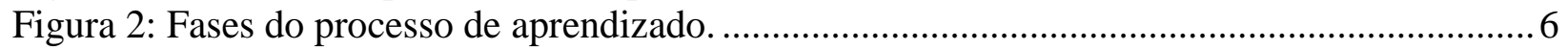

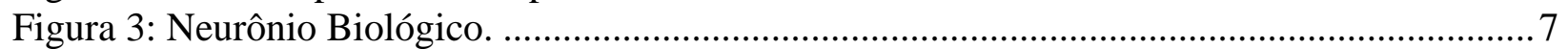

Figura 4: Neurônio Artificial........................................................................................... 9

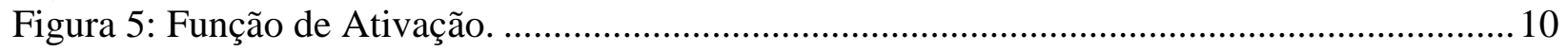

Figura 6: Conexões em uma Rede Neural Artificial. ................................................................ 12

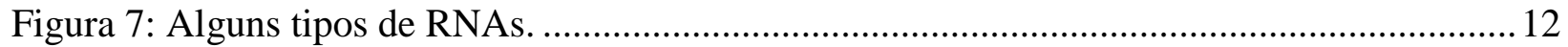

Figura 8: Esboço do algoritmo de aprendizado Delta Rule. .................................................... 14

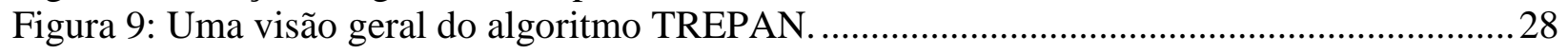

Figura 10: Uma visão geral do algoritmo MonteAmostras.....................................................30

Figura 11: Representação de condições a serem satisfeitas em uma Árvore de Decisão. .............31

Figura 12: Modelo de distribuição adotado para cada nó. ...........................................................32

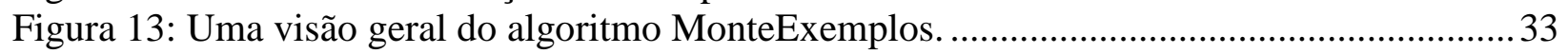

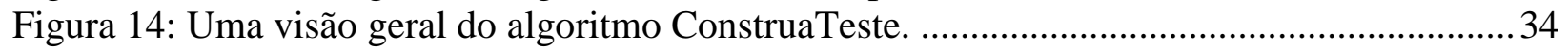

Figura 15: Uma visão geral do algoritmo ConstruaTesteMofN............................................. 34

Figura 16: Construção de um pico local a partir de duas sigmoids.............................................. 38

Figura 17: Proporções das instituições bancárias em relação ao porte. ......................................46

Figura 18: Proporções das instituições bancárias com relação a situação de solvência e insolvência...................................................................................................... 47

Figura 19: Desempenho da Árvore de Decisão do C4.5 no conjunto de teste............................53

Figura 20: Árvore de Decisão gerada pelo C4.5 ....................................................................53

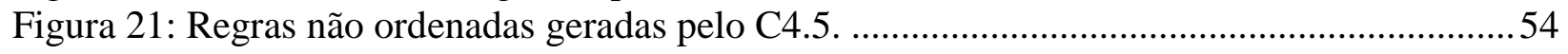

Figura 22: Desempenho do CN2 no conjunto de testes. ......................................................55

Figura 23: Conjunto de regras produzidas pelo $\mathrm{CN} 2$.............................................................56

Figura 24: Desempenho da RNA no teste utilizando 26 atributos........................................57

Figura 25: Desempenho da RNA no teste utilizando 10 atributos...........................................58

Figura 26: Desempenho da RNA no conjunto de teste utilizando 10 atributos e junção dos conjuntos de treinamento e de teste.......................................................................59

Figura 27: Desempenho das RNAs no teste utilizando 10 atributos e diversos níveis de ruído...60

Figura 28: Desempenho do TREPAN no conjunto de teste.................................................61

Figura 29: Árvore de Decisão gerada pelo método teste-simples do algoritmo TREPAN...........62

Figura 30: Árvore de gerada pelo método disjuntivo do algoritmo TREPAN..........................63

Figura 31: Árvore de gerada pelo método m-de-n do algoritmo TREPAN. .............................6 63

Figura 32: Melhores resultados alcançados por cada um dos métodos na fase de testes..............64

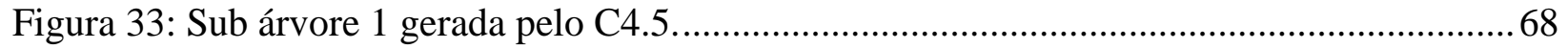

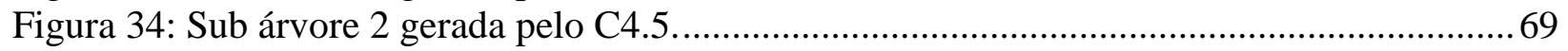

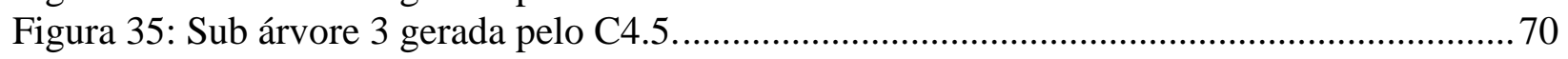

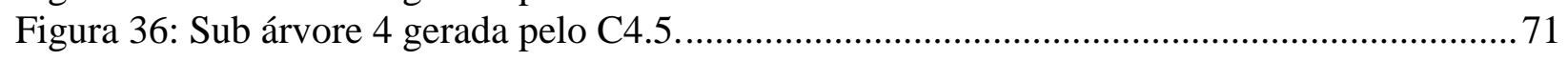

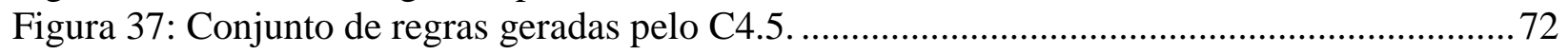

Figura 38: Conjunto de regras geradas pelo CN2 ............................................................. 73

Figura 39: Sub Árvore de Decisão 1 gerada pelo método teste-simples do TREPAN. ................75

Figura 40: Sub Árvore de Decisão 2 gerada pelo método teste-simples do TREPAN. ................ 76 
Figura 41: Sub Árvore de Decisão 3 gerada pelo método teste-simples do TREPAN. ................77

Figura 42: Sub Árvore de Decisão 4 gerada pelo método teste-simples do TREPAN................78

Figura 43: Árvore de Decisão gerada pelo método disjuntivo do TREPAN. ............................... 79

Figura 44: Árvore de Decisão gerada pelo método m-de-n do TREPAN.................................... 80

Figura 45: Desempenho por classes alcançado pelas RNAs e pelos algoritmos C4.5, CN2 e

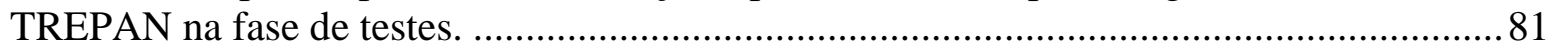

Figura 46: Árvore de Decisão extraída pelo algoritmo C4.5 árvore. .......................................... 85

Figura 47: Regras extraídas pelo algoritmo C4.5 regra. .......................................................... 85

Figura 48: Conjunto de regras extraídas pelo algoritmo CN2 ...................................................86

Figura 49: Árvore de Decisão extraída pelo método teste-simples do TREPAN........................88

Figura 50: Árvore de Decisão extraída pelo método disjuntivo do TREPAN. ..............................89

Figura 51: Árvore de Decisão extraída pelo método m-de-n do TREPAN. .................................89

Figura 52: Resultado por classes para as RNAs e para os algoritmos C4.5, CN2, RNA e

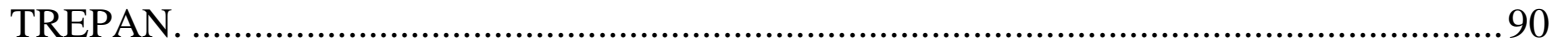

Figura 53: Eliminação do bias de um neurônio............................................................................ 98

Figura 54: Neurônios selecionados pelo método Por que soma do EN aplicado à classe de

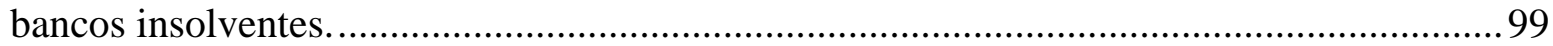

Figura 55: Neurônios selecionados pelo método Por que soma do EN aplicado à classe de

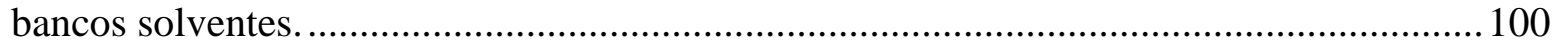

Figura 56: Neurônios e conexões selecionados pelo método Por que ccg do EN aplicado à classe

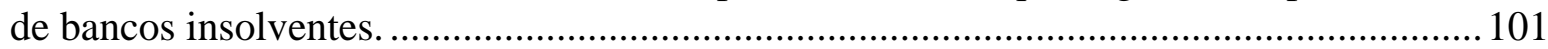

Figura 57: Neurônios e conexões selecionados pelo método Por que ccg do EN aplicado à classe

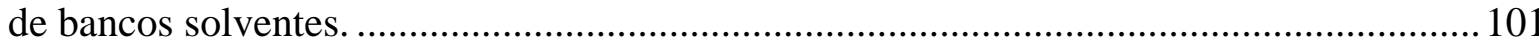

Figura 58: Neurônios e conexões selecionados pelo método Por que pau do EN aplicado à classe de bancos insolventes. ....................................................................................... 102

Figura 59: Neurônios e conexões selecionados pelo método Por que pau do EN aplicado à classe

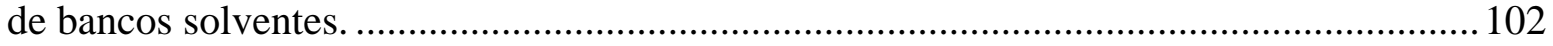

Figura 60: Neurônios selecionados pelo método Como soma do EN aplicado às entradas........ 103

Figura 61: Neurônios selecionados pelo método Como ccg do EN aplicado às entradas. ......... 104

Figura 62: Neurônios selecionados pelo método Como pau do EN aplicado às entradas. .......... 104 


\section{Lista de Tabelas}

Tabela 1: Defasagem entre a data de falência do banco e a última informação disponível..........48

Tabela 2: Desempenho das Árvores de Decisão gerada pelo C4.5 .......................................52

Tabela 3: Desempenho das regras gerada pelo C4.5 ........................................................52

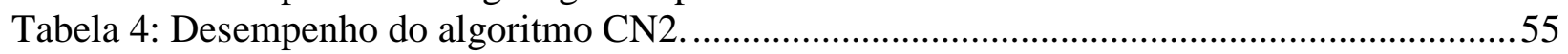

Tabela 5: Desempenho da RNA utilizando 26 atributos ..................................................... 57

Tabela 6: Desempenho da RNA utilizando 10 atributos..........................................................58

Tabela 7: Desempenho da RNA utilizando 10 atributos e junção dos conjuntos de treinamento e

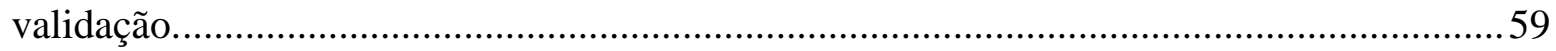

Tabela 8: Desempenho alcançado pelo algoritmo TREPAN. .....................................................61

Tabela 9: Melhores taxas de acertos alcançadas pelas RNAs e pelos algoritmos C4.5, CN2 e

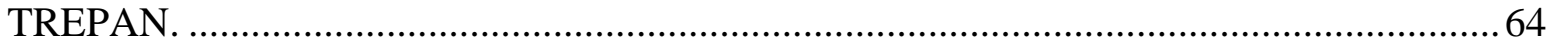

Tabela 10: Desempenho alcançado pelo algoritmo C4.5 árvore.................................................68

Tabela 11: Desempenho alcançado pelo C4.5 regra. .................................................................. 72

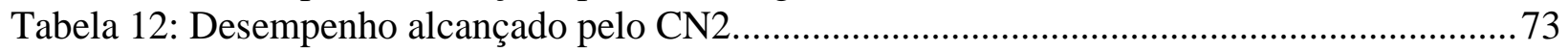

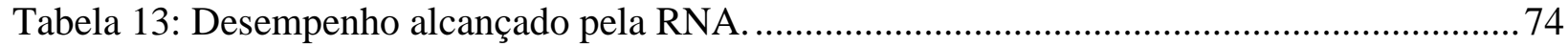

Tabela 14: Desempenho alcançado pelo algoritmo TREPAN...............................................75

Tabela 15: Desempenho alcançado pelas RNAs e pelos algoritmos C4.5, CN2 e TREPAN na

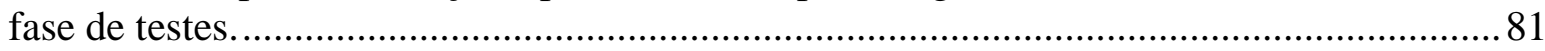

Tabela 16: Taxa de acertos alcançada pelo algoritmo C4.5 árvore............................................ 84

Tabela 17: Taxa de acertos alcançada pelo algoritmo C4.5 regra..........................................85

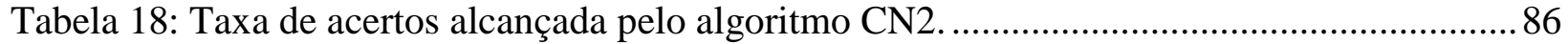

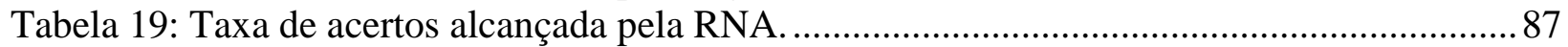

Tabela 20: Taxa de acertos conseguida pelo algoritmo TREPAN .............................................8 88

Tabela 21: Desempenho alcançado pelas RNAs e pelos algoritmos C4.5, CN2 e TREPAN......89

Tabela 22: Método Por que soma do EN aplicado à classe de bancos insolventes......................99

Tabela 23: Método Por que soma do EN aplicado à classe de bancos solventes...................... 100

Tabela 24: Método Por que ccg do EN aplicado à classe de bancos insolventes....................... 100

Tabela 25: Método Por que ccg do EN aplicado à classe de bancos solventes........................... 101

Tabela 26: Método Por que pau do EN aplicado à classe de bancos insolventes. .................... 102

Tabela 27: Método Por que pau do EN aplicado à classe de bancos solventes. ........................ 102

Tabela 28: Método Como soma do EN aplicado às entradas.................................................. 103

Tabela 29: Método Como ccg do EN aplicado às entradas................................................... 103

Tabela 30: Método Como pau do EN aplicado às entradas. ................................................... 104 


\section{Resumo}

Este trabalho descreve experimentos realizados com Redes Neurais Artificiais e algoritmos de aprendizado simbólico. Também são investigados dois algoritmos de extração de conhecimento de Redes Neurais Artificiais. Esses experimentos são realizados com três bases de dados com o objetivo de comparar os desempenhos obtidos. As bases de dados utilizadas neste trabalho são: dados de falência de bancos brasileiros, dados do jogo da velha e dados de análise de crédito. São aplicadas sobre os dados três técnicas para melhoria de seus desempenhos. Essas técnicas são: partição pela menor classe, acréscimo de ruído nos exemplos da menor classe e seleção de atributos mais relevantes. Além da análise do desempenho obtido, também é feita uma análise da dificuldade de compreensão do conhecimento extraído por cada método em cada uma das bases de dados. 


\section{Abstract}

This work describes experiments carried out witch Artificial Neural Networks and symbolic learning algorithms. Two algorithms for knowledge extraction from Artificial Neural Networks are also investigates. This experiments are performed whit three data set with the objective of compare the performance obtained. The data set used in this work are: Brazilians banks bankruptcy data set, tic-tac-toe data set and credit analysis data set. Three techniques for data set performance improvements are investigates. These techniques are: partition for the smallest class, noise increment in the examples of the smallest class and selection of more important attributes. Besides the analysis of the performance obtained, an analysis of the understanding difficulty of the knowledge extracted by each method in each data bases is made. 


\section{Introdução}

Neste trabalho são apresentados alguns métodos de aprendizado de máquina capazes de extrair conhecimentos de conjuntos de dados. O conhecimento extraído pode ser representado na forma de Regras de Produção ou Árvores de Decisão, como é o caso dos algoritmos CN2 [CLA89] e C4.5 [QUI93], respectivamente. O conhecimento também pode ser representado através de um complexo conjunto de parâmetros interligados por fórmulas matemáticas não triviais, como é o caso das Redes Neurais Artificiais (RNAs) [BEA92][HAY99].

Cada uma das três formas de representação de conhecimento mencionadas possui suas vantagens e desvantagens. As Regras de Produção e Árvores de Decisão exigem um esforço maior de implementação e manutenção dentro de um sistema computacional. Por outro lado, são mais fáceis de serem compreendidas pelos seres humanos. As RNAs são implementadas e alteradas com maior facilidade. Por outro lado, entender o que acontece em uma RNA é uma tarefa complicada.

Visando uma maior compreensão do conhecimento representado através de RNAs, este trabalho investiga algoritmos de extração de conhecimento de RNAs. São apresentados os algoritmos TREPAN e RULEX que transformam o conhecimento de uma RNA para a forma de Árvore de Decisão e Regras de Produção, respectivamente. Também é apresentado o algoritmo EN que informa quais são os neurônios mais importantes de uma RNA para a classificação/regressão de uma dada base de dados.

As RNAs, também conhecidas como Modelos Conexionistas, foram propostas para resolver problemas em que os seres humanos alcançam boa performance e são de difícil tratamento pelos computadores tradicionais. Entre estes problemas, talvez o exemplo mais clássico seja o reconhecimento de imagens, como o rosto de pessoas. Os modelos de RNAs são geralmente compostos por várias unidades de processamento geralmente não lineares (neurônios), que trabalham em paralelo e são organizados em um padrão semelhante às Redes Neurais Biológicas. A modelagem matemática de uma RNA é realizada basicamente em termo de seus neurônios, sua arquitetura e seus paradigmas e algoritmo de aprendizado. 
O interesse crescente em RNAs se deve principalmente ao seu bom desempenho na solução de problemas, como o reconhecimento de padrões. A capacidade de adaptação de uma Rede Neural é outra característica muito importante. A ausência da necessidade de suposição inicial de uma hipótese, dispensa a necessidade de regressões estatísticas para encontrar parâmetros de um suposto modelo de comportamento. A suposição do modelo fica a cargo das conexões e neurônios da RNA.

Um dos grandes problemas encontrados na aplicação de Redes Neurais Artificiais é que elas não explicam o raciocínio envolvido na solução do problema. Isso pode levar seus usuários a não confiar nos resultados obtidos e ao conseqüente abandono da solução encontrada. Um outro caso seria a aceitação dos valores fornecidos pela Rede Neural Artificial sem questionamento, o que torna o processo mais susceptível a erros.

O objetivo deste trabalho é a investigação da utilização de Redes Neurais Artificiais em problemas reais e aplicação de técnicas de extração de conhecimento de Redes Neurais Artificiais treinadas. As técnicas de extração de conhecimento de RNA auxiliam o entendimento dos resultados obtidos. Sem a capacidade de explicação, as RNAs são vistas atualmente como “caixas pretas" capazes de fornecer um resultado baseado em um dado de entrada, mas incapazes de explicar como chegaram ao resultado fornecido.

Este texto está organizado da seguinte maneira: O Capítulo 2 apresenta uma visão geral de aprendizado de máquina. Concentra-se em alguns algoritmos de aprendizado de máquina, no caso CN2, C4.5 e Redes Neurais Artificiais. No Capítulo 3 são descritos 3 algoritmos de extração de conhecimento de Redes Neurais Artificiais. Estes algoritmos são: o TREPAN, o EN e o RULEX. O Capítulo 4 mostra experimentos realizados com os algoritmos CN2, C4.5, Redes Neurais Artificiais e TREPAN, cruzando e analisando estes resultados. O Capítulo 5 finaliza esta dissertação apresentando conclusões e propondo trabalhos futuros. 


\section{Aprendizado de Máquina}

A aquisição de conhecimento é geralmente a atividade que demanda maior esforço durante a construção de Sistemas Baseados em Conhecimento. Esta tarefa é geralmente executada com auxílio direto de especialistas, tratando conceitos abstratos.

A área de Aprendizado de Máquina surgiu da tentativa de amenizar tal problema, propiciando uma forma alternativa de extração de conhecimento do ambiente através de exemplos. Este conhecimento extraído pode ser armazenado de várias formas, dentre elas, podem ser citadas:

- Regras de Produção;

- Árvores de Decisão;

- Redes Neurais Artificiais (através de sua arquitetura e seus pesos).

Regras de Produção e Árvores de Decisão são obtidos através de algoritmos simbólicos como, por exemplo, o CN2 [CLA89] e C4.5 [QUI93]. Os algoritmos simbólicos CN2 e C4.5 expressam o conhecimento extraído de um ambiente em uma maneira compreensível para os seres humano. Por outro lado, as Redes Neurais Artificias representam este conhecimento através dos pesos das conexões existentes entre os seus neurônios e sua arquitetura, que não são tão compreensíveis.

O enfoque principal de Aprendizado de Máquina são os dados ou exemplos considerados para representar o ambiente em questão. Os dados colhidos do mundo real são geralmente carregados de ruídos. As possíveis causas destes ruídos são, de acordo com Clark [CLA87]:

- Ruídos provocados por transcrição: os exemplos representativos de um ambiente são apresentados sob a forma de registro. Os processos de criação destes registros e transcrição dos atributos dos exemplos são geralmente realizados com erros devido à insuficiência de informação, má classificação por especialistas, etc. 
- Ruídos provocados por linguagem de descrição insuficiente: nem sempre é possível obter uma linguagem de descrição que consiga fornecer os subsídios necessários para cobrir todos os aspectos que devem ser considerados em um problema.

A presença de ruídos nos exemplos provoca o aparecimento de exceções. Tanto os algoritmos de aprendizado CN2 e C4.5 quantos as RNAs conseguem propiciar um tratamento razoável destas exceções, obtendo um bom desempenho na tarefa de classificação.

\subsection{Fases do processo de aprendizado}

Sobre um ponto de vista simplista, ilustrado na Figura 1, os algoritmos CN2, C4.5 e RNAs podem ser encarados como classificadores que recebem estímulos de entrada e geram respostas, de acordo com o conhecimento adquirido por um processo de aprendizado.

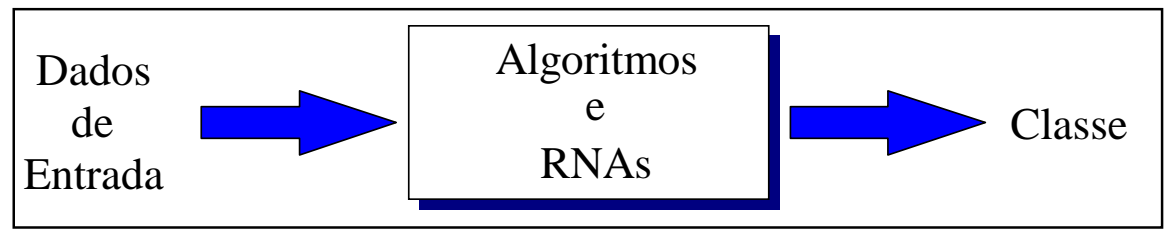

Figura 1: Processo de aprendizado simplificado.

As principais diferença entre estas técnicas estão na forma de representação e manipulação do conhecimento extraído. As Regras de Produção e Árvores de Decisão, geradas pelos algoritmos CN2 e C4.5, são fáceis de serem analisadas e compreendidas por especialistas. A identificação de regras relevantes sobre um determinado domínio pode ser mais interessante do que a obtenção de um classificador de alta performance.

O conhecimento extraído utilizando RNAs é representado através de um conjunto de valores, sem significado explícito, que são pesos das conexões existentes entre seus neurônios. Por outro lado, as RNAs são sistemas independentes que conseguem manipular este conhecimento de forma mais direta, sem a necessidade da construção de um Motor de Inferência.

As fases do processo de aprendizado dos algoritmos CN2, C4.5 e das RNAs são bastante semelhantes, como ilustra a Figura 2. O ponto de partida para todas as técnicas é a obtenção dos 
dados que representam um determinado domínio. Em todas essas abordagens, é necessário uma etapa de pré-processamento anterior ao início do treinamento.

O pré-processamento dos dados exigidos pelo $\mathrm{CN} 2$ e $\mathrm{C} 4.5$ consiste basicamente da declaração dos tipos de atributos e a conversão dos dados para o formato exigido pelos algoritmos. O fato destes algoritmos trabalharem com atributos discretos, numéricos, desconhecidos e irrelevantes reduz drasticamente o esforço de pré-processamento.

O pré-processamento exigido pelas RNAs já é um pouco mais complexo. Os atributos numéricos devem ser normalizados dentro de uma escala de valores. Os atributos simbólicos precisam ser codificados em valores numéricos. Os valores desconhecidos precisam ser preenchidos utilizando-se de métodos como médias dos valores do atributo e definição de novos valores.

O conjunto de dados devidamente pré-processado deve ser então dividido em subconjuntos distintos de treinamento, validação e teste. Os algoritmos CN2 e C4.5 utilizam apenas conjuntos de treinamento e teste. As RNAs podem utilizar o conjunto de validação como um critério de parada do processo de aprendizagem.

A fase de testes é a ultima etapa do processo e é necessária para verificar se a extração de conhecimento foi bem sucedida. Através da utilização do conjunto de testes, que é constituído por exemplos nunca vistos durante o treinamento, é possível verificar se o conhecimento obtido é bom e genérico o suficiente para o reconhecimento destes exemplos. 


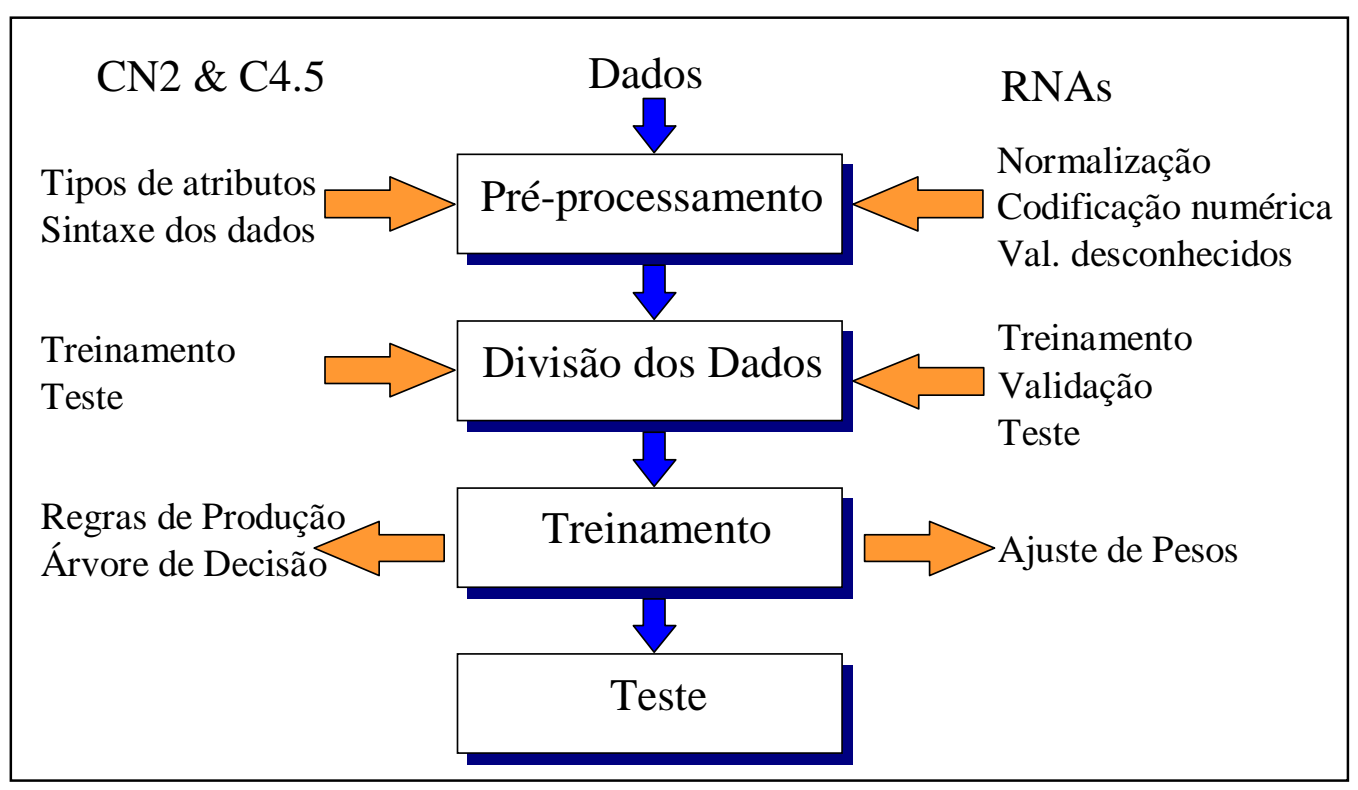

Figura 2: Fases do processo de aprendizado.

\subsection{Algoritmos de aprendizado de máquina}

Existem vários algoritmos de aprendizado de máquina. A seguir é dado uma visão geral dos três algoritmos utilizados nesta dissertação. Seguindo a linha conexionista são apresentadas as Redes Neurais Artificiais e seguindo a linha simbolista são apresentados os algoritmos C4.5 e CN2.

\subsubsection{Redes Neurais Artificiais}

As Redes Neurais Artificiais representam um das áreas de aprendizado de máquina que tem apresentado uma grande expansão. A seguir é feita uma discussão sobre o que é e como funciona uma Rede Neural Artificial. 


\subsubsection{Inspiração}

Como descrito em [HAY99], uma Rede Neural Artificial (RNA) é um modelo matemático cuja grande inspiração é o cérebro humano. O cérebro humano é uma estrutura de processamento altamente complexa, não linear e paralela. Ao contrário da arquitetura tradicional de computadores de Von Neumann (um único processador seqüencial e complexo), o cérebro humano possui uma grande quantidade de processadores conhecidos como neurônios que executam funções mais simples. O neurônio é uma célula um tanto diferente das outras existente no corpo humano. Entre outras coisas, ele apresenta a capacidade de transmissão de impulsos nervosos à outros neurônios e células musculares.

No corpo humano, existe uma grande variedade de tipos de neurônios cujas funções ainda não são totalmente conhecidas. Contudo, estes neurônios são basicamente constituídos de dentritos, corpo celular (soma) e axônio. Os dentritos são as portas de entradas de impulsos químicos para o neurônio. O corpo celular recebe as entradas provenientes dos dentritos, soma estas entradas seguindo algum modelo e gera um sinal de ativação ou não para o axônio. $\mathrm{O}$ axônio é o canal de transmissão do impulso elétrico de saída produzido pelo neurônio. O fluxo de informação dentro de um neurônio ocorre sempre no sentido dos dentritos para o axônio. A representação de um neurônio biológico é ilustrada na Figura 3.

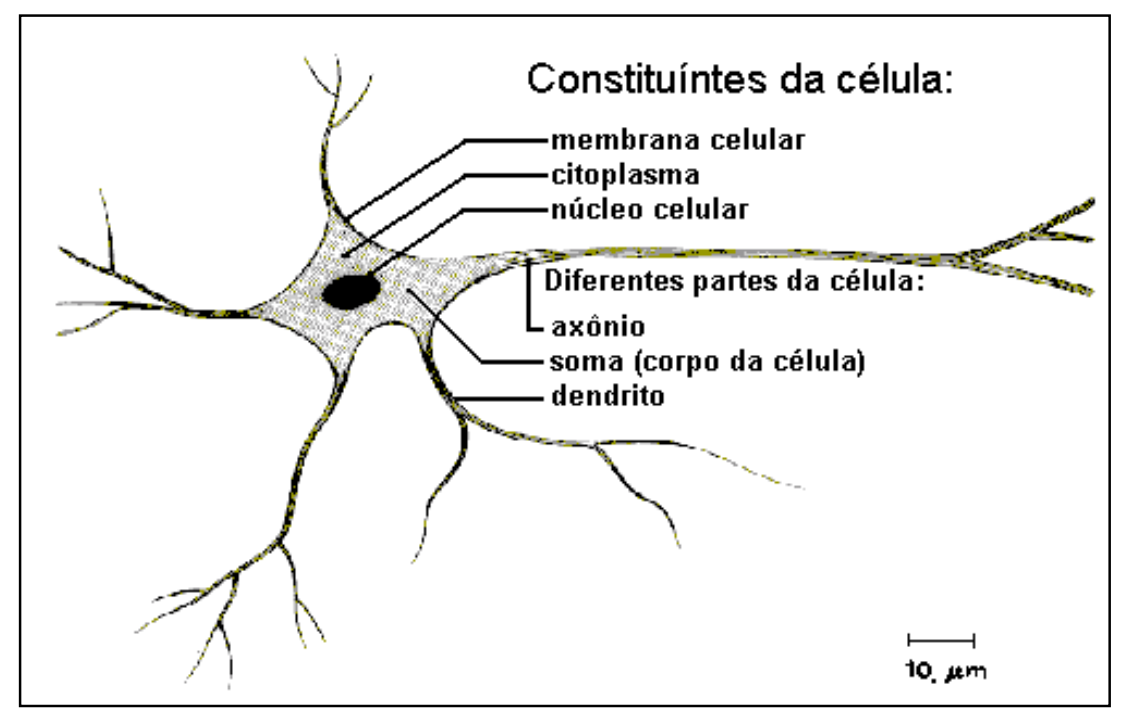

Figura 3: Neurônio Biológico.

No cérebro humano, os neurônios são altamente conectados através de regiões conhecidas como sinapse. A sinapse pode ser inibitória ou excitatória. Uma sinapse excitatória 
contribui positivamente para a ativação de um neurônio. Por outro lado, uma sinapse inibitória influencia a desativação de um neurônio. Sinapses diferentes possuem diferentes intensidade, que influenciam em escalas maiores ou menores no comportamento de outros neurônios.

Os modelos de Redes Neurais Artificiais são geralmente compostos por várias unidades de processamento não lineares (neurônios simplificados) que trabalham em paralelo e são organizados em um padrão semelhante às Redes Neurais Biológicas. A modelagem matemática de uma RNA depende basicamente de seus neurônios, sua arquitetura e seu paradigma e algoritmo de aprendizagem.

As Redes Neurais Artificiais, também conhecidas como Modelos Conexionistas, foram propostas para resolver problemas em que os seres humano alcançam boa performance e que não têm sido eficientemente resolvidos pelos computadores tradicionais. As Redes Neurais Artificiais têm sido largamente utilizadas em problemas práticos devido a algumas características provenientes de sua inspiração original, o cérebro humano. Entre estas características, as principais são [HAY99]:

1) Não linearidade: um neurônio é um dispositivo não linear;

2) Mapeamento de entradas e saídas: habilidade de mapeamento de um conjunto de entradas para um conjunto de saídas;

3) Adaptabilidade: uma RNA é treinada para atuar em um ambiente e pode ser facilmente adaptada para abranger mudanças ocorridas neste ambiente;

4) Tolerância à falhas: uma RNA é capaz de funcionar mesmo que alguns neurônios ou conexões sejam perdidos ou danificados.

Problemas que podem utilizar Redes Neurais Artificiais incluem: reconhecimento de imagens, classificação de empresas solventes ou insolventes e previsão de preços de ações na bolsas de valores.

O processo de modelagem de uma RNA pode ser realizado a nível dos seguintes elementos básicos: neurônio, arquitetura, paradigma e algoritmo de aprendizado. As próximas seções discutem estes elementos. 


\subsubsection{Neurônios Artificiais}

Existe uma grande variedade de modelos de neurônios propostos e estudados. As diferenças básicas entre esses modelos concentram-se no tipo de entrada (binária ou contínua), tipo de saída e função de ativação [HAY99]. A representação de um neurônio artificial é ilustrada na Figura 4.

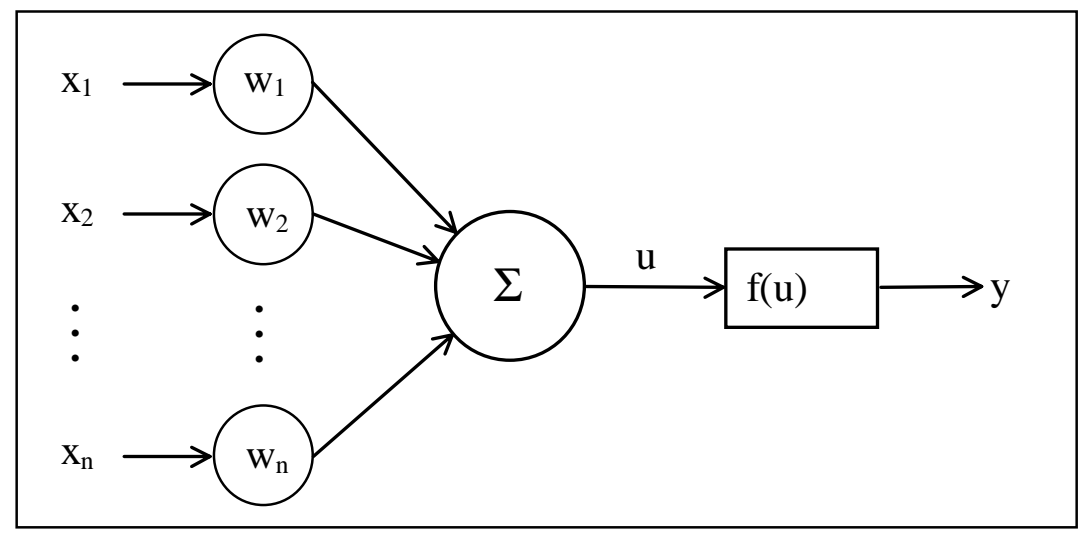

Figura 4: Neurônio Artificial.

O estado de ativação dos neurônios é definido através da função de ativação e representa a situação destes neurônio dentro da RNA. O estado de ativação de um neurônio pode assumir valores binários (0 para inativo e 1 para ativo), bipolares (-1 e 1) ou valores reais nos intervalos de 0 a 1 ou -1 a 1.

A função de ativação é calculada a partir de um somatório envolvendo os estímulos de entrada de um neurônio e a intensidade das sinapses associadas à cada uma destas entradas, gerando um estado de ativação. Os estímulos de entrada de um neurônio são representados através de um vetor de entrada $\mathrm{X}=\left[\begin{array}{llll}\mathrm{x}_{1} & \mathrm{x}_{2} & \ldots & \mathrm{x}_{\mathrm{n}}\end{array}\right]^{\mathrm{T}}$, e a intensidade da sinapse através de um vetor de pesos $\mathrm{W}=\left(\begin{array}{llll}\mathrm{w}_{1} & \mathrm{~W}_{2} & \ldots & \mathrm{W}_{\mathrm{n}}\end{array}\right]^{\mathrm{T}}$. Os estímulos de entrada do neurônio são ponderados pelo vetor de pesos através da Equação 1.

$$
\mathrm{u}=\sum_{\mathrm{i}=1}^{\mathrm{n}} \mathrm{w}_{\mathrm{i}} x_{\mathrm{i}}-\theta
$$


O valor $\theta$ é conhecido como threshold do neurônio. O valor desta ponderação é submetido à função de ativação $f(u)$. Existe uma grande variedade de funções de ativação. As principais funções são ilustradas na Figura 5.

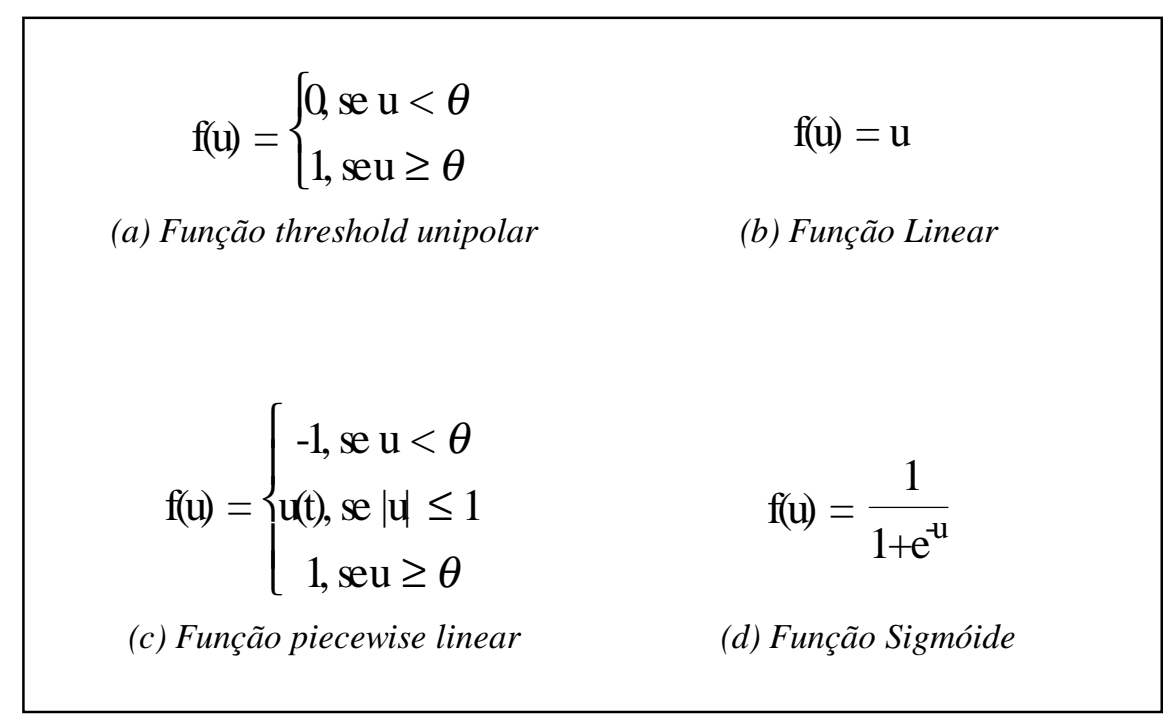

Figura 5: Função de Ativação.

A função de saída de um neurônio $o(f(u))$ é computada sobre o valor da função de ativação e geralmente é uma função identidade. Cada conexão de um neurônio, $u_{i}$, possui um peso associado e pode ser classificada em três tipos distintos:

- excitatória: $\mathrm{w}_{\mathrm{i}}>0$;

- inibitória: $\mathrm{w}_{\mathrm{i}}<0$;

- inexistente: $\mathrm{w}_{\mathrm{i}}=0$.

O primeiro modelo de neurônio artificial foi proposto por McCulloch \& Pitts em 1943. O neurônio de McCulloch \& Pitts utilizava uma função de ativação threshold unipolar (Figura 5a), estado de ativação binário e função de saída linear. 


\subsubsection{Arquitetura}

A arquitetura de uma RNA define a forma como seus neurônios estão organizados. Existem vários tipos de arquiteturas que se distinguem umas das outras em função do número de camadas e dos arranjos das conexões.

De uma maneira genérica, as RNAs possuem uma camada de entrada, zero ou mais camadas intermediárias ou escondidas e uma camada de saída. A camada de entrada é utilizada para captar estímulos externos e repassá-los para a camada intermediária. A camada de saída apenas retrata o resultado produzido pela RNA em resposta à uma dada entrada. Entre as camadas de entrada e saída pode haver uma ou mais camadas intermediárias cujas saídas dos neurônios não são acessadas por procedimentos externos à RNA.

Entre as RNAs sem camadas intermediárias, os principais exemplos são o Single Layered Perceptron [HAY99] e o ADAptative LINear Elemente (ADALINE) [HAY99]. As principais RNAs com uma ou mais camadas intermediárias são as redes MLP (MultLayered Perceptron).

A forma de conexão entre neurônios dentro um RNA com uma ou mais camadas intermediárias pode assumir as seguintes formas:

- Completamente Conectadas: todo neurônio de uma camada, a menos os da camada de saída, esta totalmente conectado com os neurônios da camada posterior;

- Parcialmente Conectadas: alguns neurônios de uma camada estão parcialmente conectados aos neurônios da camada posterior;

- Localmente Conectadas: é um tipo de conexão parcial orientada por algum tipo de funcionalidade.

Também podem haver conexões em forma de loops e conexões laterais entre neurônios. Com relação ao tipo de conexões presentes, as RNAs podem ser classificadas da seguinte forma:

- Redes feedforward: RNAs sem loops de conexões, com o sinal fluindo em uma única direção; 
- Redes recorrentes: RNAs que apresentam conexões com loops. São mais utilizadas em sistemas dinâmicos. Em uma rede recorrente, as entradas passadas podem ser lembradas e influenciar a próxima saída gerada;

- Lattices: RNAs em que neurônios estão dispostos em matrizes.

A Figura 6 ilustra um exemplo de uma rede MLP feedforward com 1 camada intermediária:

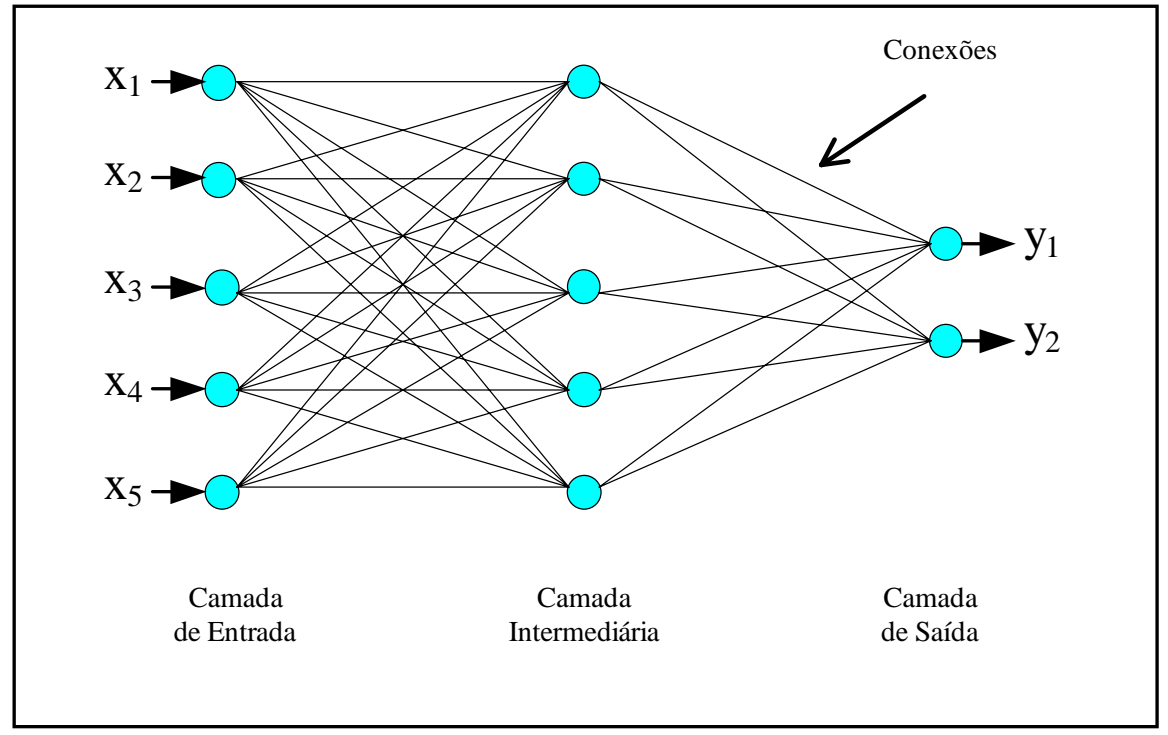

Figura 6: Conexões em uma Rede Neural Artificial.

A Figura 7(a) ilustra um modelo de RNA parcialmente conectada e recorrente e a Figura 7(b) ilustra um modelo de RNA com uma camada bidimensional e conexões laterais:

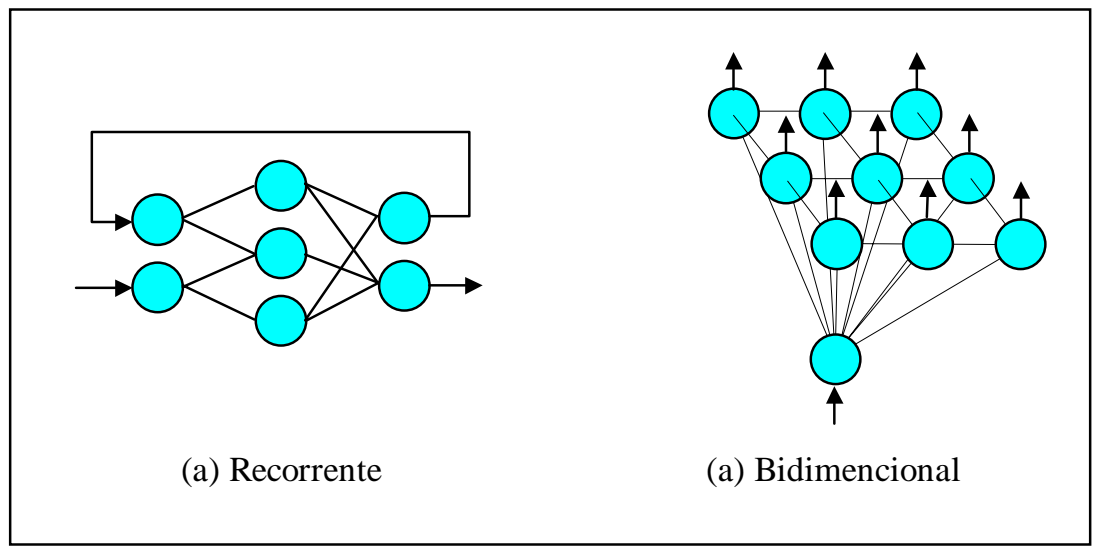

Figura 7: Alguns tipos de RNAs. 


\subsubsection{Paradigmas e Algoritmos de Aprendizado}

Uma das características mais interessante de uma RNA é a sua habilidade de aprender a partir do seu ambiente e melhorar seu desempenho ao longo do tempo. Esta aprendizagem ocorre através de um processo iterativo de ajustes aplicados aos pesos sinápticos e thresholds. Idealmente, a RNA sabe mais sobre seu ambiente após cada iteração. O ajuste iterativo dos pesos e thresholds é realizado através de uma algoritmo de aprendizado seguindo algum paradigma de aprendizado.

O algoritmo de aprendizado consiste de um conjunto de regras bem definidas para resolver um problema de aprendizagem. Existe uma grande variedade de algoritmos de aprendizagem que diferem basicamente entre si pela forma de ajuste dos pesos. Os algoritmos de aprendizagem conexionistas podem ser divididos em quatro classe principais:

- Aprendizado por correção de erro: o ajuste dos pesos e thresholds são efetuados de maneira a obter um erro mínimo;

- Aprendizado Hebbiano: o ajuste do peso de uma conexão entre dois neurônios ocorre somente quando este neurônios estão simultaneamente ativos;

- Aprendizado competitivo: neurônios competem entre si para serem ativados;

- Aprendizado de Boltzman: algoritmo estocástico baseado em termodinâmica e teoria da informação;

Uma propriedade importante das RNAs é que elas “aprendem” seu ambiente de atuação através de exemplos. A maneira de apresentar estes exemplos para RNAs, ou seja, a forma de interação existente entre o ambiente e uma RNA, pode se dar através de três paradigmas de aprendizado:

- Aprendizado supervisionada: existe a figura do "professor" que oferece a resposta desejada e a RNA ajusta seus pesos baseado no erro entre sua resposta e esta resposta desejada.

- Aprendizado por reforço: aprendizado por tentativa e erro em que a rede é recompensada em caso de sucesso e punida em caso de fracasso; 
- Aprendizado não supervisionado: não existe a figura do professor e a RNA extrai as características estatisticamente relevantes das entradas e as divide em classes.

Os exemplos de aplicações mais conhecidos de RNAs geralmente envolvem algoritmos de aprendizado por correção de erros e o paradigma supervisionado. O primeiro algoritmo de aprendizado supervisionada e por correção de erro foi desenvolvido por Widrow e Hoff [BEA92] e é conhecido como Delta Rule. O Delta Rule pode apenas ser utilizados em RNAs sem camadas intermediária (SLP, ADALINE, etc...). Ele é esboçado pela Figura 8.

enquanto não for obtido um erro global aceitável da RNA faça para cada exemplo p faça

Apresenta o exemplo p para a RNA;

para todo neurônio $j$ da camada de saída faça calcula o erro $\delta_{j}$;

para todas as conexões de entrada i faça ajusta o peso $w_{i j}$;

fim-para

fim-para

fim-para

fim-enquanto

Figura 8: Esboço do algoritmo de aprendizado Delta Rule.

$\mathrm{O}$ erro $\delta_{j}$ é calculado como a diferença entre a resposta desejada e a resposta produzida pela RNA sem camadas intermediárias, como mostra a Equação 2.

$$
\delta_{j}=d_{j}-y_{j}
$$

em que:

$d_{j}$ : saída desejada do neurônio $j$;

$y_{j}:$ saída produzida pelo neurônio $j$;

O ajuste dos pesos da camada de entrada é realizado através da Equação 3

$$
w_{i j}(t+1)=w_{i j}(t)+\eta x_{i} \delta_{j}
$$


em que:

$i$ : índice do neurônio da camada de entrada;

$j$ : índice do neurônio da camada de saída;

$w_{i j}(t)$ : peso sináptico associado à entrada $i$ do neurônio $j$;

$\eta$ : taxa ou velocidade de aprendizagem;

$x_{i}$ : entrada $i$ do neurônio $j$;

$\delta_{j}$ : erro do neurônio $j$.

O algoritmo de aprendizado utilizado para treinar RNAs com múltiplas camadas intermediárias é conhecido com Generalized Delta Rule ou BackPropagation. Neste algoritmo, o ajuste de pesos e thresholds é baseado no Delta Rule. Na camada de saída, o erro é calculado proporcionalmente à diferença entre a saída desejada e saída produzida, como ilustra a Equação 4. Uma vez que as saídas desejadas dos neurônios das camadas intermediárias são desconhecidas, os erros destes neurônios são calculados através da Equação 5.

$$
\delta_{j}=y_{j}^{\prime}\left(d_{j}-y_{j}\right)
$$

em que:

$$
\begin{aligned}
& d_{j}: \text { saída desejada do neurônio } j ; \\
& y_{j}: \text { saída atual do neurônio } j
\end{aligned}
$$

$$
\delta_{i}=y_{i}^{\prime} \sum_{j} w_{i j} \delta_{j}
$$

em que:

$i$ : índice do neurônio da camada intermediária em que se deseja calcular o erro;

j : índice do neurônio da camada posterior;

$\delta_{i}$ : erro do neurônios $i$ pertencente à camada intermediária em que se deseja calcular o erro;

$y_{j}$ : saída atual do neurônio $j$

$w_{i j}$ : pesos sinápticos entre o neurônio $i$ de uma camada intermediária e o neurônio j da camada posterior. 


\subsubsection{O algoritmo CN2}

O algoritmo CN2 [CLA89] foi desenvolvido a partir do estudo dos algoritmos ID3 [QUI83] e AQ [MIC69]. Esse algoritmo gera regras de classificação a partir de um conjunto de exemplos, para isso é utilizado um processo de busca.

O processo de busca utilizado pelo $\mathrm{CN} 2$ consiste em selecionar as condições para cobrir os exemplos de treinamento de uma determinada classe de forma gradativa. Em cada iteração ele procura por um complexo ${ }^{1}$ que cobre um grande número de exemplos de uma classe $\mathrm{C}$ e poucos de outra. Quando um complexo é considerado bom, os exemplos cobertos por ele são removidos do conjunto de treinamento e a regra "if <complexo> então C" é adicionada ao final da lista de regras. A última regra na lista é uma regra padrão (default), que classifica novos exemplos baseado na classe mais freqüente. Este processo é repetido até que complexos satisfatórios não sejam mais encontrados.

O sistema procura por complexos realizando uma busca geral-para-específica. Durante a busca, o CN2 armazena um conjunto de tamanho limitado que indica os melhores complexos encontrados. O sistema examina somente especializações desse conjunto deixando de fora uma parte dos complexos. Um complexo é especializado através da adição de um novo termo conjuntivo ou através da remoção de um elemento disjuntivo de um dos seus seletores.

Atributos contínuos são dividindo em subfaixas discretas. Testes em tais atributos examinam se um valor é maior, menor ou igual aos valores dos limites da subfaixa. A faixa completa de valores e tamanho de cada subfaixa é fornecida pelo usuário. Os valores de atributos não conhecidos são substituídos pelo valor mais freqüente (ou média da subfaixa mais comum, no caso de valores numéricos) do atributo no conjunto de treinamento.

A versão original do CN2 construía o conjunto de regras de maneira ordenada e avaliava a significância das regras através da função Entropia [CLA89]. Alterações proposta por Peter Clark e Robin Boswell em [CLA91] possibilitaram a geração de regras desordenadas que

\footnotetext{
${ }^{1}$ Um complexo é definido come sendo uma conjunção de seletores. Seletores são testes simples dos atributos. São exemplos de seletores: $\operatorname{tms}=0, \mathrm{tms}=\mathrm{o}$ ou tls $=\mathrm{x}$ e pessoas $>2$.
} 
puderam também ser avaliadas através da Função Laplace [CLA91]. As regras desordenas são mais apropriadas para compreensão.

\subsubsection{CN2 com Entropia}

O algoritmo CN2 faz duas decisões durante o processo de aprendizado e emprega duas funções de avaliação para tomar as decisões. Primeiro ele avalia a qualidade do complexo, determinando se um novo complexo deverá substituir o melhor complexo encontrado e qual deverá ser descartado se o tamanho máximo for alcançado. Computacionalmente, isto envolve primeiro encontrar o conjunto $E^{\prime}$ de exemplos cobertos pelo complexo e, em segundo lugar, encontrar a distribuição de probabilidade $\mathrm{P}=\left(p_{1}, \ldots, p_{\mathrm{n}}\right)$ dos exemplos em $\mathrm{E}^{\prime}$ entre classes (em que $n$ é o número de classes encontrado no conjunto de treinamento). O CN2 usa então a medida de entropia mostrada na Equação 6 para avaliar a qualidade do complexo.

$$
\text { Entropia }=-\sum_{i} p_{i} \log _{2}\left(p_{i}\right)
$$

A Segunda função de avaliação verifica se um complexo é significativo. Para isso, é verificado se ele consegue localizar regularidades improváveis de acontecer, refletindo uma correlação genuína entre os valores de atributos e classes. Para avaliar a significância, o CN2 compara a distribuição esperada, considerando que a escolha dos exemplos é aleatória.

Para o teste de significância, o sistema usa a estatística proporcional. Isto é dado pela Equação 7 , em que a distribuição $\mathrm{F}=\left(f_{1}, \ldots, f_{\mathrm{n}}\right)$ é a freqüência observada de distribuição de exemplos entre classes satisfazendo um dado complexo e $\mathrm{E}=\left(e_{1}, \ldots, e_{\mathrm{n}}\right)$ é a freqüência de distribuição esperada do mesmo número de exemplos baseada na suposição de que o complexo seleciona exemplos aleatoriamente.

$$
2 \sum_{i=1}^{n} f_{i} \log \left(\frac{f_{i}}{e_{i}}\right)
$$




\subsubsection{O uso de Laplace}

O problema do uso do $\mathrm{CN} 2$ com o método Entropia de busca heurística é que o mesmo tende a selecionar regras muito específicas cobrindo somente alguns exemplos. Esta é uma característica indesejável, especialmente quando há presença de ruídos nos dados.

Uma alternativa ao uso do método da Entropia é o uso do método Laplaciano. O erro Laplaciano é dado através da Equação 8.

$$
\text { LaplaceAccuracy }=\frac{\left(n_{c}+1\right)}{\left(n_{t o t}+k\right)}
$$

em que:

$k$ é o número de classes do domínio;

$n_{c}$ é o número de exemplos na classe predita $c$ coberta pela regra;

$n_{\text {tot }}$ é o total de exemplos cobertos pela regra.

\subsubsection{O algoritmo C4.5}

O aspecto principal da extração de conhecimento executada pelo algoritmo C4.5 [QUI93]

é a construção da Árvore de Decisão. Em um problema de classificação, os nós folhas da árvore correspondem às classes. Os demais nós são atributos dos exemplos utilizados para classificação. As ramificações são rotuladas com os valores dos atributos. Se um atributo for discreto, a ramificação será rotulada com os valores discretos deste atributo. Se um atributo for contínuo, a ramificação será rotulada com intervalos de valores destes atributos.

A Árvore de Decisão gerada é posteriormente podada e descrita sobre o formato de Regras de Produção. Uma regra de produção é formada por um caminho existente entre a raiz e um nó folha da árvore. O conjunto de Regras de Produção gerado é desordenado. 
No algoritmo C4.5 é de fundamental importância a geração de Árvores de Decisão. O algoritmo de geração de Árvores de Decisão é baseado no algoritmo de Hunt [HUN66] cujo esqueleto se baseia em três possibilidades sobre um conjunto $T$ contendo classes $C_{1}, C_{2}, \ldots, C_{k}$ :

1. $T$ contem um ou mais exemplos, sendo todos da classe $C_{j}$. A Árvore de Decisão para $T$ é uma folha que identifica a classe $C_{j}$.

2. T não contem exemplos. A Árvore de Decisão também é uma folha, mas a classe associada deve ser determinada através de informações exteriores à árvore $T$. Por exemplo, o nó pode ser associado à classe com maior número de ocorrências.

3. $T$ contem exemplos pertencentes à mais de uma classe. Neste caso, a idéia é refinar $T$ em subconjuntos que contenham o menor número de classes diferentes possível. Um teste de divisão do conjunto $T$ é escolhido e a divisão de $T$ através deste teste resulta nos subconjuntos $T_{1}, T_{2}, \ldots, T_{n}$. A árvore de divisão para o conjunto $T$ passa a ser formada por um nó de decisão e um conjunto de nós filhos, em que para cada nó é aplicado recursivamente os processos 1,2 e 3 .

De acordo com o esqueleto do algoritmo de Hunt, é possível gerar muitas Árvores de Decisão consistentes. Isto se deve ao fato de que cada nó pode ser dividido de várias maneiras possíveis. A geração de todas as Árvores de Decisão possíveis, para a escolha da melhor, é um problema do tipo NP-completo, ou seja, possui um elevado custo computacional. Para solucionar este problema, é adotado critérios de avaliação do melhor teste em cada nó.

O algoritmo de Hunt utiliza o critério do ganho para avaliação do teste de divisão de cada nó. Embora o critério do ganho obtenha bons resultados, ele possui uma deficiência que precisa ser levada em consideração: ele dá preferencia a testes com muitas alternativas (saídas). Uma alternativa ao uso do critério do ganho é o uso do critério de proporção do ganho. $\mathrm{O}$ algoritmo C4.5 adota o critério de proporção do ganho como critério de avaliação do teste de divisão do nó. 


\subsubsection{Critério do ganho}

Suponha um possível teste com $n$ resultados que divide o conjunto de treinamento $\mathrm{T}$ em subconjuntos $T_{1}, T_{2}, \ldots, T_{n}$. Se este teste for avaliado sem explorar subdivisões subsequentes dos $T_{i}$ 's, a única informação possível para ser avaliada é a distribuição de classes em $\mathrm{T}$ e em seus subconjuntos. Para auxilio na definição do critério do ganho, considere a seguinte definição: seja $S$ um conjunto de exemplos e $f r e q\left(C_{i}, S\right)$ o número de exemplos em $S$ que pertence a classe $C_{i}$ e $|S|$ é o número de exemplos no conjunto $S$.

O ganho de informação obtido pode ser visto da seguinte forma: a informação representada pelo exemplo depende de sua probabilidade e pode ser medida em bits como sendo o negativo do logaritmo da base 2 daquela probabilidade. Imagine que um exemplo seja selecionado aleatoriamente do conjunto $S$ de exemplos e que ele pertença à classe $C j$. Este exemplo tem probabilidade dada pela Equação 9 e a informação armazenada é dada pela Equação 10.

$$
\begin{gathered}
\frac{\operatorname{freq}\left(C_{j}, S\right)}{|S|} \\
-\log _{2}\left(\frac{\text { freq }\left(C_{j}, S\right)}{|S|}\right) \text { bits }
\end{gathered}
$$

Para encontrar a informação esperada dos exemplos pertencentes à classe, soma-se todas as informações obtidas a partir da freqüência desta classe em $S$, dado pela Equação 11.

$$
\inf o(S)=-\sum_{j=1}^{k} \frac{\operatorname{freq}\left(C_{j}, S\right)}{|S|} \times \log _{2}\left(\frac{\text { freq }\left(C_{j}, S\right)}{|S|}\right) \text { bits }
$$

Quando aplicado ao conjunto de exemplos de treinamento, info(T) mede a quantidade média de informação necessária para identificar a classe de um exemplo em T. Esta quantidade é também conhecida como entropia de T. 
Considere, agora, uma medida similar depois que $\mathrm{T}$ foi dividido de acordo com as $n$ saídas de um teste X. A informação esperada pode ser encontrada como a soma em relação aos subconjuntos $\mathrm{T}_{i}$, como mostrado na Equação 12. A quantidade, mostrada na Equação 13 mede a informação que é armazenada dividindo $\mathrm{T}$ em relação ao teste $\mathrm{X}$. O critério de ganho, então seleciona um teste que maximize este ganho de informação.

$$
\begin{gathered}
\inf o_{x}(T)=\sum_{i=1}^{n} \frac{\left|T_{i}\right|}{|T|} \times \inf o\left(T_{i}\right) \\
\operatorname{gain}(X)=\inf o(T)-\inf o_{x}(T)
\end{gathered}
$$

\subsubsection{Critério de proporção de ganho}

Para resolver o problema encontrado no critério do ganho, o critério de proporção do ganho faz uma normalização do ganho de cada saída do teste. Por analogia, com a definição de info $(S)$, tem-se a Equação 14:

$$
\text { split inf } o(X)=-\sum_{i=1}^{n} \frac{\left|T_{i}\right|}{|T|} \times \log _{2}\left(\frac{\left|T_{i}\right|}{|T|}\right)
$$

Isto representa o potencial de informação gerado dividindo T em $n$ subconjuntos. Logo, a Equação 15 expressa a quantidade de informação regada pela divisão de T. Se a divisão for muito simples, a informação de divisão deverá ser pequena e esta proporção deverá ser instável. Para evitar isso, o critério de proporção de ganho seleciona um teste para maximizar esta taxa, assumindo a condição de que o ganho de informação deverá ser grande, ou pelo menos maior do que o ganho médio sobre todos os testes examinados.

$$
\operatorname{gain} \operatorname{ratio}(X)=\frac{\operatorname{gain}(X)}{\text { splitinf } o(X)}
$$




\subsection{Sumário do Capítulo}

Neste Capítulo foram apresentadas diferentes abordagens de aprendizado de máquina. Foram mostradas as fases de um processo de aprendizado de máquina e três métodos de aprendizado de máquina que são as Redes Neurais Artificiais, o algoritmo CN2 e o algoritmo C4.5.

Através dos métodos de aprendizado de máquina é possível construir classificadores eficazes que adquirem seu conhecimento baseados em informações que eles extraem dos dados. Esta característica é de grande ajuda para os seres humanos, pois pode deixar a cargo do computador o árduo trabalho de identificação da classe de cada padrão.

Uma limitação das Redes Neurais Artificiais é que elas não representam o conhecimento adquirido de maneira compreensível. Com o objetivo de superar esta limitação, no próximo Capítulo são discutidos alguns algoritmos para extração de conhecimento de Redes Neurais Artificiais. 


\section{Extração de Conhecimento de Redes Neurais Artificiais}

A aplicação de RNAs em diversos domínios tem sido intensificada nos últimos anos, como indicam os bons resultados e constantes pesquisas. No entanto, todo o poder oferecido pelas RNAs esbarram em um problema: sua incapacidade para explicar de forma compreensível suas decisões. Este problema é o fator de motivação para as várias pesquisas relacionadas ao desenvolvimento de técnicas de extração de conhecimento de RNAs. Essas técnicas têm a finalidade de fornecer uma certa capacidade de explicação.

Em contraste com as RNAs, o conhecimento representado por algoritmos simbólicos de Inteligência Artificial é geralmente mais amigável e de mais fácil compreensão. Uma maneira de entender melhor o conhecimento contido nas RNAs é através da extração de conhecimento simbólico das RNAs. Existem vários algoritmos que realizam extração de conhecimento de RNAs, entre eles podem ser citados: KT (Knowledgetron) [FU94], EN (Explanation Facility) [PAU92], M-of-N [TOW93], RULEX [AND95b] e TREPAN (TREes PArroting Networks) [CRA96a]. A principal dificuldade de entender os conceitos representados pelas RNAs está no fato do conhecimento estar armazenado na forma de uma grande quantidade de parâmetros e estes parâmetros serem manipulados através de complicadas fórmulas matemáticas.

Uma definição de extração de conhecimento de RNA é dada por Craven \& Shavlik [CRA94]: "Dado uma rede neural treinada e os exemplos usados para treina-la, produz uma descrição simbólica da rede concisa e precisa".

Como pode ser visto em Andrews et al. [AND95a], existem diversas razões que tornam a extração de conhecimento de RNAs uma tarefa importante. A seguir são mostradas algumas estas razões:

- Explanação: É importante que se saiba como um sistema de aprendizado tomou determinada decisão. O objetivo da explanação é permitir que o usuário explore o conhecimento do sistema. Idealmente, é preciso que a explanação responda a questões sobre aspectos relevantes a respeito do conhecimento do sistema. A explanação é importante para a aceitação das RNAs pelos usuários; 
- Validação: A validação é importante quando se quer um grau maior de confiança no conhecimento armazenado pela RNA. Em aplicações de alto risco, onde uma falha traria conseqüências graves, é fundamental que se valide o conhecimento adquirido antes de sua utilização;

- Exploração de Dados e Indução de Teorias: Com o passar do tempo, as RNAs têm provado ser uma ferramenta poderosa para exploração de dados, com a capacidade de descobrir dependências e relações desconhecidas dentro de um conjunto de dados. Sem a capacidade de explicação dos conhecimentos armazenados em uma RNA, essas descobertas ficam codificadas e sem serem apreciadas;

- Melhorar a generalização de soluções envolvendo RNAs: Quando um conjunto de dados limitado ou não representativo é utilizado no processo de treinamento de uma RNA, é difícil prever quando a generalização poderá falhar. Nestes casos, a extração de conhecimento de RNAs é capaz de fornecer um conjunto de regras simbólicas, que podem ser analisadas por um especialista na tentativa de encontrar pontos em que a generalização irá falhar;

- Integração entre Sistemas Simbólicos e conexionistas: O conhecimento extraído na forma de regras if... then... ou Árvores de Decisão facilita a integração com sistemas simbólicos baseados em conhecimentos. As regras criam uma linguagem comum entre as duas técnicas, facilitando a sua integração;

- Redefinição da RNA: As regras extraídas da rede podem ainda ser utilizadas para verificar a adequação da arquitetura escolhida para a aplicação na qual a rede está sendo utilizada.

É importante ressaltar que a extração de conhecimento de uma RNA é uma tarefa que exige recursos e esforços adicionais. Por isso, deve ser bem justificada para não apresentar efeitos negativos.

\subsection{Classificação de Algoritmos de Extração de conhecimento de RNAs}

Com a diversidade de técnicas de extração de conhecimento de RNAs existentes e o frequiente surgimento de novas técnicas, é importante que se tenha métodos de classificação destas técnicas em classes distintas. 
Craven \& Shavlik [CRA94] descrevem um sistema para classificação de técnicas de extração de conhecimento de RNAs em termos de:

1. Métodos baseados em busca: Métodos que realizam a tarefa de extração de conhecimento como um problema de busca. Exploram o espaço de regras candidatas e testam cada uma individualmente baseando-se na rede para ver se elas são válidas;

2. Métodos baseados em aprendizado: Métodos que realizam a tarefa de extração de conhecimento como um problema de aprendizado indutivo. Nesta tarefa de aprendizado o conceito principal é a função representada pela RNA. A RNA é utilizada para verificação se conceitos gerados cobrem instâncias especificas.

Uma esquema mais completo para classificação de técnicas de extração de conhecimento de RNAs é dado por Andrews et al. [AND95a]. Este esquema é descrito como um sistema para classificação de técnicas de extração de conhecimento de RNAs em termos de:

1. Poder expressivo das regras extraídas: Foca diretamente o resultado final do processo de extração de conhecimento de RNAs. As técnicas de extração de regras podem ser classificadas em:

a) Proposicionais ou booleanas: Extrai regras na forma if... then... else;

b) Não convencionais: Extrai regras na forma de lógica fuzzy ou probabilistica.

2. Lucidez: Este tipo de classificação amplia o esquema de classificação proposto por Craven \& Shavlik [CRA94]. Classifica as técnicas de extração de conhecimento em:

a) Decomposicionais: As técnicas pertencentes à esta classe extraem regras através de uma análise a nível individual das unidades de uma RNA. São analisadas as unidades intermediárias e de saída de uma RNA, bem como as ligações existentes entre estas unidades;

b) Pedagógicas: As técnicas pertencentes à esta classe, analisam uma RNA como sendo uma "caixa preta". A RNA é utilizada como um classificador com a finalidade de gerar exemplos para o algoritmo de aprendizado;

c) Ecléticas: As técnicas pertencentes à esta classe combinam características pertencentes às classes decomposicionais e pedagógicas. São extraídas informações internas da RNA com o objetivo de complementar o algoritmo de aprendizado. 
3. Regime de treinamento das RNAs: Corresponde à arquitetura e requisitos de treinamento impostos à RNA pelo método de extração, ou seja, o escopo das redes em que os métodos podem ser aplicados.

4. Qualidade das regras extraídas: A qualidade das regras extraídas leva em conta algumas medias de desempenho [TOW93] que incluem:

a) Exatidão ou taxa de acertos: As regras devem classificar corretamente exemplos não vistos no treinamento;

b) Fidelidade: A regras devem representar exatamente as mesmas informações contidas na RNA;

c) Consistência: As regras devem manter a mesma classificação dada pela RNA em treinamentos da RNA utilizando diferentes exemplos de treinamento;

d) Compreensibilidade: A compreensibilidade é medida através do tamanho do conjunto de regras, em termos da quantidade de regras, e número de regras antecedentes por regra.

5. Complexidade do algoritmo: Leva em conta critérios para avaliação de complexidade do algoritmo. Como exemplo pode ser citado a avaliação do espaço de busca de cada algoritmo.

\subsection{O Algoritmo TREPAN}

O algoritmo para extração de conhecimento de Redes Neurais Artificiais TREPAN (TREes PArroting Networks) [CRA96a][CRA96b] possui como finalidade representar o conhecimento armazenado em uma Rede Neural Artificial em forma de uma Árvore de Decisão. A tarefa que o algoritmo realiza é gerar uma Árvore de Decisão tomando como entrada uma RNA treinada e os dados utilizados para o seu treinamento. Este algoritmo não leva em consideração a arquitetura interna da rede, o que o torna genérico o suficiente para ser aplicado à maioria dos modelo de Redes Neurais Artificiais.

O algoritmo TREPAN emprega o mesmo princípio utilizado pelos algoritmos convencionais de indução de Árvores de Decisão, como CART [BRE84] e C4.5 [QUI93], que constróem uma Árvore de Decisão através de particionamentos recursivos do conjunto de exemplos. Um diferencial do TREPAN em relação aos algoritmos convencionais de indução de Árvores de Decisão é que o TREPAN constrói a Árvore de Decisão através do método de busca do melhor caso (best-first) ao invés de utilizar a busca em profundidade (depth-first). 
A classe de cada exemplo utilizado no processo de obtenção da Árvore de Decisão é definida através de um oráculo (questionador) constituído pela própria RNA treinada. Ou seja, dado um exemplo para o oráculo, este retorna a classe a qual pertence este exemplo. Vale a pena ressaltar que a classe indicada pelo oráculo em alguns casos pode não ser a mesma classe indicada nos exemplos de treinamento para estes mesmos casos. Isto é normal pois quase todas as RNAs estão sujeitas a erros após o treinamento. Por outro lado, a verdadeira classe a qual pertence o exemplo não é importante para o algoritmo. O objetivo é construir uma Árvore de Decisão que represente da melhor maneira possível o conhecimento contido na RNA.

O processo de expansão da Árvore de Decisão é controlado através de uma lista contendo somente nós folhas. Um nó é inserido nesta lista e posteriormente é removido para ser expandido em outros nós folhas filhos ou se tornar um nó folha que não pode mais ser expandido. O nó que é removido da lista de nós não retorna mais a esta lista. Em seu lugar, são inseridos os nós folhas filhos resultantes desta expansão. O processo de expansão de um nó é realizado através da escolha de um teste de divisão para este nó e a criação de um nó folha filho para cada resultado obtido deste teste.

Para cada nó pertencente à fila de nós é armazenado um subconjunto dos exemplos de treinamento, um conjunto que pode ser chamado de conjunto de condições e criado um conjunto de exemplos complementares. O subconjunto dos exemplos de treinamento é constituído pelos exemplos de treinamento que alcançam o nó. O conjunto de exemplos complementares possui exemplos gerados de forma aleatória ou exemplos que não fizeram parte do treinamento da RNA e que alcançam o nó. O subconjunto de exemplos de treinamento e o conjunto de exemplos complementares são utilizados para seleção do teste de divisão do nó interno ou para determinar a classe alcançada pelo nó folha. O conjunto de condições é formado por testes condicionais de divisão de nós realizados sobre atributos. Os exemplos de treinamento e exemplos complementares devem satisfazer este conjunto de testes condicionais para alcançar o nó associado. A Figura 9 mostra de maneira resumida o corpo principal do algoritmo TREPAN. 


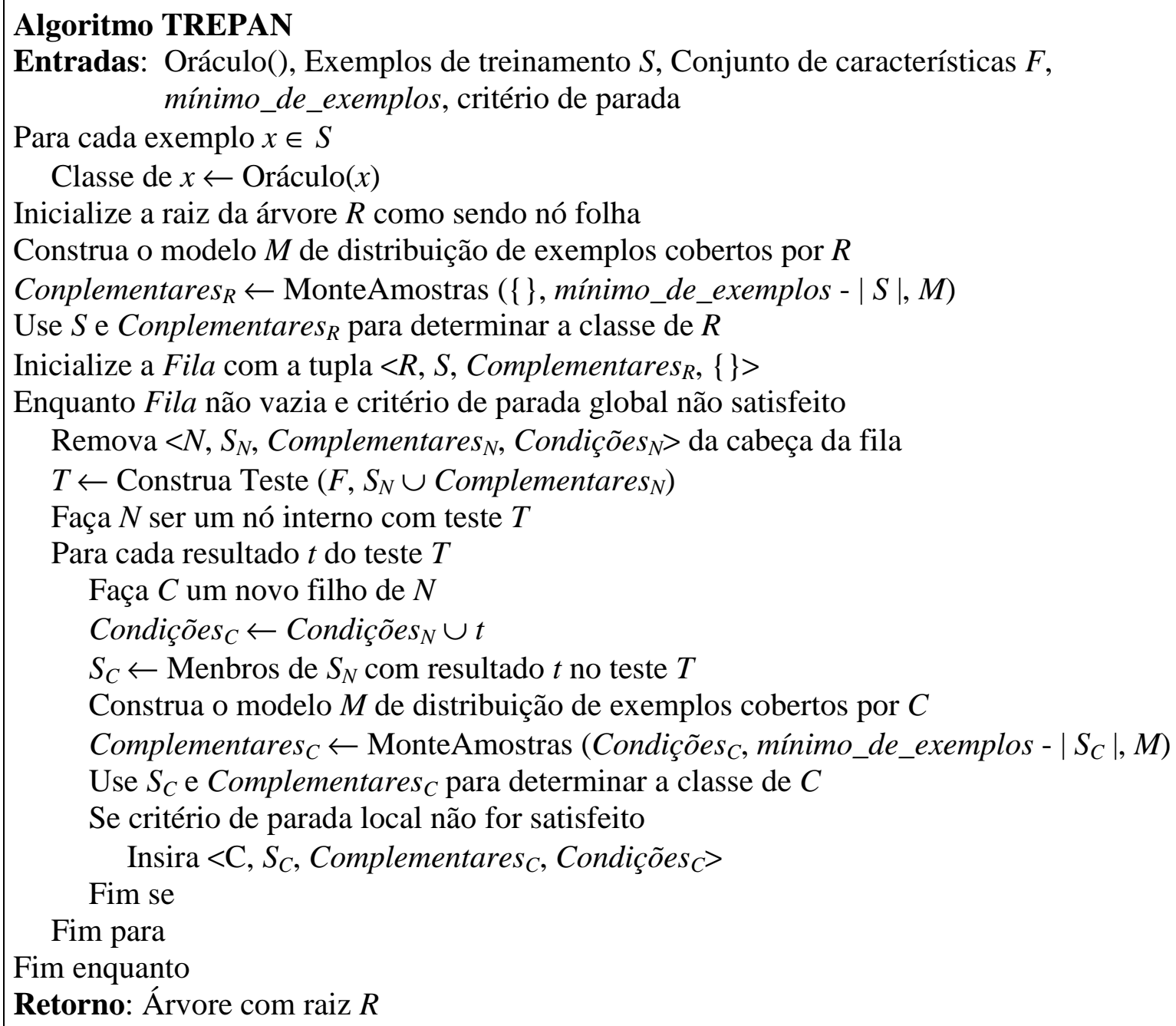

Uma limitação dos algoritmos convencionais de indução de Árvores de Decisão é que o número de exemplos usados para a escolha do teste de divisão de um nó diminui com a profundidade da árvore. Logo, testes de nós em profundidades elevadas são baseados em poucos exemplos. Para resolver este problema, o TREPAN utiliza o conjunto de exemplos complementares, garantindo assim, que exista uma quantidade mínima de exemplos alcançando o nó antes da escolha do teste de divisão do nó interno ou da escolha da classe do nó folha.

\subsubsection{Tipos de árvores geradas pelo TREPAN}

Existem três métodos de geração de árvores disponíveis no TREPAN: o método testesimples, o método disjuntivo e o método $m$-de- $n$. A diferença entre estes métodos disponíveis no 
TREPAN é o número de testes condicionais de cada nó da Árvore de Decisão gerada e o número de testes condicionais que necessitam ser satisfeitos para que o nó possua valor verdade. Como forma de exemplificar cada um dos métodos de geração de Árvores de Decisão do TREPAN, pode-se dizer que:

1. teste-simples: gera Árvores de Decisão em que cada nó possui um teste condicional sobre um único atributo. Ex.: cor = azul.

2. disjuntivo: gera Árvores de Decisão, em que cada nó possui um ou mais teste condicional separados por disjunções. Ex.: cor $=$ azul ou cor $=$ branco ou capacidade $>100$.

3. $m$-de-n: gera Árvores de Decisão, em que cada nó possui um teste do tipo $m$-de- $n$. Este teste pode ser visto como uma disjunção de testes condicionais, em que toda a expressão possui valor "verdadeiro" quando pelo menos $m$ dos $n$ testes condicionais possuir valor "verdadeiro". Ex.: 3 de $\{$ cor $=$ azul, cor $=$ banco, capacidade $>100$, vazão $<=10$, altura $>50$, forma $=$ cilíndrica $\}$.

\subsubsection{Montando exemplos complementares}

Conforme dito anteriormente, é necessário uma quantidade mínima de exemplos para que se escolha um teste de divisão de um nó interno ou a classe de um nó folha. No entanto, somente com exemplos de treinamentos, nem sempre é possível ter esta quantidade mínima de exemplos que alcançam os nós mais profundos da árvore. Assim, sendo $\left|S_{N}\right|$ a quantidade de exemplos de treinamento que alcançam o nó $N$ e mínimo_de_exemplos a quantidade mínima de exemplos que devem alcançar o nó $N$, se $\left|S_{N}\right|<$ mínimo_de_exemplos, devem ser adicionados (mínimo_de_exemplos - $\left|S_{N}\right|$ ) exemplos que alcançam o nó $N$. A Figura 10 ilustra o algoritmo "MonteAmostras" utilizado para montar exemplos complementares utilizados pelo TREPAN. 


\section{MonteAmostras}

Entradas: condições, número de exemplos $m$, modelo $M$

exemplos $\leftarrow\{\}$

Se $m>0$

Para $m$ interações faça

$x \leftarrow$ MonteExemplo (condições, $M$ )

classe de $x \leftarrow$ oráculo $(x)$

Fim para

exemplos $\leftarrow$ exemplos $\cup\{x\}$

Fim se

Retorno: exemplos

Figura 10: Uma visão geral do algoritmo MonteAmostras.

A adição de novos exemplos pode ser feita de duas maneiras:

1. Existem domínios em que a aquisição de novos exemplos é muito fácil, como é o caso de dados adquiridos através de leitura de sensores. Quando existir uma grande quantidade de dados disponíveis, é necessário que se faça uma seleção dos exemplos mais significativos para que um treinamento melhor e mais rápido seja feito. Nesse caso, os exemplos que não foram selecionados para conjunto de treinamento podem ser adicionados ao conjunto de exemplos complementares que alçam o nó.

2. Existem domínios em que os dados são escassos, tornando assim o trabalho de encontrar novos exemplos uma tarefa muito difícil. Para este caso, novos exemplos podem ser adquiridos de maneira aleatória levando-se em conta o modelo de distribuição coberto pelos dados.

A adição de novos exemplos deve levar em conta o conjunto de condições necessárias para que o nó seja alcançado. Como exemplos pode ser citado o caso de um nó que possua como conjunto de condições os seguintes testes condicionais: $\left(x_{1}=\right.$ verdade $)$ e $\left(x_{2}=\right.$ verdade ou $x_{3}=$ verdade). Um novo exemplo que alcance este nó deve ser escolhido de maneira que satisfaça este conjunto de condições. A Figura 11 ilustra esse caso em que ( $x_{1}=$ verdade) é atribuído ao nó raiz e ( $x_{2}=$ verdade ou $x_{3}=$ verdade $)$ é representado através de um teste M-of-N aplicado ao nó filho do nó raiz. Após cada exemplo do conjunto complementar ter sido montado conforme as condições necessárias para se atingir o nó, é encontrada a classe a qual pertence este exemplos com a ajuda do oráculo. 


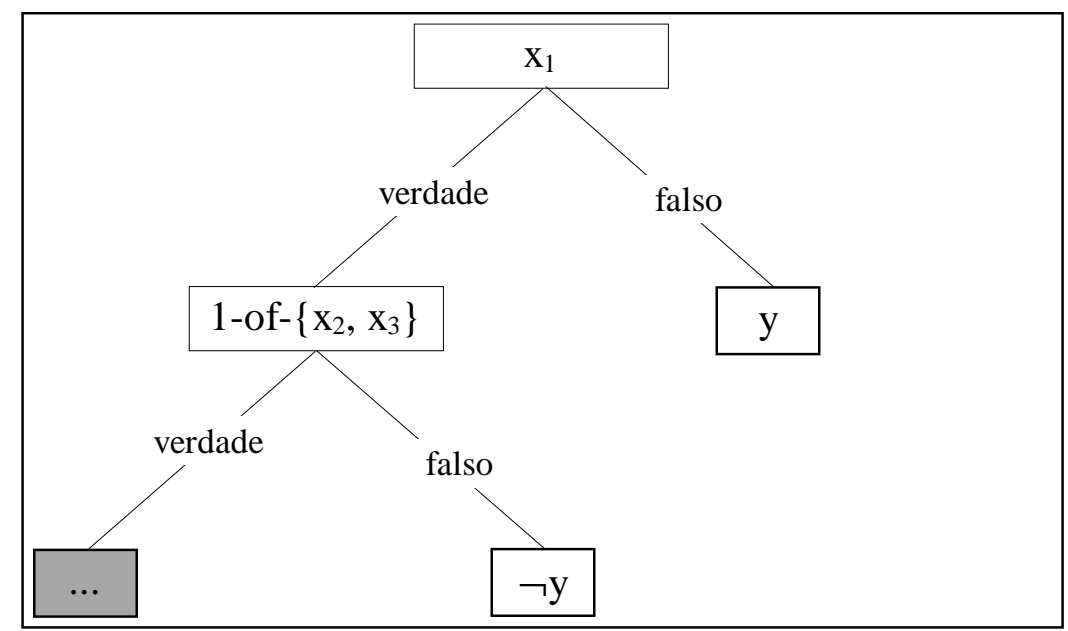

Figura 11: Representação de condições a serem satisfeitas em uma Árvore de Decisão.

Para escolher novos exemplos através de modelos de distribuição de dados, o TREPAN assume como padrão o modelo de distribuição marginal [CRA96b] baseado em um único atributo. A distribuição marginal de uma variável aleatória é a sua distribuição independente de qualquer outra variável.

O TREPAN utiliza a distribuição empírica [SIL86] para modelar atributos de natureza discreta e a função de núcleo de densidade [SIL86] para modelar atributos contínuos. A distribuição empírica de atributos é simplesmente a distribuição de valores que ocorre em uma amostra do atributos. A função de núcleo de densidade é mostrada na Equação 16.

$$
f(x)=\frac{1}{m} \sum_{j}^{m}\left[\frac{1}{\sqrt{2 \pi} \sigma} e^{-\left(\frac{x-\mu_{j}}{2 \sigma}\right)^{2}}\right]
$$

em que $m$ é o número de exemplos de treinamento, $\mu_{j}$ é o j-esimo atributo e $\sigma$ é a amplitude do núcleo Gaussiano. O TREPAN atribui o valor de $1 / \sqrt{m}$ para $\sigma$.

Uma limitação do TREPAN é o uso de distribuições marginais que não levam em consideração as dependências entre variáveis. Este problema é resolvido através do cálculo de distribuições em cada nó utilizando somente exemplos de treinamento que alcancem o nó. Em alguns casos, a distribuição encontrada para um nó pode ser enganosa. Este fato se deve ao 
número reduzido de exemplos de treinamento que alcançam nós mais profundos. Para estes casos, são aplicados testes estatísticos para verificar se a distribuição encontrada para um nó é significativamente diferente da distribuição contida no pai deste nó. Caso a distribuição seja significativamente diferente da distribuição do pai, a distribuição encontrada localmente é adotada. Caso contrário, a distribuição do pai é adotada. Para atributos discretos é adotado o teste estatístico $\chi^{2}$ [SAC84] e para valores reais o teste kolmogorov-Smirnov [SAC84]. A Figura 12 ilustra um exemplo em que a distribuição do nó 2 é significativamente diferente do nó 1 , mas a distribuição do nó 3 não é significativamente diferente do nó 2 . Como resultado, é adotada para o nó 3 a distribuição do nó 2 .

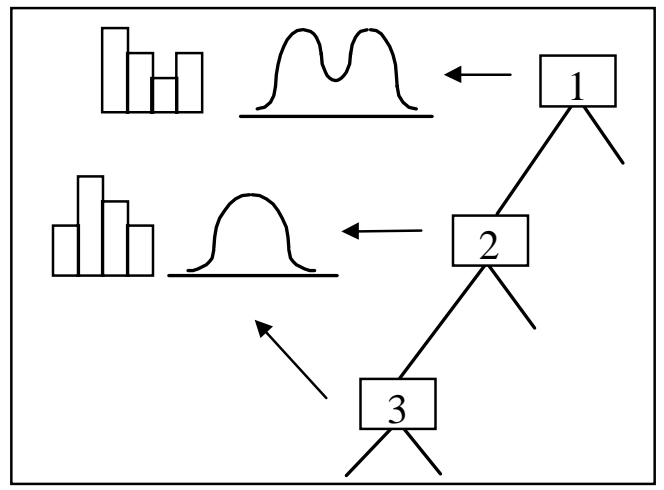

Figura 12: Modelo de distribuição adotado para cada nó.

O algoritmo "MonteExemplos" usado para criar novos exemplos ilustrado na Figura 10 é descrito com mais detalhes na Figura 13. Este algoritmo toma como base o modelo de distribuição de cada atributo $x_{i}$ e o conjunto de condições necessárias para se atingir o nó. 


\section{MonteExemplos \\ Entradas:}

Para cada atributo $x_{i}$

hard_constraints $s_{i} \leftarrow$ disjunção de $x_{i}$

$g\left(x_{i}\right) \leftarrow f\left(x_{i} \mid\right.$ hard_constraints $\left._{i}\right)$

Fim para

Para cada disjunção $T$ de condições

Enquanto $T$ não satisfeito

Para cada literal $l_{i j}$ de $x_{i}$ em $T$

$$
\operatorname{Pr}\left(l_{i j}\right) \leftarrow \frac{\operatorname{Pr}_{g\left(x_{i}\right)}\left(l_{i j}\right)}{\sum_{i j} \operatorname{Pr}_{g\left(x_{i}\right)}\left(l_{i j}\right)}
$$

Fim para

$s_{i j} \leftarrow$ literal selecionado randomicamente de acordo com $\operatorname{Pr}\left(l_{i j}\right)$

hard_constraints $_{i} \leftarrow$ hard_constraints ${ }_{i} \cup s_{i j}$

$g\left(x_{i}\right) \leftarrow f\left(x_{i} \mid\right.$ hard_constraints $\left._{i}\right)$

Fim enquanto

Fim para

Para cada $x_{i}$

$x_{i} \leftarrow$ valor selecionado aleatóriamente da distribuição $g\left(x_{i}\right)$

Fim para

Retorno: exemplo $x$

Figura 13: Uma visão geral do algoritmo MonteExemplos.

\subsubsection{Criando testes de divisão do nós}

O trabalho de escolha de um teste de divisão de um nó envolve a decisão de como particionar o espaço de exemplos que alcançam o nó. A Figura 14 mostra o algoritmo "ConstruaTeste" utilizado para escolha de um teste de divisão para um nó. O teste de divisão de nós utilizado pelo TREPAN é do tipo $m$-of- $n$. Como exemplo podemos citar o teste 2-of$\left\{x_{1}, \neg x_{2}, x_{3}\right\}$, que é logicamente equivalente a $\left(x_{1} \wedge \neg x_{2}\right) \vee\left(x_{1} \wedge x_{3}\right) \vee\left(\neg x_{2} \wedge x_{3}\right)$. A construção do teste de divisão do nó é semelhante ao método utilizado pelo algoritmo ID2-of-3 [MUR91]. A Figura 15 mostra o algoritmo "ConstruaTesteMofN", que é responsável pela construção de testes $m$-of- $n$. 


\section{ConstruaTeste}

Entradas: características, exemplos

$C \leftarrow$ AcheTestesCandidatos(características, exemplos)

melhor_teste $\leftarrow$ verdade

Para cada $c \in C$

Se ganho( $c$, exemplos $)>\operatorname{ganho}($ melhor_teste, exemplos $)$

$$
\text { melhor_teste } \leftarrow c
$$

Fim se

Fim para

melhor_mofn_teste $\leftarrow$ ConstruaTesteMofN(melhor_teste, $C$, exemplos)

Retorno: melhor_mofn_teste

Figura 14: Uma visão geral do algoritmo ConstruaTeste.

\section{ConstruaTesteMofN}

Entradas: melhor_teste, $C$, exemplos

Inicialize Beam contendo somente melhor_teste

Repita

beam_changed $\leftarrow$ false

Para cada $t \in$ Beam

Para cada $c \in C$

Para cada operador $\in\{m-o f-n+1, m+1-o f-n+1\}$

$t^{\prime} \leftarrow$ operador $(t, c)$

Se $t$ ' e $t$ são significantemente diferentes

Se ganho(t') > ganho(t") // t" é o pior teste em Beam

Subistitua t" por t' em Beam

beam_changed $\leftarrow$ verdade

Fim se

Fim se

Fim para

Fim para

Fim para

Até que beam_changed $=$ false

Retorno: melhor teste em Beam

Figura 15: Uma visão geral do algoritmo ConstruaTesteMofN.

O processo de construção dos testes $m$-of- $n$ é realizado através de buscas heurísticas. Primeiro é feita a seleção dos melhores testes binários para o nó utilizando o critério de ganho de informação [QUI93]. Para atributos que possuem somente dois valores, o teste assume estes dois valores como resultados do teste. Para atributos discretos que assumem mais de dois valores, são feitos testes binários do tipo sim ou não sobre cada valor que o atributo pode assumir. Para atributos reais são considerados valores limites para o teste (ex: $\left.x_{1}<0.75, x_{1} \geq 0.75\right)$. 
Os testes binários selecionados são utilizados no processo de busca para formar os testes $m$-of- $n$. Estes testes binários são manipulados através dos seguintes operadores:

- $m$-of- $n+1$ : Este operador adiciona um novo teste simples ao conjunto $m$-of-n mantendo $m$ constante. Exemplos: 2-of- $\left\{x_{1}, x_{2}\right\} \Rightarrow 2-o f-\left\{x_{1}, x_{2}, x_{3}\right\}$.

- $m+1-o f-n+1$ : Este operador adiciona um novo teste simples ao conjunto $m$-of- $n$ e incrementa m. Exemplo: 2-of- $\left\{x_{1}, x_{2}\right\} \Rightarrow 3-o f-\left\{x_{1}, x_{2}, x_{3}\right\}$.

\subsection{0 método EN}

O método EN (Explanation Facility)[PAU92] relaciona neurônios de entrada com neurônios de saída ou neurônios de saída com neurônios de entrada, sendo também capaz de mostrar a sequiência de neurônios utilizados para estes relacionamentos. Estas características auxiliam na descoberta dos neurônios de entrada ou de saída mais importantes bem como quais as conexões mais usadas, ajudando assim, no re-projeto de RNAs e melhor compreensão dos conhecimentos armazenados nas conexões.

Esta técnica busca a identificação dos caminhos de propagação mais significantes da rede, uma vez que as redes são formadas, na maioria das vezes, por um número de neurônios muito grande e distribuídos em várias camadas.

Para melhor explicar o método EN devem ser consideradas algumas definições: Dada uma Rede Neural com $N$ camadas, definir $n(l)$ como sendo o número de neurônios na camada $l$, sendo $l=1, \ldots, N$. Definir também o conjunto de neurônios de entrada $E=\{1,2, \ldots, n(1)\}$ e o conjunto de neurônios de saída $S=\{1,2, \ldots, n(N)\}$.

O EN fornece os mecanismos de explicação Porque, Como e Trace que são definidos da seguinte forma:

- O mecanismo Por que: relaciona a saída de uma RNA com sua entrada. Resulta em um subconjunto $E^{\prime}$ de neurônios de entrada quando escolhido um subconjunto $S^{\prime}$ de neurônios de saída. 
- O mecanismo Como: relaciona a entradas de uma RNA com sua saída. Resulta em um subconjunto $S^{\prime}$ de neurônios de saída quando escolhido um subconjunto $E$ ' de neurônios de entrada.

- O mecanismo Trace: para os mecanismos Por que e Como, mostra a seqüência de neurônios intermediários utilizados durante o processo de resolução.

Como critério para seleção de pesos e neurônios durante o processo de resolução, o método adota originalmente o critério "pau". Dois novos critérios "ccg" e "soma" foram propostos em [BAT97]. Os três critérios trabalham com o princípio de que pesos com maior valor absoluto influenciam mais na ativação de neurônios. Os critérios para seleção de pesos e neurônios podem ser definidos da seguinte forma:

- Critério "pau": Dado um grau de explicação $d>0$, é selecionada uma fração $d$ de pesos com maior valor absoluto contidos entre as camadas $l-1$ e $l$. Os neurônios da camada $l$ que recebem estes pesos são escolhidos para a próxima iteração, entre as camadas $l$ e $l+1$. Somente os pesos ligados aos neurônios escolhidos da camada $l$ são utilizados para a escolha de neurônios na camada $l+1$. A sequiência de escolha de neurônios forma um caminho de explicação.

- Critério "ccg": É semelhante ao critério pau. A única diferença é que os pesos são considerados com seus valores reais.

- Critério "soma": Os pesos que chegam a um neurônio da camada $l$ são somados. Os valores das somas de cada neurônio são ordenados e é selecionada uma fração $d>0$ de neurônios com os maiores valores. Somente neurônios selecionados na camada $l$ são utilizados na escolha de neurônios da camada $l+1$. A seqüência de escolha de neurônios forma um caminho de explicação.

Os mecanismos Como, Por que e Trace são aplicáveis aos três critérios mencionados, sendo que: o mecanismo Como caminha da camada de entrada $E$ até a camada de saída $S$ e o mecanismo Por que caminha da camada de saída $S$ até a camada de entrada $E$.

A explicação dada pelo mecanismo EN é dada seguindo três conceitos que devem ser analisados em conjunto para dar um significado adequado aos grupos de neurônios de entrada selecionados. Estes conceitos são: 
- Pesos maiores contribuem mais, assumindo que as entradas estão normalizadas;

- Nós com entrada significativa podem ser agrupados, e estes grupos constroem e representam conceitos;

- Relacionando informações específicas da aplicação para cada neurônio, pode-se associar um significado concreto aos neurônios de entrada.

\subsection{O método RULEX}

O método de extração de conhecimento de RNAs RULEX [AND95b] [AND95c] trabalha com um tipo específico de RNA que no caso é conhecida como rede CEBP (Constrained Error Backpropagation). Este tipo de RNA possui funções de ativação do tipo LRU (Local Responsive Units). O método RULEX e a rede CEBP são discutidos a seguir.

\subsubsection{A rede CEBP}

A rede CEBP (Constrained Error Backpropagation) possui uma arquitetura MLP (Multi Layer Perceptron) com funções de ativação do tipo LRU (Local Responsive Units). A função de ativação LRU tem como base a diferença de duas funções sigmoid e se comporta de forma semelhante a uma função RBF (Radial Basis Function). Somente será produzida uma resposta significante se a entrada estiver dentro da área de resposta da LRU.

Basicamente, a função sigmoid $f(u)=1 /\left(1+e^{-u}\right)$ é usada na forma $f(a x-c-b / 2)-f(a x-c+b / 2)$

para montar um pico local em uma dimensão como é mostrado na Figura 16. O parâmetro $c$ define o centro do pico e o parâmetro $b$ define a largura do pico. 


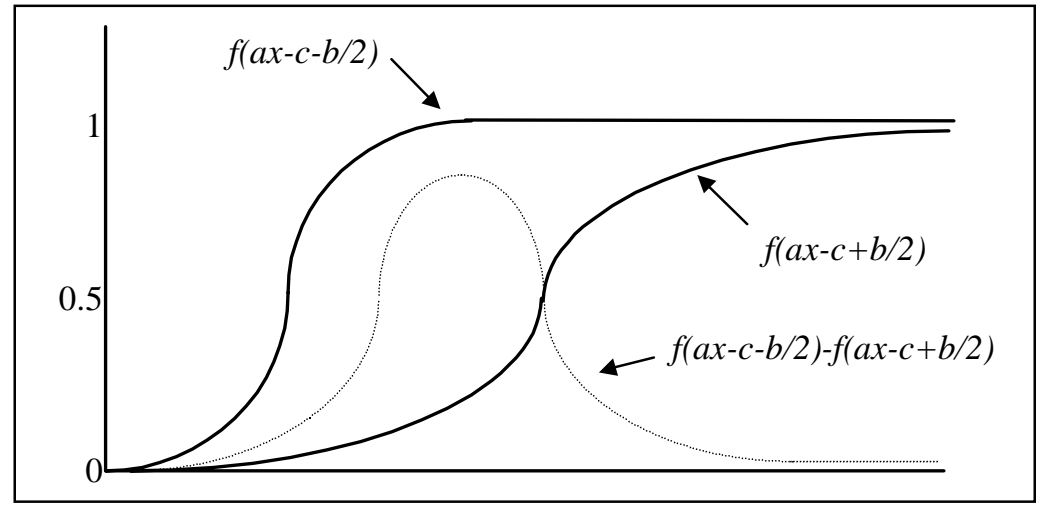

Figura 16: Construção de um pico local a partir de duas sigmoids.

Estas LRUs podem ser compostas em um espaço $N$-dimencional através da conjunção de vários picos. A saída do i-ésimo pico é calculado através da Equação 17:

$$
O_{i}=U_{i}^{+}-U_{i}^{-}
$$

em que:

$$
\begin{gathered}
U_{i}^{+}=\frac{1}{1+e^{-\left(x_{i}-c_{i}+b_{i}\right) k_{i}}} \\
U_{i}^{+}=\frac{1}{1+e^{-\left(x_{i}-c_{i}-b_{i}\right) k_{i}}}
\end{gathered}
$$

em que $x_{i}$ é a entrada da $i$-ésima dimensão, $c_{i}$ a coordenada do centro do pico, $b_{i}$ a amplitude do pico e $k_{i}$ é o inclinação do pico.

A intersecção de $N$ picos forma um pico local no ponto de intersecção com picos secundários em outros pontos. Estes picos secundários podem ser removidos através da aplicação de uma função sigmoidal mostrada na Equação 20:

$$
V=\frac{1}{1+e^{-\left(\sum_{i=1}^{N}\left(U_{i}^{+}-U_{i}^{-}\right)-B\right) K}}
$$

em que $B$ é igual à dimensão de entrada e $K$ recebe valores no intervalo de 4 a 8 . 
A rede mais apropriada para classificação binária pode ser criada com uma camada de entrada, uma camada intermediária contendo $n$ neurônios com funções de ativação LRU e uma unidade de saída com a função de ativação ilustrada pela Equação 21:

$$
O=\sum_{\mu=1}^{N} V_{\mu} w_{\mu}
$$

O treinamento deste tipo de RNA envolve o ajuste dos parâmetros da LRU e os pesos existentes na RNA.

\subsubsection{Fixando respostas localmente em cada unidade}

Para facilitar o trabalho de extração de conhecimento, é necessário que se configure a RNA de forma que cada exemplo seja classificado por exatamente uma LRU. Ou seja, ao ser calculada a Equação 3.6 é necessário que $V_{\mu} w_{\mu}=1$ para $\mu=j$ sendo $j$ um valor fixo entre 1 e $n$, e $V_{\mu} w_{\mu}=0$ para $\mu \neq j$. Após o treinamento da rede, cada exemplo deve estar ativando uma única LRU, a seguir, cada LRU será transformada em uma regra.

Por exemplo, considerando $V_{j}=0.5$, é necessário $w_{j}=2$ para se ter $O=1$. Supondo que duas RLUs sejam ativadas para um dado exemplo produzindo $O=2$ quando se esperava $O=1$. Neste caso, a saída obtida é significantemente diferente da saída esperada, provocando assim a backpropagação do erro. Se, neste caso, não for permitida a alteração de pesos, a RNA será obrigada a deslocar o centro da LRU e fazer com que somente uma LRU esteja ativa para este exemplo.

\subsubsection{Extraindo regras de RNAs através do RULEX}

Cada LRU $N$-dimensional pode ser convertida em uma regra baseada em seus $N$ picos. Tal regra pode ser escrita da seguinte forma:

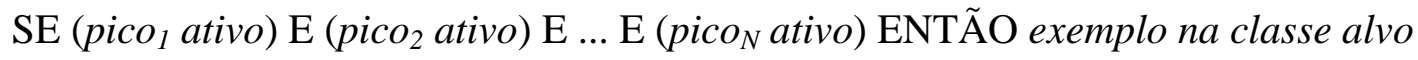


A LRU é ativada quando todos os componentes $x_{i}$ do exemplos se encaixarem no intervalo de ativação de cada pico. O intervalo de ativação de cada pico pode ser encontrado através de manipulações algébricas na Equação 3.6 em que pode-se chegar nos valores de $x_{i_{\min }} \mathrm{e}$ $x_{i_{\max }}$ mostrados nas Equações 22 e 23, respectivamente.

$$
\begin{gathered}
x_{i_{\text {min }}}=c_{i}-b_{i}+\frac{2.45}{k_{i}} \\
x_{i_{\max }}=c_{i}+b_{i}-\frac{2.45}{k_{i}}
\end{gathered}
$$

logo, para verificar se o pico $i$ está ativo, é só verificar se $x_{i_{\min }} \leq x_{i} \leq x_{i_{\max }}$.

\subsection{Sumário do Capítulo}

Neste Capítulo foram apresentados algoritmos de extração de conhecimento de Redes Neurais Artificiais. Foram apresentados três algoritmos: o TREPAN, o EN e o RULEX. Estes algoritmos procuram apresentar o conhecimento armazenado em uma Rede Neural Artificial de uma maneira mais simples de ser entendida pelos seres humanos.

O melhor entendimento do conhecimento armazenado em uma RNA é importante em muitos aspectos. Entre os benefícios trazidos pela representação do conhecimento de forma mais simples estão: o aumento de confiança dos seres humanos em RNAs, auxílio no reprojeto de RNAs e a validação de RNAs.

O próximo Capítulo traz experimentos realizados com algoritmos de extração de conhecimento. Os resultados são analisados e apresentados através de tabelas e gráficos. 


\section{Experimentos}

Neste Capítulo são apresentados os experimentos realizados com os algoritmos CN2, C4.5, TREPAN e com RNAs. Para isso foram utilizadas três bases: dados de falência de bancos brasileiros, jogo da velha e análise de crédito. Os experimentos são apresentados em forma de tabelas e gráficos visando o melhor entendimento dos resultados obtidos.

A seguir é realizada uma discussão sobre o trabalho de pré-processamento, anterior à fase de extração de conhecimento. Também é apresentado um breve resumo sobre cada uma das bases de dados utilizadas. Posteriormente, é apresentado o trabalho realizado em cada uma das bases de dados.

\subsection{Visão geral do pré-processamento dos Dados}

As Redes Neurais Artificiais e os algoritmos de aprendizado simbólico exigem uma fase de pré-processamento dos dados anterior à realização do treinamento. Esse pré-processamento pode ser simples ou complexo, dependendo dos dados a serem trabalhados e do algoritmo a ser empregado.

\subsubsection{Pré-processamento dos dados para as RNAs}

O tratamento dos dados necessários para um bom aprendizado envolvendo RNAs pode ser uma tarefa trabalhosa, e assim consumir uma boa parte do processo de aprendizado. Os principais tipos de tratamentos de dados para posterior utilização por RNAs são:

- Valores desconhecidos: valores desconhecidos devem ser definidos de alguma forma. Existem várias maneiras possíveis para definição de valores desconhecidos, entre elas podem ser citadas:

- Média: valores desconhecidos de um atributo podem ser substituídos pela média de todos os seus valores. Em atributos que representam valores de uma sequiência, a média de $n$ valores anteriores e posteriores pode ser utilizada para a definição do valor desconhecido. 
- Definição de novos valores: de acordo com cada problema, valores arbitrários podem ser definidos para o preenchimento de campos desconhecidos.

- Atributos simbólicos: os valores não numéricos devem ser codificados para valores numéricos, o que pode resultar em um vetor binário ou de valores inteiros. Uma característica codificada em um vetor binário associa à cada elemento deste vetor uma unidade de entrada da rede. Uma característica codificada em valores inteiros deve ser associada à um único elemento de entrada da rede. Essa codificação deve também levar em conta a presença ou não de ordenação nos dados da seguinte forma:

- Dados não ordenados: devem ser codificados como vetores de valores binários, onde, somente um elemento do vetor é igual a 1 e os demais são iguais a 0 . Como exemplo de codificação em que não existe ordenação nos dados, pode ser citado o caso de informações sobre sexo. O sexo feminino pode ser representado pelo vetor $(0,1)$ e o sexo masculino pelo vetor $(1,0)$. O tamanho deste vetor pode ser reduzido utilizando, por exemplo, o código de Hadamard [PRA78].

- Dados ordenados: devem ser codificados em uma seqüência de números inteiros ou utilizando codificação binária em níveis de cinza. Um exemplo de codificação de características em que existe ordenação, seria a representação de classes sociais. As classes sociais $A, B$ e $C$ podem ser codificadas para os vetores binários $(1,1),(1,0)$ e $(0,0)$ ou para os inteiros $3,2,1$, respectivamente.

- Normalização: para que a rede aprenda melhor e mais rapidamente, é aconselhável a transformação de todos os atributos de valores reais para um mesmo intervalo. Dados com atributos em escalas diferentes podem confundir a rede fazendo que esta dê mais importância para aqueles com maiores valores. Os intervalos mais comuns são de 0 a 1 ou de -1 a 1 e podem ser obtidos através da Equação 24.

$$
y_{i}=\left(\frac{\left(x_{i}-x_{\min }\right)\left(y_{\text {max }}-y_{\text {min }}\right)}{x_{\text {max }}-x_{\text {min }}}\right)+y_{\text {min }} \quad \text {, para } i=1 . . n
$$


em que:

$y_{i}:$ valor normalizado;

$x_{i}$ : valor a ser normalizado;

$x_{\min }$ : menor valor do intervalo origem da normalização;

$x_{\max }$ : maior valor do intervalo origem da normalização;

$y_{\min }$ : menor valor do intervalo destino da normalização;

$y_{\max }$ : maior valor do intervalo destino da normalização;

$n$ : quantidade de valores a serem normalizados.

\subsubsection{Pré-processamento dos dados para o CN2 e C4.5}

Em geral, o pré-processamento exigido pelos algoritmos CN2 e C4.5 é rápido e simples de ser feito. Atributos simbólicos e numéricos são tratados diretamente por esses algoritmos.

Esses algoritmos simbólicos possuem uma política interna para manipular atributos desconhecidos e irrelevantes. Os valores desconhecidos são representados pelo símbolo de interrogação (?). Os valores irrelevantes são representados pelo símbolo asterisco (*).

Os dois algoritmos exigem a declaração dos tipos de atributos de entrada e de classes. Os conjuntos de exemplos devem ser definidos em termos dos tipos desses atributos, seguindo uma sintaxe mínima exigida. Um conjunto de exemplos para o algoritmo CN2 deve ter os atributos de entrada separados por espaços em branco, seguidos da classe e um ponto e vírgula. Um conjunto de exemplos para o C4.5 deve ter os atributos de entrada separados por vírgula seguidos pela especificação da classe associada.

\subsubsection{Divisão do conjunto de dados}

A divisão do conjunto de dados para os algoritmos CN2 e C4.5 foi feita com $75 \%$ para o conjunto de treinamento e $25 \%$ para o conjunto de testes. Para as RNAs foi feita uma divisão de $50 \%$ para o conjunto de treinamento e $25 \%$ para o conjunto de teste. Os $25 \%$ dos dados restantes foram deixados no conjunto de validação. Esta divisão foi realizada seguindo os critérios propostos em PROBREN1 [PRE94]. 
Para obtenção de um bom resultado, devem ser feitas várias divisões diferentes do mesmo conjunto de dados em conjuntos de treinamento e de testes. Este método, chamado de cross validation [RIP96], fornece uma estimativa mais realista do erro a ser cometido pelo método de classificação utilizado.

Deve ser observada nesta divisão a importância de manter a mesma proporção entre as classes para os conjuntos de treinamento e de validação. O conjunto de treinamento, com uma quantidade muito maior de exemplos de uma classe em relação às demais, faz com que o aprendizado favoreça os exemplos da maior classe. O conjunto de teste com uma distribuição de classes balanceada favorece uma análise estatística mais confiável dos resultados obtidos.

Em dados que apresentam uma diferença significativa entre o tamanho das classes envolvidas, o aprendizado pode favorecer a classe de maior número, atribuindo menor importância para a classe com menos exemplos. Para solucionar este problema algumas medidas podem ser tomadas:

- Partição pela menor classe ou redução de classes: exemplos da classe com maior número de exemplos podem ser eliminados aleatoriamente para construção do conjunto de treinamento com igual número de classes;

- Acréscimo de dados com ruídos: a técnica de redução de classes não pode ser aplicada quando o conjunto de dados final se tornar muito reduzido. Este problema pode ser solucionado através da inclusão de uma taxa de ruído nos dados originais da menor classe, gerando assim, novos padrões. Também podem ser replicados exemplos com o objetivo de aumento do número total de exemplos. Nessa dissertação, este caso será referenciado como adição de exemplos com $0 \%$ de ruído;

- Seleção de dados: realizar seleção de exemplos mais relevantes do domínio, descartando exemplos não significativos. 


\subsubsection{Pré-processamento dos dados para o algoritmo TREPAN}

O algoritmo TREPAN deve ser aplicado sobre uma RNA previamente treinada. Como entradas para o algoritmo devem ser fornecidos: os dados de treinamento, validação e teste, informações sobre a natureza dos atributos de entrada, a arquitetura da rede, os valores dos pesos dos neurônios, o valor de bias de cada neurônio e os parâmetros de treinamento exigidos pelo TREPAN.

Assim como os algoritmos simbólicos e conexionistas, o algoritmo TREPAN também exige uma fase de pré-processamento. Uma vez de posse dos dados pré-processados para as RNAs, o próximo passo é montar os arquivos com informações sobre a arquitetura, os pesos e o tipo e nome de cada entrada.

\subsection{Critério de avaliação dos resultados}

Com o objetivo de avaliar o desempenho alcançado pelas técnicas discutidas neste trabalho, é comparado o conhecimento por RNAs com o conhecimento extraído através do uso de técnicas simbólicas. Existem três maneiras diferentes de avaliar a qualidade do conhecimento extraído:

- Taxa de acertos;

- Compreensibilidade;

- Grau de "surpresa" ou descobertas de informações previamente desconhecidas.

Este trabalho avalia o desempenho das técnicas de extração de conhecimento em termos de sua taxa de acertos e compreensibilidade dos conhecimentos extraídos. A análise para descobertas de informações desconhecidas requer um conhecimento maior do domínio dos dados, o que requer o auxílio de um especialista. Nessa dissertação, três bases de dados distintas são utilizadas: falência de bancos, jogo da velha e análise de crédito. 


\subsection{Falência de bancos}

O processo de estabilização da economia brasileira exigiu uma adaptação rigorosa das instituições bancárias à nova situação. A queda acentuada da inflação e o aumento das taxas de crédito provocaram a declaração de falência de cerca de 34 bancos entre os anos de 1994 e 1996.

Este experimento foi conduzido utilizando dados sobre 246 Instituições Bancárias brasileiras de micro (44\%), pequeno (22\%), médio (23\%) e grande (11\%) porte. Estas proporções são melhor ilustradas na Figura 17. A origem do capital destas instituições é de natureza privado nacional, estrangeiro, oficial federal, oficial estadual e associação estrangeira.

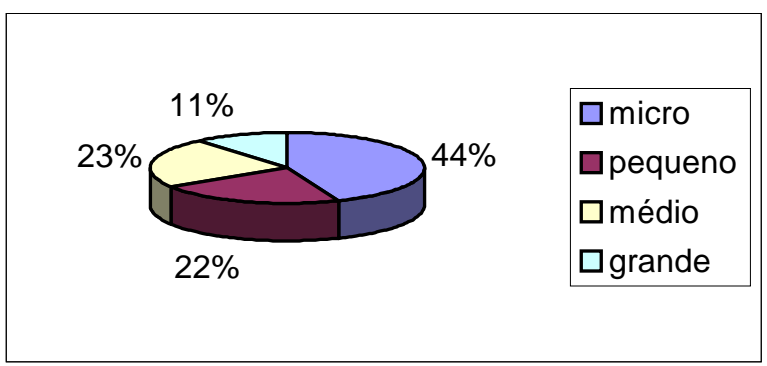

Figura 17: Proporções das instituições bancárias em relação ao porte.

O objetivo deste experimento é o de classificar bancos solventes e insolventes baseado em indicadores da situação financeira atual desses bancos. Um banco é considerado insolvente se estiver sob intervenção, ou se foi vendido ou liquidado. A proporção de exemplos relativos às classes de bancos solventes e insolventes pode ser vista na Figura 18. As seguintes proporções são encontradas: 212 exemplos de Instituições solventes (86 \%) e 34 exemplos de Instituições insolventes $(14 \%)$.

Todas as informações sobre bancos solventes foram colhidas em junho de 1995. As informações sobre os bancos insolventes foram colhidas na data mais próxima anterior à sua falência, entre o período de dezembro de 1993 a julho de 1995. Os dados foram fornecidos pelo Professor Alberto Matias da Faculdade de Economia e Administração da Universidade de São Paulo (FEA - USP Ribeirão Preto). 


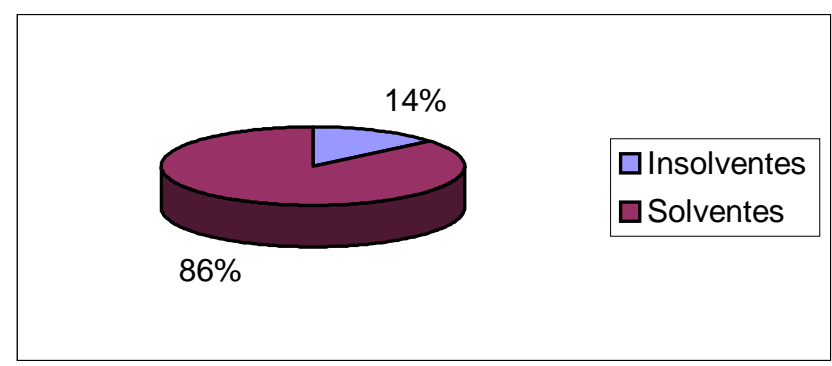

Figura 18: Proporções das instituições bancárias com relação a situação de solvência e insolvência.

Como pode ser visto na Figura 18, a dificuldade encontrada neste conjunto de exemplos foi a grande diferença existente na quantidade de casos pertencentes às classes de bancos solventes e insolventes. Essa dificuldade se deve ao reduzido número de casos para a classe de bancos insolventes. Foram analisadas duas alternativas para a solução destes problemas: redução do número de exemplos da classe com mais exemplos e aumento do número de exemplos da classe menor, através da inclusão de dados com e sem ruídos.

Foram consideradas duas listas de atributos do conjunto original para essa tarefa de classificação. A primeira lista contem todos os atributos deste conjunto, totalizando 26 atributos. A segunda lista foi formada por 10 atributos selecionados entre os anteriores através do Teste-t de correlação [MIL90] [ALM97]. Estes atributos são indicadores que descrevem a situação financeira atual das instituições bancárias.

O conjunto de 26 atributos é formado pelos seguintes atributos: capitalização, imobiliário própria, imobiliário total, capital de giro, alavancagem, encaixe, cobertura voluntária, liquidez corrente, assistência financeira, adequação de prazos, inadimplência, aprovisionamento, comprometimento, custo de intermediação, custo de pessoal, custo administrativo, custo total, geração rendas, margem bruta, margem operacional, margem liquida, rentabilidade do patrimônio líquido, aplicações totais, captações totais, recursos de intermediação financeira, crescimento das reservas liquido.

O conjunto de 10 atributos é constituído por: ativo, capital de giro, alavancagem., comprometimento, custo de intermediação, custo de pessoal, custo administrativo, geração de rendas, rentabilidade do patrimônio líquido, captações totais. 


\begin{tabular}{|c|c|c|c|}
\hline Instituição & Última situação & Insolvência & $\begin{array}{c}\text { defasagem } \\
\text { (meses) }\end{array}$ \\
\hline BANESPA & jun/94 & dez/94 & 6 \\
\hline NACIONAL & jun/95 & nov/95 & 5 \\
\hline ECONOMICO & jun/95 & ago/95 & 1 \\
\hline BANERJ & $\mathrm{dez} / 94$ & $\mathrm{dez} / 94$ & 0 \\
\hline ITAMARATI & jun/95 & jul/96 & 13 \\
\hline BANORTE & jun/95 & nov/95 & 4 \\
\hline AGRIMISA & $\mathrm{dez} / 94$ & abr/95 & 3 \\
\hline BANCO ROSA & jun/94 & $\mathrm{mar} / 95$ & 8 \\
\hline BANQUEIROZ & jun/95 & $\mathrm{mar} / 96$ & 8 \\
\hline MERCANTIL & jun/95 & ago/95 & 1 \\
\hline BANCESA & jun/94 & fev/95 & 8 \\
\hline OPEN & jun/94 & jan/95 & 7 \\
\hline MARTINELLI & jun/95 & jun/96 & 11 \\
\hline BANCORP & jun/94 & nov/94 & 5 \\
\hline BERON & $\mathrm{dez} / 94$ & fev/95 & 2 \\
\hline PRODUBAN & $\mathrm{dez} / 94$ & $\mathrm{jan} / 95$ & 1 \\
\hline ATLANTIS & jun/94 & nov/94 & 5 \\
\hline BFC BANCO & jun/95 & dez/95 & 5 \\
\hline BEMAT & $\mathrm{dez} / 94$ & fev/95 & 1 \\
\hline MAPPIN & jun/95 & jul/96 & 12 \\
\hline HERCULES & $\operatorname{dez} / 93$ & jul/94 & 7 \\
\hline UNIVERSAL & jun/95 & jun/96 & 12 \\
\hline INVESTCORP & jun/95 & dez/95 & 5 \\
\hline BFI & jun/95 & abr/96 & 10 \\
\hline BIG & $\operatorname{dez} / 94$ & ago/95 & 8 \\
\hline SELLER & jun/94 & nov/94 & 5 \\
\hline GARAVELO & $\mathrm{dez} / 93$ & jul/94 & 7 \\
\hline GNPP & jun/95 & $\mathrm{dez} / 95$ & 5 \\
\hline DRACMA & jun/95 & $\mathrm{mar} / 96$ & 9 \\
\hline ADOLPHO OLIVEIRA & jun/94 & nov/94 & 5 \\
\hline COMERCIAL DE SP & dez/94 & ago/95 & 8 \\
\hline BRASBANCO & $\operatorname{dez} / 93$ & set/94 & 9 \\
\hline BANCO SAO JORGE & jun/94 & $\mathrm{mar} / 95$ & 8 \\
\hline FININVEST & $\operatorname{dez} / 94$ & $\mathrm{jan} / 95$ & 1 \\
\hline
\end{tabular}

Tabela 1: Defasagem entre a data de falência do banco e a última informação disponível.

O problema de falência de bancos encaixa-se no contexto de reconhecimento de padrões. Um dos objetivos fundamentais do reconhecimento de padrões é o de classificação: dado uma entrada, ela é analisada para obter informações relevantes a respeito de uma determinada classe a que ela pertence. Alguns dos experimentos de classificação envolvendo dados de falência de bancos brasileiros foram realizados em conjunto com o aluno de mestrado Hélio Diniz. 


\subsubsection{Divisão dos conjuntos de dados e acréscimo de dados com ruído}

A diferença entre o número de exemplos existente em cada classe prejudica 0 desempenho na identificação de exemplos pertencentes à menor classe. A seguir é descrita a formação dos conjuntos de treinamento, validação e teste através das técnicas de Redução de classes e de Acréscimo de dados com Ruídos:

- Partição pela menor classe: foram eliminados exemplos da classe de bancos solventes dos conjuntos de treinamento e validação:

- Conjunto de Treinamento: formado por 18 exemplos de bancos solventes e 18 de bancos insolventes, totalizando 36 exemplos.

- Conjunto de Validação: formado por 8 exemplos de bancos solventes e 8 de bancos insolventes, totalizando 16 exemplos.

- Conjunto de Teste: formado por 186 exemplos de bancos solventes e 8 de bancos insolventes.

- Acréscimo de dados com ruídos: foram adicionados novos exemplos à classe de bancos insolventes:

- Conjunto de Treinamento: formado por 106 exemplos de bancos solventes, 108 exemplos de bancos insolventes. A formação dos 108 exemplos de bancos insolventes utilizou 18 exemplos originais de bancos insolventes e 90 exemplos formados a partir da inclusão de dados com ruídos nos 18 exemplos de bancos insolventes originais.

- Conjunto de Validação: formado por 53 exemplos de bancos solventes e 48 exemplos de bancos insolventes. A formação dos 48 exemplos de bancos insolventes utilizou 8 exemplos originais de bancos insolventes e 40 exemplos formados a partir da inclusão de ruídos nos 8 exemplos de bancos insolventes originais.

- Conjunto de Teste: formado por 53 exemplos de bancos solventes e 48 exemplos de bancos insolventes. A formação dos 48 exemplos de bancos insolventes utilizou 8 
exemplos originais de bancos insolventes e 40 exemplos formados a partir da inclusão de ruídos nos 8 exemplos de bancos insolventes originais.

Os níveis de ruídos introduzidos nos dados originais foram de 0\%, 10\%, $20 \%$ e 30\% seguindo um modelo de distribuição uniforme [MIL90]. Para uma análise mais segura dos resultados obtidos, foram feitas 3 divisões diferentes do mesmo conjunto original de dados, gerando assim, 3 conjuntos de treinamento, 3 conjuntos de validação e 3 conjuntos de testes para cada nível de ruído adicionado. Nos experimentos com os algoritmos CN2 e C4.5, o conjunto de treinamento foi formado com a junção dos conjuntos de treinamento e validação previamente descritos.

\subsubsection{Pré-processamento dos dados de bancos}

O pré-processamento realizado nos dados de falência de bancos brasileiros para as RNAs, foi a normalização dos atributos de entrada para o intervalo de -1 a 1 utilizando a Equação 24. Valores desconhecidos foram substituídos por zero após a normalização. Nenhum outro tipo de codificação foi necessária, pois todos os dados assumem valores do tipo real.

O pré-processamento realizado para as saídas foi a codificação das classes de bancos solventes e insolventes na forma de dois neurônios na camada de saída, de acordo com o seguinte critério:

- Banco insolvente:

- $\quad$ Neurônio $1=1$

- $\quad$ Neurônio $2=0$

- Banco solvente:

- Neurônio $1=0$

- $\quad$ Neurônio 2 = 1

Para os algoritmos CN2 e C4.5, o pré-processamento realizado consistiu de poucas alterações dos valores originais. Foi realizada a substituição de valores desconhecidos pelo 
símbolo “?” e a colocação dos dados em um formato capaz de ser lido pelos algoritmos CN2 e C4.5.

\subsubsection{Resultados dos Experimentos}

Nos experimentos com RNAs do tipo MLP, foram feitas várias modificações em parâmetros chave visando sempre uma melhoria nos resultados obtidos. Foram modificados parâmetros referentes ao número de camadas escondidas, número de neurônios nas camadas escondidas e parâmetros específicos do algoritmo de aprendizado. Os experimentos utilizando os algoritmos CN2, C4.5 e TREPAN foram realizados com os parâmetros padrões atribuídos quando estes são iniciados.

Durante a realização dos experimentos com o conjunto original de dados contendo 26 atributos e com o mesmo conjunto de dados com uma seleção de 10 atributos, constatou-se que o conjunto de dados contendo uma seleção de 10 atributos obteve um desempenho melhor. Por esse motivo, os experimentos envolvendo os algoritmos CN2, C4.5 e TREPAN foram realizados com o conjunto de dados com a seleção de 10 atributos.

Experimentos adicionais com esta mesma base de dados também encontram-se publicados em [ALM97], [MAR97], [MAR98] e [MAR99].

\subsubsection{Resultados utilizando C4.5}

Os experimentos com o algoritmo C4.5 utilizaram o conjunto de dados contendo uma seleção de 10 atributos do problema de falência de bancos brasileiros.

A Tabela 2 mostra o desempenho alcançado pelas Árvores de Decisão geradas pelo algoritmo C4.5. Como pode ser visto, o melhor resultado na fase de teste foi obtido pela adição de $20 \%$ de ruído, embora a adição de $30 \%$ de ruído também tenha levado a um bom desempenho. Para o experimento realizado com a técnica de partição pela menor classe, o conjunto de teste possuía somente 8 exemplos de bancos insolventes e 186 exemplos de bancos 
solventes. Esta grande diferença entre o número de exemplos de cada classe contribuiu para uma alta taxa global de acertos, uma vez que os acertos na classe de banco solventes foi muito alta, enquanto a taxa de acertos na classe de bancos insolventes foi baixa. Esta conclusão foi tomada através de uma avaliação mais detalhada das taxas de acertos alcançadas por cada classe, que pode ser vista na Figura 19.

\begin{tabular}{|c|c|c|}
\cline { 2 - 3 } \multicolumn{1}{c|}{} & \multicolumn{2}{c|}{ Taxa de acertos (\%) } \\
\hline Dados & Treinamento & Teste \\
\hline Part. pela menor classe & $78,2 \pm 4,0$ & $91,6 \pm 1,6$ \\
\hline 0\% ruído & $98,9 \pm 0,3$ & $71,9 \pm 12,8$ \\
\hline 10\% ruído & $97,0 \pm 3,2$ & $67,0 \pm 8,7$ \\
\hline 20\% ruído & $98,1 \pm 1,1$ & $77,2 \pm 7,5$ \\
\hline 30\% ruído & $92,2 \pm 5,9$ & $75,2 \pm 9,1$ \\
\hline \multicolumn{2}{|c|}{ Tabela 2: Desempenho das Árvores de Decisão gerada pelo C4.5. }
\end{tabular}

A Tabela 3 mostra o desempenho alcançado através das regras geradas pelo C4.5. O desempenho alcançado foi muito parecido com o obtido pelas Árvores de Decisão para o mesmo conjunto de dados.

\begin{tabular}{|c|c|c|}
\cline { 2 - 3 } \multicolumn{1}{c|}{} & \multicolumn{2}{c|}{ Taxa de acertos $(\%)$} \\
\hline Dados & Treinamento & Teste \\
\hline Part. pela menor classe & $80,1 \pm 4,4$ & $91,6 \pm 1,6$ \\
\hline 0\% ruído & $99,1 \pm 0,2$ & $71,2 \pm 5,2$ \\
\hline 10\% ruído & $95,1 \pm 5,8$ & $67,0 \pm 8,7$ \\
\hline 20\% ruído & $97,9 \pm 1,0$ & $78,1 \pm 8,0$ \\
\hline 30\% ruído & $91,6 \pm 4,6$ & $77,9 \pm 4,7$ \\
\hline
\end{tabular}

Tabela 3: Desempenho das regras gerada pelo C4.5.

A Figura 19 mostra os desempenhos por classes e globais alcançados no conjunto de teste pelas Árvores de Decisão gerada através do C4.5. A figura mostrando o desempenho alcançado pelas regras no conjunto de testes não será mostrada por apresentar praticamente o mesmo comportamento das Árvores de Decisão. Como pode ser observado na Figura 19, o melhor desempenho global foi alcançado com o acréscimo de dados com $20 \%$ de ruído, embora o acréscimo de dados com 30\% de ruído também tenha apresentado um bom resultado. A Figura 19 torna claro que a elevada taxa de acertos global obtida pelo conjunto com partição pela menor classe se deve à predominância da taxa de acertos da classe com maior número de exemplos. Para esse caso, a média aritmética dos acertos entre as classes de bancos solventes e insolventes é de $69,6 \%$. 


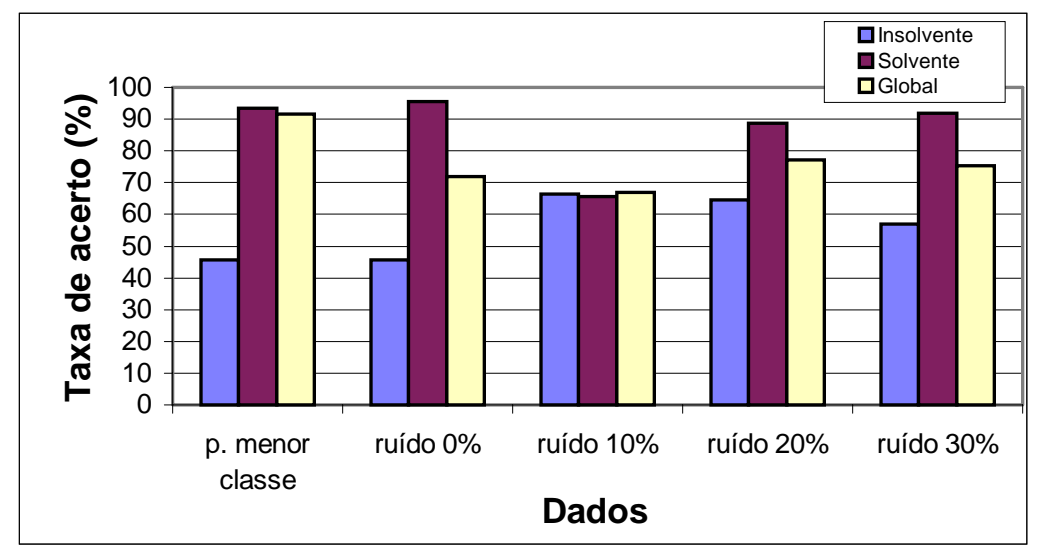

Figura 19: Desempenho da Árvore de Decisão do C4.5 no conjunto de teste.

Dado que para cada nível de ruído foi realizados três experimentos, a Árvore de Decisão apresentada na Figura 20 foi a que obteve desempenho intermediário entre as três árvores extraídas a partir dos experimentos com acréscimo de dados com 30\% de ruídos. Esta árvore possui 14 nós, 15 folhas e altura 9.

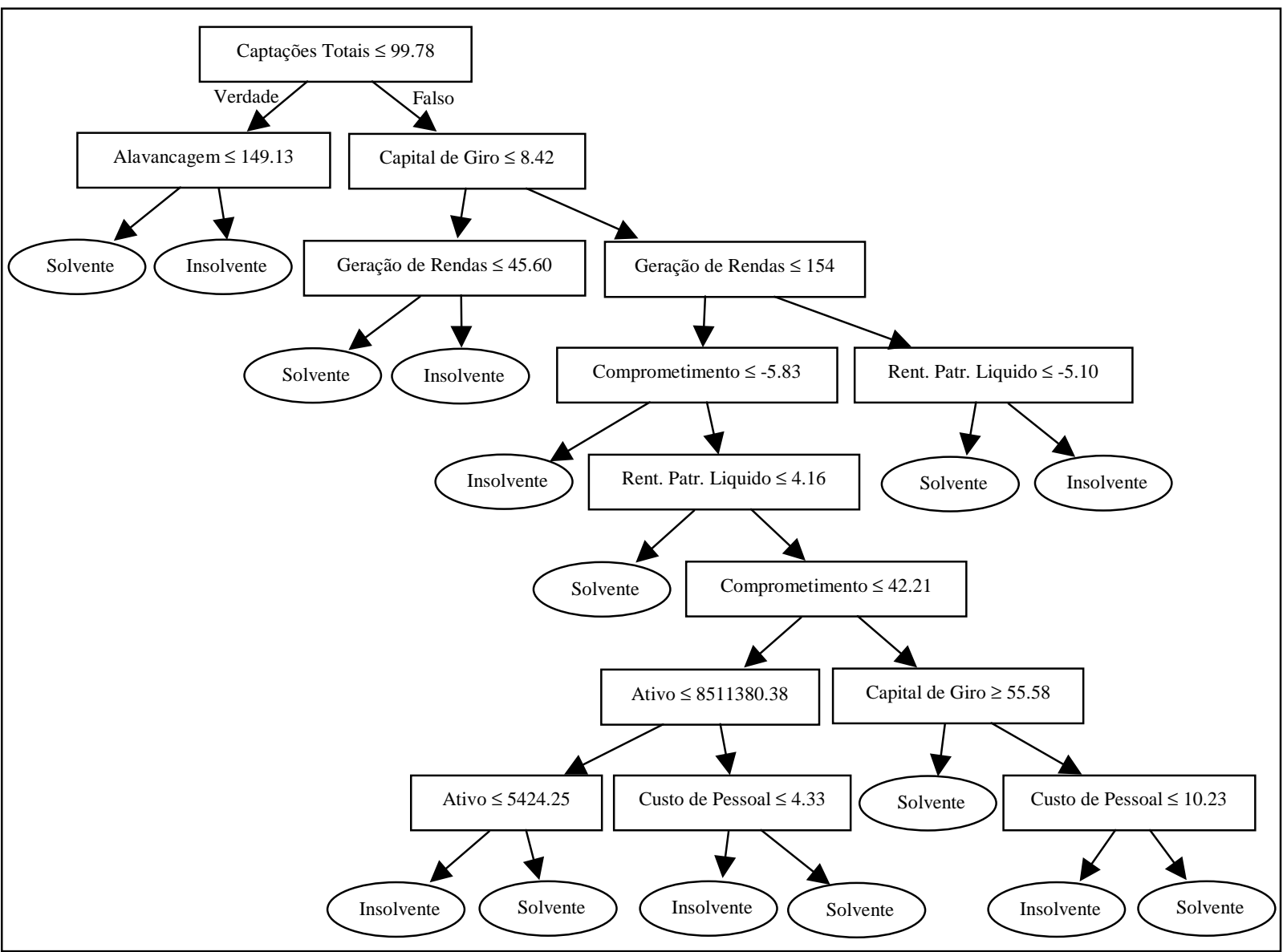

Figura 20: Árvore de Decisão gerada pelo C4.5. 
O mesmo critério utilizado para a escolha da Árvore de Decisão apresentado na Figura 20 foi adotado para a escolha do conjunto de regras não ordenadas apresentadas na Figura 21. Como pode ser visto nesta figura, o algoritmo $\mathrm{C} 4.5$ extraiu para a partição com desempenho médio um conjunto de 14 regras, incluindo a regra padrão (default).

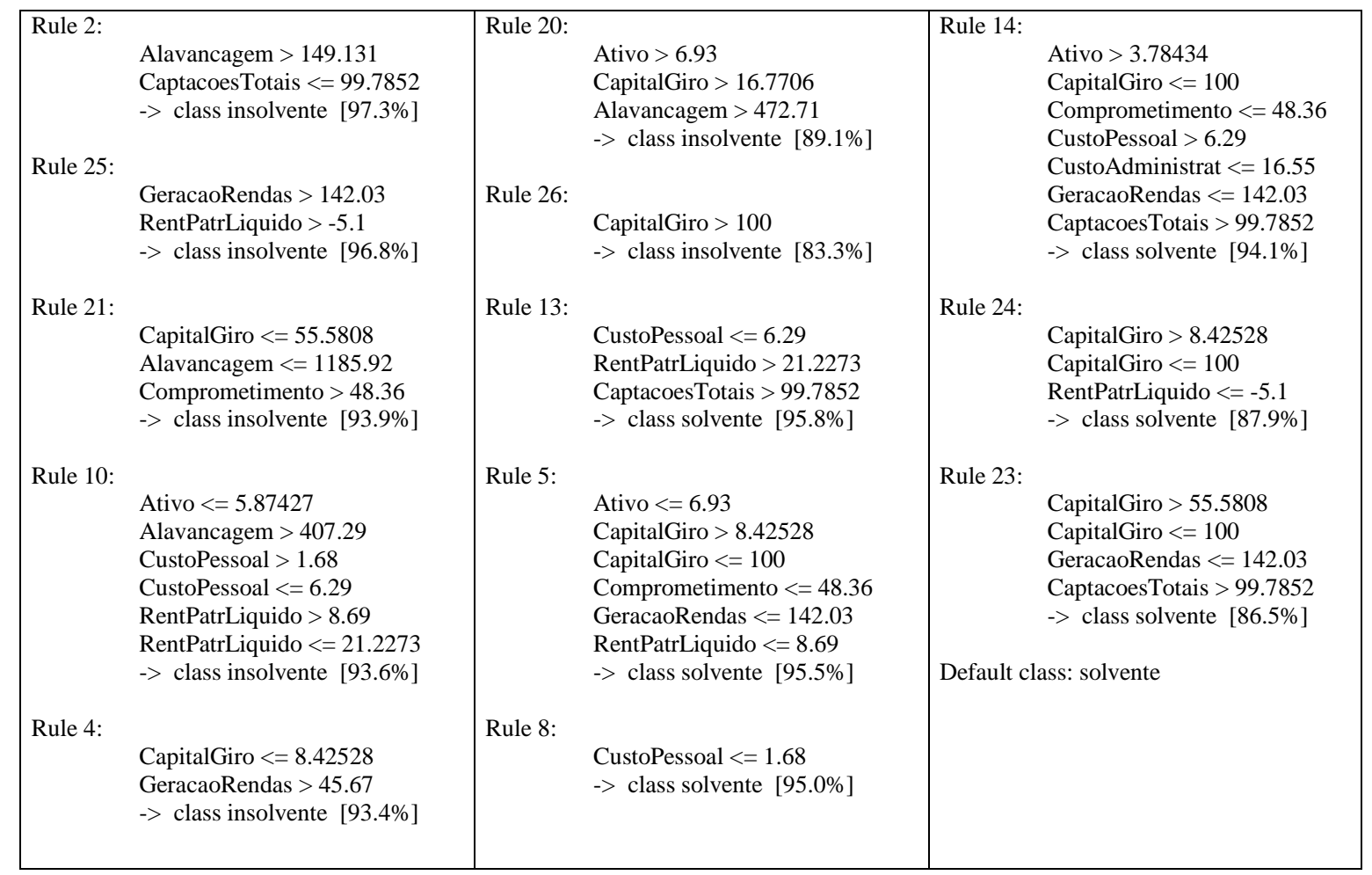

Figura 21: Regras não ordenadas geradas pelo C4.5.

\subsubsection{Resultados utilizando CN2}

Para os experimentos com o algoritmo CN2, também foi utilizado o conjunto de dados contendo uma seleção de 10 atributos de falência de bancos brasileiros.

O desempenho médio alcançado pelo algoritmo CN2, utilizando o método Laplaciano, é mostrado pela Tabela 4. Esta tabela mostra, que o melhor e o segundo melhor resultado na fase de teste, foram obtidos com o acréscimo de dados com 30\% e 20\% de ruído respectivamente. 


\begin{tabular}{|c|c|c|}
\cline { 2 - 3 } \multicolumn{1}{c|}{} & \multicolumn{2}{c|}{ Taxa de acertos $(\%)$} \\
\hline Dados & Treinamento & Teste \\
\hline Part. pela menor classe & $97,5 \pm 1,1$ & $68,7 \pm 7,4$ \\
\hline 0\% ruído & $93,7 \pm 2,9$ & $67,0 \pm 4,9$ \\
\hline 10\% ruído & $91,2 \pm 2,4$ & $66,3 \pm 9,6$ \\
\hline 20\% ruído & $90,4 \pm 1,6$ & $73,6 \pm 10,9$ \\
\hline $30 \%$ ruído & $90,5 \pm 3,7$ & $74,9 \pm 12,4$ \\
\hline
\end{tabular}

Tabela 4: Desempenho do algoritmo CN2.

A Figura 22 mostra o desempenho médio alcançado por cada classe e também o desempenho global no conjunto de testes. Como pode ser visto, o melhor desempenho foi conseguido com a adição de dados com 30\% de ruído. Também pode ser visto que as duas classes obtiveram um desempenho similar quando adicionado dados com $10 \%$ de ruído. É importante ressaltar que o desempenho global apresentados pela partição pela menor classe está fortemente baseado na classe de bancos solventes. Apesar do desempenho conseguido por bancos insolventes ter sido superior a $50 \%$, este resultado está baseado em um número muito pequeno de exemplos. A média aritmética dos desempenhos das 2 classes é de 63,9\%, enquanto que o desempenho global calculado é de $68,7 \%$.

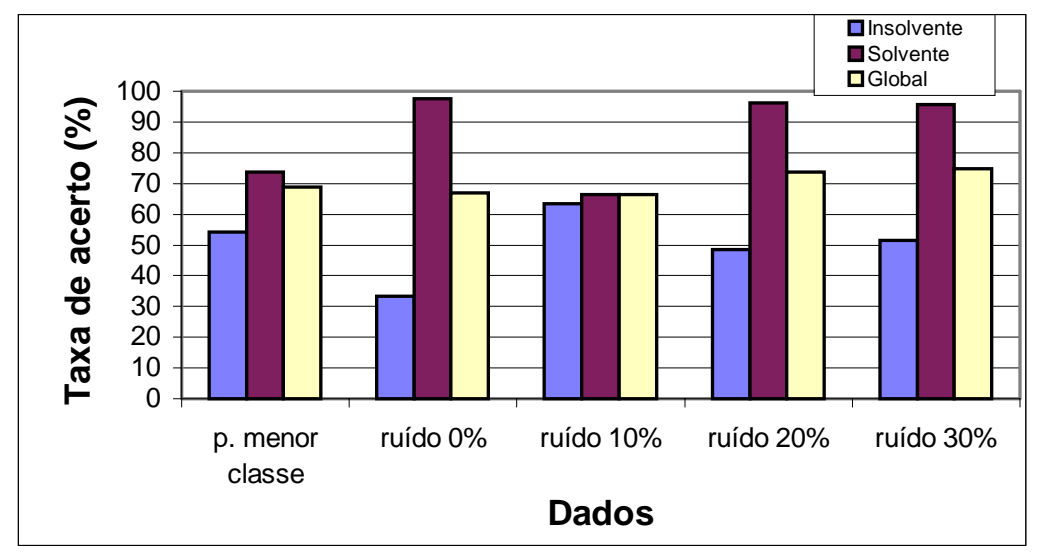

Figura 22: Desempenho do CN2 no conjunto de testes.

A Figura 23 apresenta o conjunto de regras extraído do conjunto de dados com $30 \%$ de ruído. Foi considerada a partição com desempenho médio. Nessa dissertação, as Regras de Produção e Árvores de Decisão serão exibidas sempre para a partição com desempenho médio. Este conjunto possui 19 regras, incluindo a regra padrão (default). Estas regras são do tipo não ordenadas, o que permite uma análise independente para cada uma delas. Isso torna as regras não ordenadas mais fáceis de serem entendidas do que regras ordenadas. Como pode ser visto na 
Figura 23, o algoritmo CN2 extraiu um conjunto de regras formado por 19 regras, incluindo a regra padrão (default).

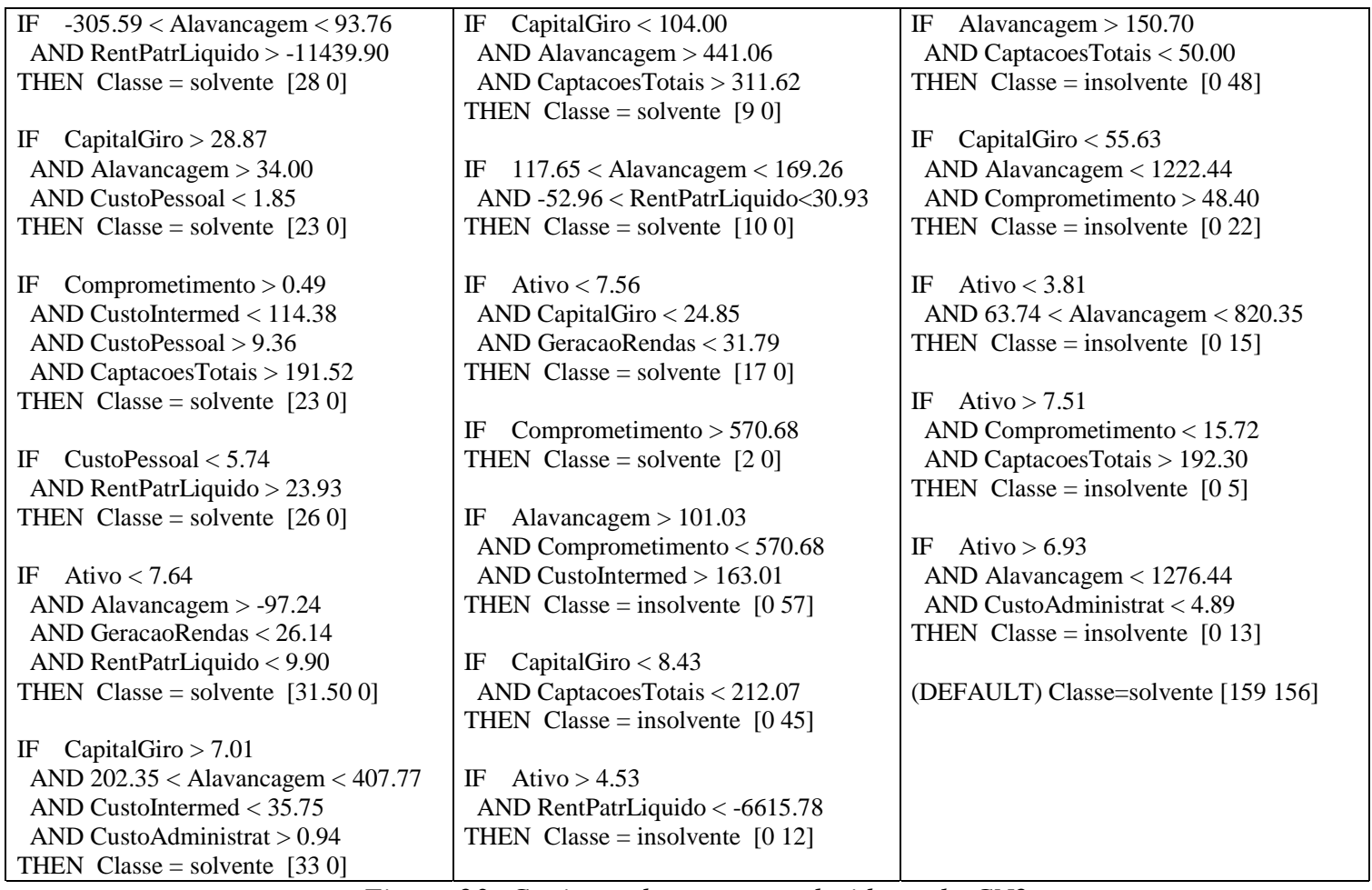

Figura 23: Conjunto de regras produzidas pelo CN2.

\subsubsection{Resultados utilizando RNAs}

Experimentos utilizando dados de instituições bancárias brasileiras foram realizados com RNAs do tipo MLP (Mult Layer Percepton)[HAY99] de arquitetura 10-9-2-2 e 26-4-2-2. Para treinamento foi utilizado o algoritmo de atualização de pesos Rprop (Resilient Backpropagation)[RIE93] durante 1000 ciclos na fase de treinamento. Os experimentos foram realizados utilizando o simulador de Redes Neurais SNNS (Sttutgart Neural Network Simulator) [ZEL95].

Os desempenhos alcançado pelas RNAs utilizando acréscimo de dados com diferentes taxas de ruído são apresentados na Tabela 5. Esta tabela mostra as taxas de acertos alcançadas nas etapas de treinamento, validação e teste com a utilização de 26 atributos. Para cada situação é mostrado a média e o desvio padrão de três experimentos realizados. Como pode ser visto nesta tabela, a adição de dados com ruído melhorou as taxas de acertos. A melhor taxa de acertos para 
o conjunto de validação foi atingida com a adição de dados com 10\% de ruído. O melhor desempenho na fase de teste foi alcançada com a adição de dados com $20 \%$ de ruído.

A Figura 24 mostra as taxas médias de acertos de instituições bancárias solventes, insolventes e as taxas médias de acertos globais. Os resultados apresentados nesta figura representam os resultados alcançados pelo conjunto de testes com partição pela menor classe e com acréscimo de dados com 0\%, 10\%, 20\% e 30\% de ruído. Pode-se observar que o desvio padrão para esse experimento foi alto. Isto sugere a presença de atributos poucos significativos para o problema, que "confundem” as RNAs.

\begin{tabular}{|c|c|c|c|}
\cline { 2 - 4 } \multicolumn{1}{c|}{} & \multicolumn{3}{c|}{ Taxa de acertos $(\%)$} \\
\hline Dados & Treinamento & Validação & Teste \\
\hline Part. pela menor classe & $59,2 \pm 41,7$ & $45,8 \pm 39,7$ & $49,8 \pm 43,7$ \\
\hline $0 \%$ ruído & $50,6 \pm 27,2$ & $44,5 \pm 33,5$ & $38,9 \pm 21,3$ \\
\hline 10\% ruído & $66,1 \pm 8,9$ & $65,0 \pm 5,8$ & $50,8 \pm 4,6$ \\
\hline $20 \%$ ruído & $64,3 \pm 7,9$ & $61,4 \pm 2,0$ & $52,8 \pm 4,9$ \\
\hline $30 \%$ ruído & $57,0 \pm 19,9$ & $51,8 \pm 23,5$ & $44,6 \pm 7,5$ \\
\hline
\end{tabular}

Tabela 5: Desempenho da RNA utilizando 26 atributos

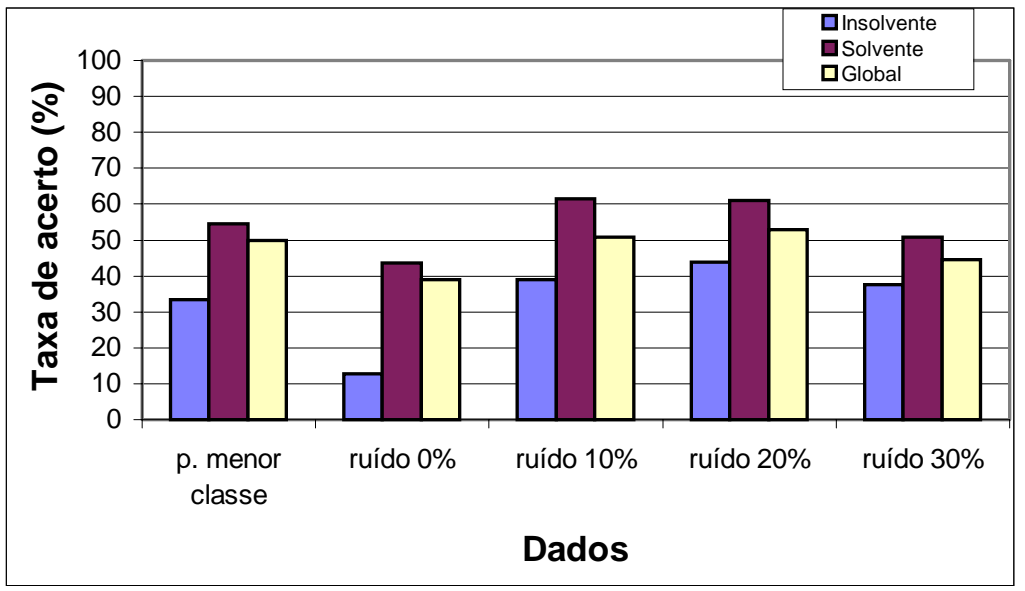

Figura 24: Desempenho da RNA no teste utilizando 26 atributos.

Os desempenhos alcançados na fase de classificação podem ser melhorados através da seleção de atributos mais representativos do problema. Foram selecionados 10 atributos dos 26 atributos originais. A Tabela 6 ilustra as taxas médias de acertos obtidas com a utilização desta seleção de 10 atributos. Como pode ser visto, esta seleção de atributos melhorou a classificação obtida em praticamente todos os níveis de ruído e para os subconjuntos com partição pela menor 
classe. As melhores taxa de acertos, na fase de treinamento e teste, foram obtidas com o acréscimo de dados com $30 \%$ de ruído.

\begin{tabular}{|c|c|c|c|}
\cline { 2 - 4 } \multicolumn{1}{c|}{} & \multicolumn{3}{c|}{ Taxa de acertos $(\%)$} \\
\hline Dados & Treinamento & Validação & Teste \\
\hline Part. pela menor classe & $66,7 \pm 24,0$ & $68,8 \pm 6,3$ & $55,0 \pm 4,6$ \\
\hline 0\% ruído & $54,4 \pm 9,3$ & $53,4 \pm 3,0$ & $46,2 \pm 4,9$ \\
\hline 10\% ruído & $64,8 \pm 18,5$ & $60,7 \pm 10,9$ & $54,4 \pm 15,5$ \\
\hline 20\% ruído & $59,7 \pm 18,2$ & $60,4 \pm 10,4$ & $48,2 \pm 13,2$ \\
\hline 30\% ruído & $71,5 \pm 19,9$ & $68,3 \pm 16,3$ & $64,7 \pm 11,4$ \\
\hline
\end{tabular}

Tabela 6: Desempenho da RNA utilizando 10 atributos.

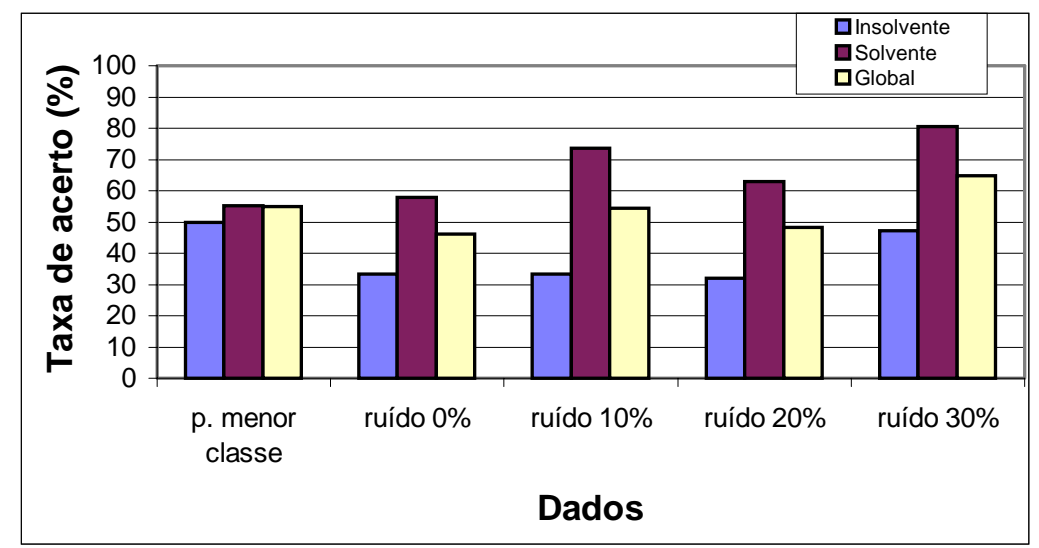

Figura 25: Desempenho da RNA no teste utilizando 10 atributos.

Uma alternativa para melhorar ainda mais os resultados obtidos pela RNA é continuar o treinamento por mais alguns poucos ciclos, utilizando a junção dos conjuntos de treinamento e de validação para atualização dos pesos. A Tabela 7 mostra os resultados obtidos com as mesmas RNAs da Tabela 6, retreinadas com 350 ciclos adicionais, definidos empiricamente, e utilizando os conjuntos de treinamento e de validação para a fase de treinamento. Os resultados mostram uma boa melhora na taxa de acertos e uma maior uniformidade dos resultados. A melhora nos resultados é obtida pela inclusão de um número maior de exemplos nos últimos ciclos do treinamento. O conjunto de validação foi utilizado somente nos últimos 350 ciclos para evitar overfitting $^{2}$.

A Figura 26 ilustra melhor as taxas médias de acertos por classes e global no conjunto de testes. Nessa figura pode-se observar que a partição pela menor classe obteve um bom

\footnotetext{
${ }^{2}$ Overffiting: ocorre quando a taxa de acertos para o conjunto de treinamento é muito alta para o conjunto de testes é baixa.
} 
desempenho na fase de treinamento e um desempenho bem pior na fase de testes. Isto sugere que os dados foram "decorados" pela rede, pelo fato de terem sido apresentados poucos exemplos para a rede na fase de treinamento.

\begin{tabular}{|c|c|c|}
\cline { 2 - 3 } \multicolumn{1}{c|}{} & \multicolumn{2}{c|}{ Taxa de acertos $(\%)$} \\
\hline Dados & Treinamento & Teste \\
\hline Part. pela menor classe & $90,4 \pm 5,1$ & $62,0 \pm 1,6$ \\
\hline 0\% ruído & $80,3 \pm 4,8$ & $65,0 \pm 2,5$ \\
\hline $10 \%$ ruído & $76,6 \pm 7,3$ & $67,7 \pm 1,2$ \\
\hline $20 \%$ ruído & $75,7 \pm 4,8$ & $69,3 \pm 5,5$ \\
\hline $30 \%$ ruído & $79,7 \pm 6,6$ & $73,2 \pm 2,6$ \\
\hline
\end{tabular}

Tabela 7: Desempenho da RNA utilizando 10 atributos e junção dos conjuntos de treinamento e validação.

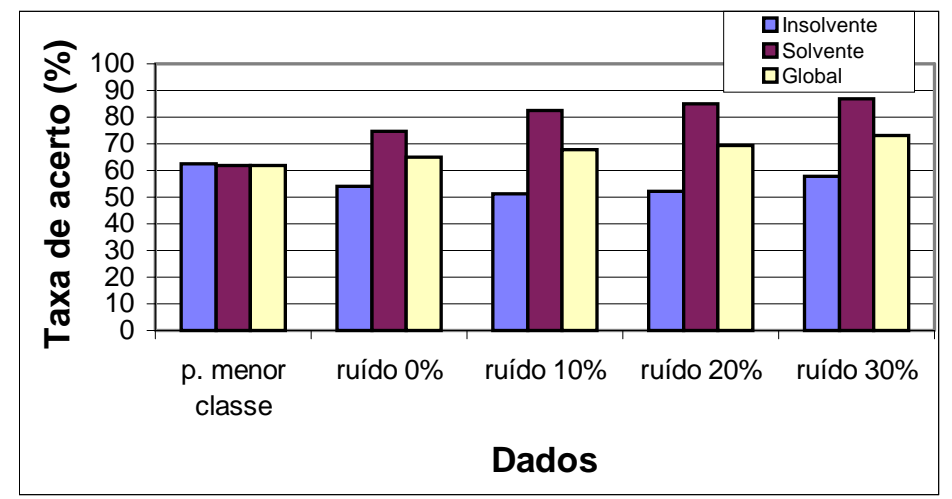

Figura 26: Desempenho da RNA no conjunto de teste utilizando 10 atributos e junção dos conjuntos de treinamento e de teste.

A Figura 27 mostra as taxas médias de acertos do conjunto de testes para cada classe. Esta figura mostra os experimentos utilizando 10 atributos com partição pela menor classe e com acréscimo de dados com $0 \%, 10 \%, 20 \%$ e $30 \%$ de ruído. Também são mostrados os resultados alcançados nos testes pelas RNAs treinadas com a junção do conjunto de treinamento e de validação. $\mathrm{O}$ pequeno número de exemplos de instituições bancárias insolventes dificulta $\mathrm{O}$ trabalho de classificação. O acréscimo de dados com ruído e a junção dos conjuntos de treinamento e de validação, durante os últimos ciclos do treinamento, melhoram o desempenho da RNA. Essa melhora se deu por causa do um aumento no número de exemplos vistos durante a fase de treinamento. Como pode ser visto na Figura 27, o melhor desempenho no conjunto de testes foi conseguido com o acréscimo de dados com $30 \%$ de ruído e a junção dos conjuntos de treinamento e validação nos últimos ciclos de treinamento. 


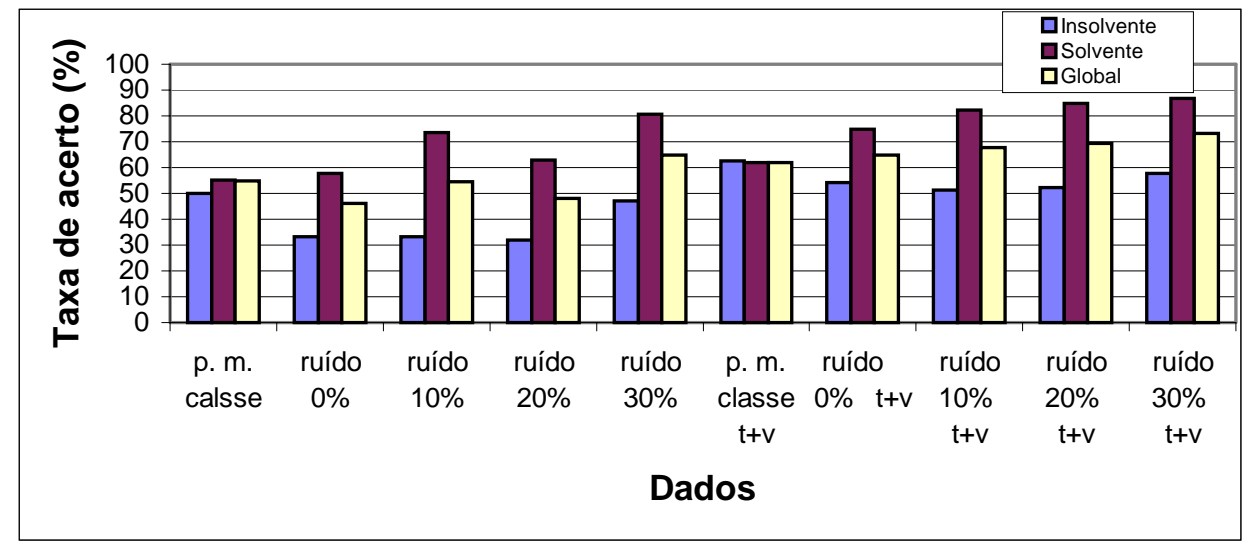

Figura 27: Desempenho das RNAs no teste utilizando 10 atributos e diversos níveis de ruído.

\subsubsection{Resultados utilizando o TREPAN}

Os desempenhos alcançados pelo algoritmo TREPAN com os métodos teste-semples, disjuntivo e $m$-de-n são apresentados na Tabela 8. Para estes experimentos foram utilizadas as RNAs treinadas com a junção dos conjuntos de treinamento e de validação nos últimos ciclos da etapa de treinamento. Os três métodos utilizados alcançaram bons resultados. Como pode ser visto na Tabela 8 e Figura 28, o melhor desempenho do algoritmo TREPAN na fase de teste foi alcançado com o uso do método m-de-n e acréscimo de dados com $20 \%$ de ruído.

O conjunto de dados com partição pela menor classe apresentou um alto desempenho na fase de teste devido a grande predominância de exemplos da classe com maior taxas de acertos. Como pode ser observado na Figura 28, o alto desempenho do teste está muito próximo do desempenho alcançado pela classe de bancos solventes, uma vez que esta classe constitui a grande maioria do conjunto de teste. Considerando a média entre os acertos obtidos em cada classe no conjunto de dados com partição pela menor classe tem-se: 73,1\% para o método testesimples, 68,5\% para o método disjuntivo e 70,2\% para o método $m$-de-n. 


\begin{tabular}{|c|c|c|c|}
\cline { 2 - 3 } \multicolumn{2}{c|}{} & \multicolumn{2}{c|}{ Taxa de acertos (\%) } \\
\hline Método & Dados & Treinamento & Teste \\
\hline \multirow{4}{*}{ teste-simples } & Part. pela menor classe & $71,8 \pm 4,0$ & $82,0 \pm 23,2$ \\
& 0\% ruído & $69,6 \pm 2,6$ & $63,7 \pm 5,5$ \\
& 10\% ruído & $71,9 \pm 2,7$ & $74,6 \pm 5,0$ \\
& 20\% ruído & $73,0 \pm 1,6$ & $70,9 \pm 3,7$ \\
& 30\% ruído & $71,5 \pm 2,9$ & $74,6 \pm 3,7$ \\
\hline \multirow{4}{*}{ disjuntivo } & Part. pela menor classe & $72,4 \pm 6,7$ & $77,8 \pm 29,9$ \\
& 0\% ruído & $71,5 \pm 3,2$ & $73,3 \pm 2,6$ \\
& 10\% ruído & $73,4 \pm 5,8$ & $66,6 \pm 6,8$ \\
& 20\% ruído & $75,3 \pm 2,5$ & $74,6 \pm 2,5$ \\
& 30\% ruído & $66,9 \pm 4,9$ & $73,2 \pm 3,4$ \\
\hline \multirow{5}{*}{ m-of- $n$} & Part. pela menor classe & $73,1 \pm 1,9$ & $88,7 \pm 11,6$ \\
& 0\% ruído & $67,7 \pm 9,4$ & $74,3 \pm 0,0$ \\
& 10\% ruído & $71,6 \pm 3,9$ & $71,6 \pm 3,8$ \\
& 20\% ruído & $76,6 \pm 2,1$ & $76,2 \pm 10,0$ \\
& 30\% ruído & $73,7 \pm 3,6$ & $73,9 \pm 4,9$ \\
\hline
\end{tabular}

Tabela 8: Desempenho alcançado pelo algoritmo TREPAN.

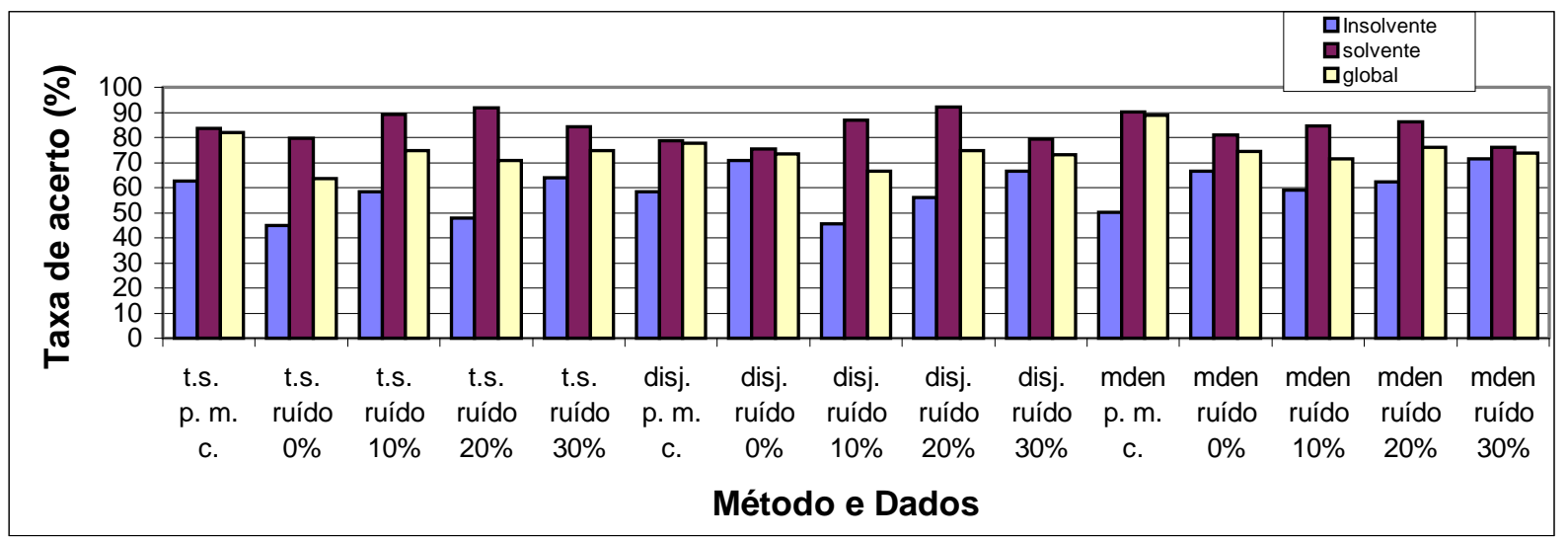

Figura 28: Desempenho do TREPAN no conjunto de teste.

A Figura 29, a Figura 30 e a Figura 31, mostram as Árvores de Decisão produzidas pelos métodos teste-simples, disjuntivo e $m$-de- $n$. Estas árvores foram geradas utilizando a partição que obteve desempenho médio entre as partições com acréscimo de dados com $30 \%$ de ruído. A Figura 29 ilustra a Árvore de Decisão produzida pelo método teste-simples, contendo 5 nós, 6 folhas e altura 6. Este tipo de árvore é de mais fácil compreensão por apresentar testes envolvendo somente um atributo em cada nó. A Figura 30 ilustra a Árvore de Decisão produzida 
pelo método disjuntivo, contendo 6 nós, 7 folhas e altura 5. Nesta árvore a complexidade para a análise é um pouco maior, pois cada nó possui testes contendo mais de um atributo. A Figura 31 ilustra a Árvore de Decisão produzida através do método $m$-de-n, contendo 9 nós, 10 folhas e altura 6. A análise deste tipo de árvore é mais complexa que a dos outros dois tipos. Na árvore do tipo $m$-de-n, cada nó possui um teste com vários atributos. Pelo menos $m$ das $n$ condições que envolvem o teste devem ser satisfeitas para que o teste retorne o valor verdade.

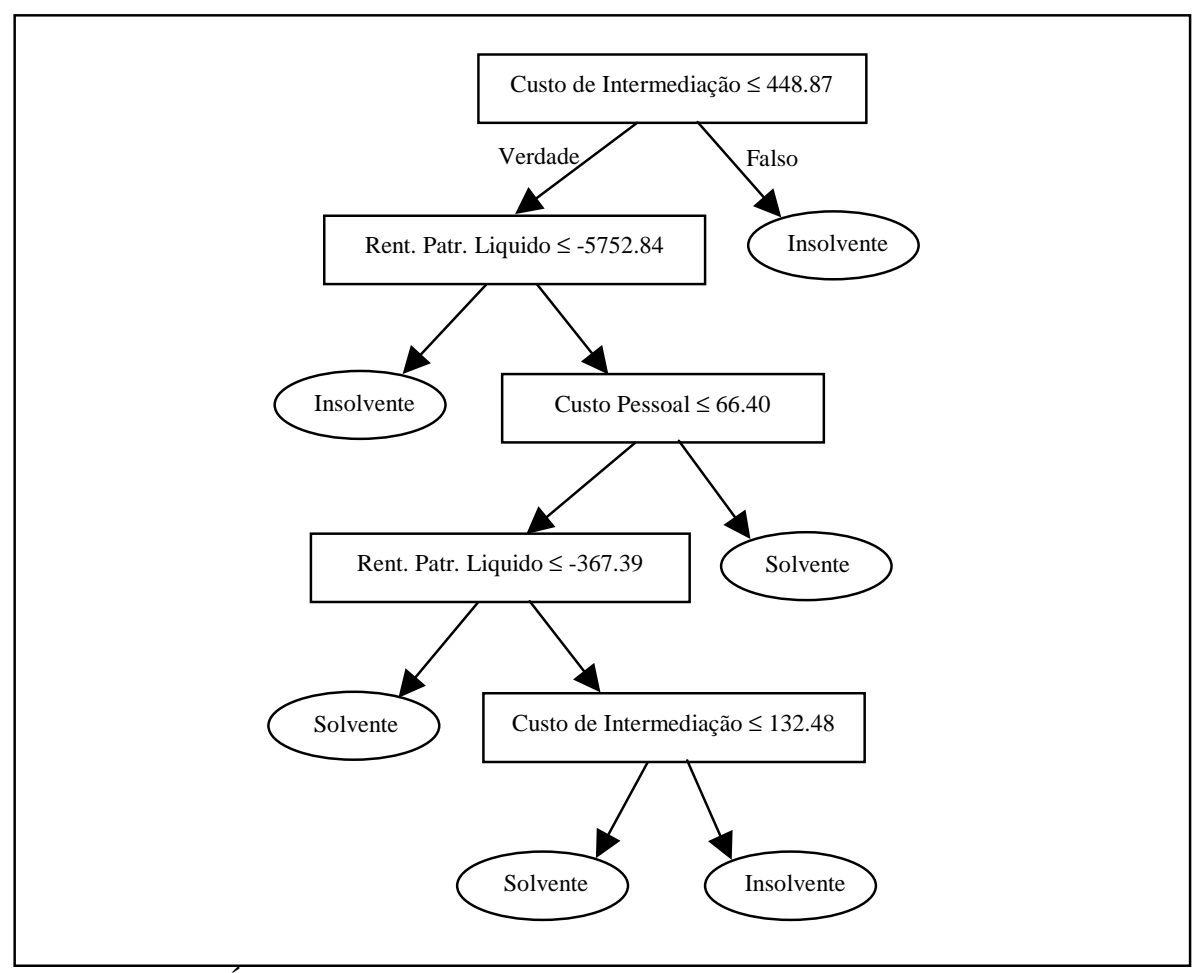

Figura 29: Árvore de Decisão gerada pelo método teste-simples do algoritmo TREPAN. 


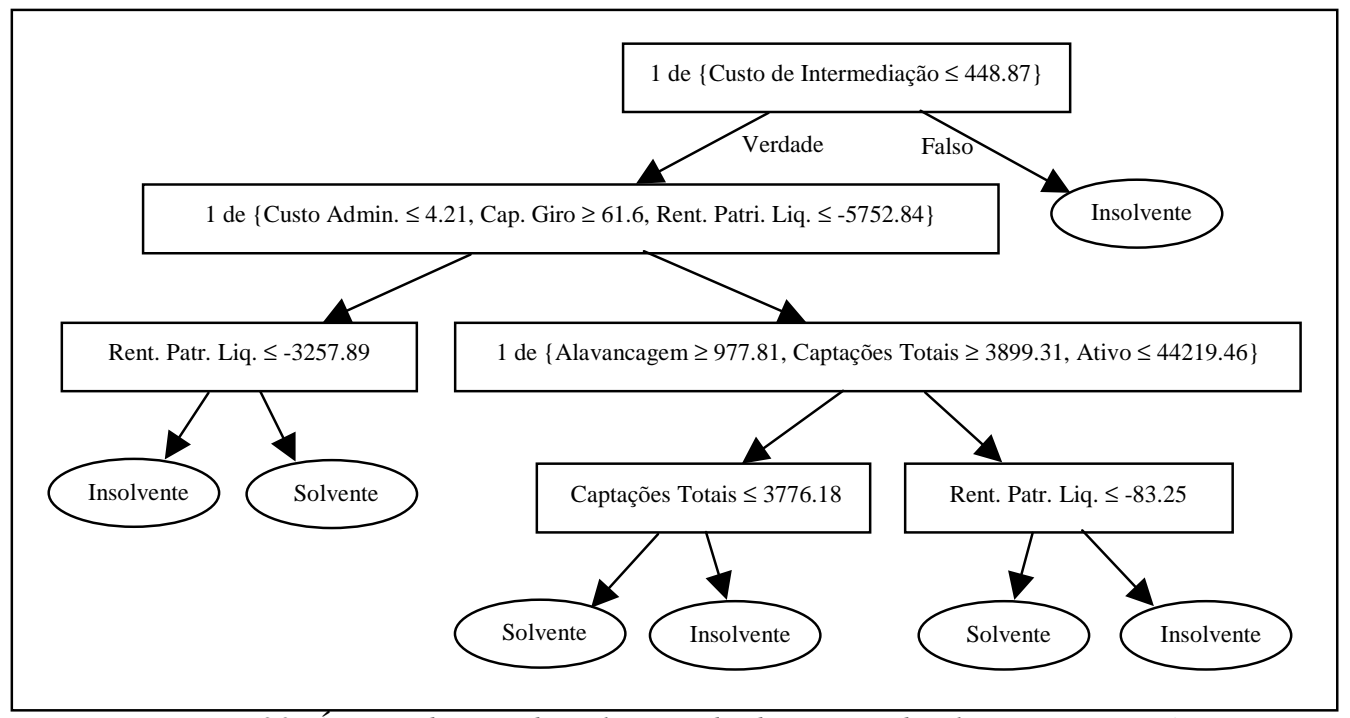

Figura 30: Árvore de gerada pelo método disjuntivo do algoritmo TREPAN.

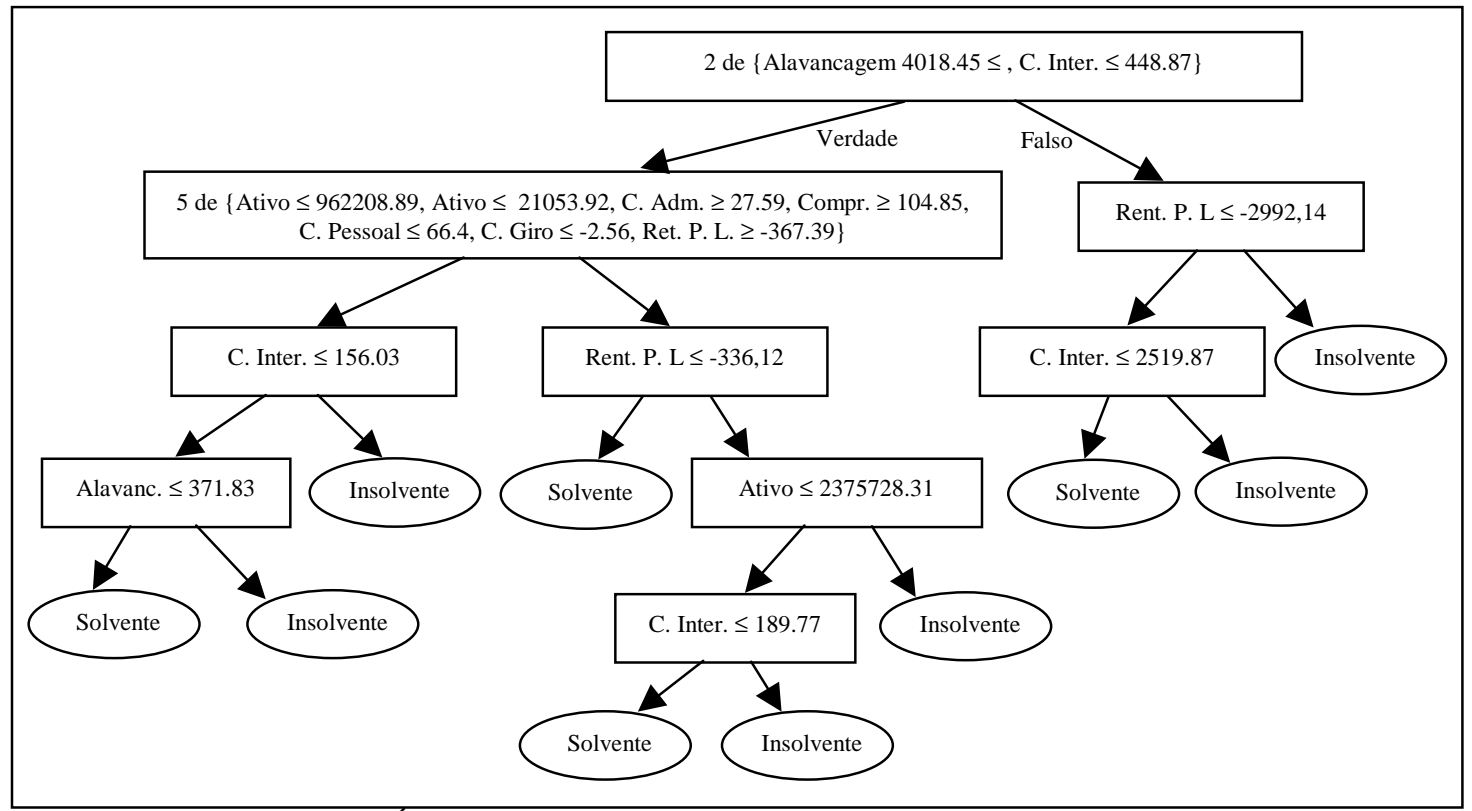

Figura 31: Árvore de gerada pelo método m-de-n do algoritmo TREPAN.

\subsubsection{Comparando os resultados}

A Tabela 9 apresenta um resumo dos principais resultados obtidos no conjunto de testes pelos algoritmos CN2, C4.5, RNA e TREPAN. Como pode ser observado, o melhor desempenho foi alcançado pelo algoritmo C4.5 regra e C4.5 árvore, seguido pelos algoritmos TREPAN, CN2 
e RNA, respectivamente. Para todos os métodos do TREPAN, o desempenho alcançado foi superior ao conseguido pela própria RNA. Isto sugere que o TREPAN consegue uma generalização melhor que as RNAs para este conjunto de dados, uma vez que os desempenhos do treinamento foram praticamente iguais para o TREPAN e para as RNAs.

\begin{tabular}{|c|c|}
\hline Algoritmo & Média \\
\hline C4.5 árvore & $77,2 \pm 7,5$ \\
\hline C4.5 regra & $78.1 \pm 8.0$ \\
\hline CN2 & $74.9 \pm 12.4$ \\
\hline RNA & $73.2 \pm 2.6$ \\
\hline TREPAN $($ teste-simples $)$ & $74.6 \pm 3.7$ \\
\hline TREPAN $($ disjuntivo $)$ & $74,6 \pm 2,5$ \\
\hline TREPAN $($ m-of- $n)$ & $76,2 \pm 10,0$ \\
\hline
\end{tabular}

Tabela 9: Melhores taxas de acertos alcançadas pelas RNAs e pelos algoritmos C4.5, CN2 e TREPAN.

A Figura 32 ilustra o desempenho de cada um dos algoritmos para o conjunto de teste. $\mathrm{O}$ melhor desempenho global foi conseguido pelo algoritmo $\mathrm{C} 4.5$ regra. Vale ressaltar que o algoritmo TREPAN conseguiu um resultado mais uniforme entre as classes. Merece especial destaque o método $m$-de- $n$, que conseguiu a maior taxa de acertos no conjunto de bancos insolventes.

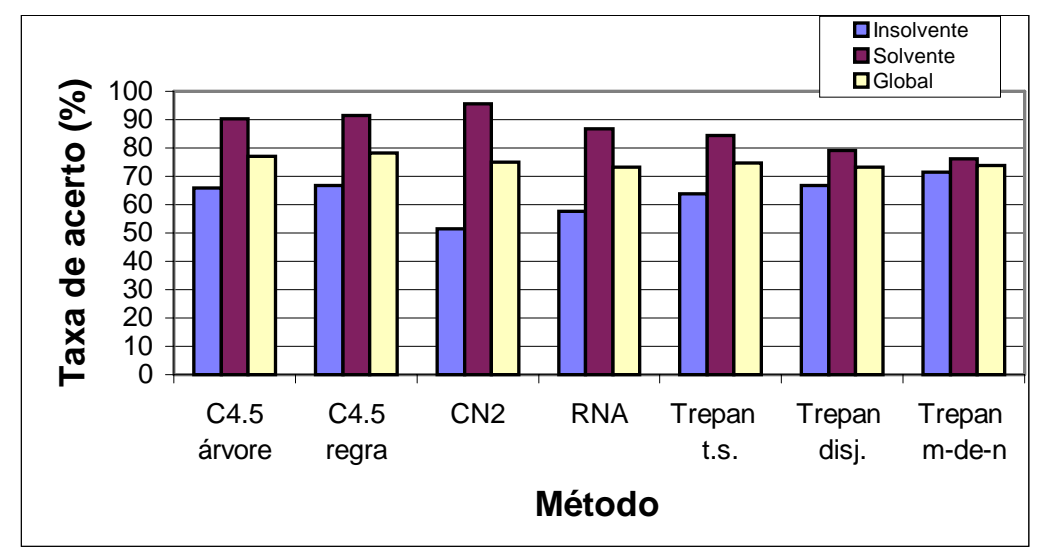

Figura 32: Melhores resultados alcançados por cada um dos métodos na fase de testes.

Para efeitos de compreensão das regras extraídas pelos algoritmos CN2 e C4.5, o algoritmo C4.5 foi melhor. O conjunto de regras extraído pelo $\mathrm{C} 4.5$ possui 14 regras, enquanto que o conjunto de regras do mesmo formato extraído pelo CN2 possui 19 regras. Portanto, pelo 
fato de ser menor, o conjunto de regras extraído pelo C4.5 é mais fácil de ser analisado por um especialista.

Com relação às árvores extraídas pelos algoritmos C4.5 e TREPAN, podem ser realizadas comparações somente entre as árvores gerada pelo algoritmo $\mathrm{C} 4.5$ árvore e pelo método testesimples do TREPAN, por serem estas árvores do mesmo tipo. A Árvore de Decisão gerada pelo C4.5 possui 14 nós, 15 folhas e altura 9. A Árvore de Decisão gerada pelo método teste-simples do TREPAN possui 5 nós, 6 folhas e altura 6. Portanto, a Árvore de Decisão gerada pelo método teste-simples do TREPAN é mais fácil de ser analisada por um especialista, por ser de tamanho menor que a gerada pelo C4.5 árvore.

\subsection{Jogo da velha}

A base de dados do jogo da velha é um conjunto de dados de domínio publico conseguido do conjunto de bases de dados para aprendizado de máquina da UCI (University of California, Irvine) [BLA98].

Estes dados contém um conjunto completo de situações finais do tabuleiro do jogo da velha. Considerando que a primeira jogada é do jogador "x", o objetivo é reconhecer a situação onde o jogador "x" ganha o jogo, ou seja, o jogador "x" possui três marcações alinhadas.

Cada situação possui nove atributos correspondendo a cada posição do tabuleiro. Cada um destes atributos possuem a seguinte denominação: tls (top-left-square); tms (top-middlesquare); trs (top-right-square); mls (middle-left-square); mms (middle-middle-square); mrs (middle-right-square); bls (bottom-left-square); bms (bottom-middle-square) e brs (bottom-rightsquare).

Os valores possíveis para cada atributo são: “x”, correspondendo à jogada do jogador "x"; “o", correspondendo à jogada do jogador "o" e "b", correspondendo a uma posição em branco no tabuleiro. As situações finais do tabuleiro podem ser classificadas de acordo com duas classes distintas: positivo ("x" ganhou o jogo) ou negativo ("x" não ganhou o jogo). 
Os experimentos realizados com o conjunto de dados do jogo da velha também encontram-se publicados em [NOB99]. Este conjunto de dados também foi utilizado em experimentos realizados em [NOB98].

\subsubsection{Divisão dos conjuntos de dados}

Esta base de dados é constituída por 958 exemplos, sendo 626 exemplos positivos $(63,5 \%)$ e 332 exemplos negativos $(36,5 \%)$.

Este conjunto de dados foi dividido como proposto por [PRE94] em subconjuntos de treinamento, validação e testes contendo 479, 239 e 240 exemplos em cada subconjunto, respectivamente. Para utilização pelos algoritmos C4.5, CN2 e TREPAN, foram unidos os conjuntos de treinamento e de validação.

O total de exemplos e a proporção de exemplos positivos e negativos em cada subconjunto de dados é dada da seguinte forma:

- Treinamento: 165 negativos e 165 positivos, total de 330 exemplos;

- Validação: 83 negativos e 83 positivos, total de 166 exemplos;

- Teste: 84 negativos e 378 positivos, total de 462 exemplos.

Foram realizados experimentos sobre três partições diferentes do conjunto de dados, cada uma delas com subconjuntos de treinamento, validação e teste. Esta divisão permite uma análise estatisticamente mais confiável dos resultados obtidos.

\subsubsection{Pré-processamento dos dados}

Para os algoritmos C4.5 e CN2, o único pré-processamento necessário foi a formatação dos dados de entrada de acordo com o formato exigido para cada um dos algoritmos. 
Para as RNAs, foi necessária a codificação de cada atributo para 3 valores binários. Esta codificação binária evita que valores de mesma importância assumam diferentes magnitudes, o que pode prejudicar o desempenho da rede. Esta codificação foi feita da seguinte forma:

- Atributos de entrada:

- valor "x": $\quad \begin{array}{lll}1 & 0 & 0\end{array}$

- valor "o": 010 ;

- valor "b": $\quad \begin{array}{lll}0 & 0 & 1 \text {; }\end{array}$

- Atributos de saída:

- valor "possível": $1 \quad 0$;

- valor "impossível": 0 1;

\subsubsection{Resultados dos Experimentos}

Os itens a seguir mostram tabelas e figuras ilustrativas dos experimentos realizados com o conjunto de dados do jogo da velha utilizando RNAs e os algoritmos C4.5, CN2, e TREPAN.

\subsubsection{Resultados utilizando C4.5}

A Tabela 10 mostra os resultados obtidos com a utilização do algoritmo C4.5 árvore no conjunto de dados do jogo da velha. Através desta tabela pode ser observado que a taxa média de acertos globais na fase de testes foi de 77,0\%. Também pode ser observado que não houve grandes diferenças nas taxas de acertos entre as classes positivo e negativo nas fases de treinamento e de teste. No teste, a taxa de acertos global ficou mais próxima da taxa de acertos dos casos negativos. Este fato se deve ao desbalanceamento existente no conjunto de teste. A taxa de acertos global no teste seria de $80 \%$ se considerado esta taxa como sendo a média entre as taxas de acertos nas classes de exemplos positivos e negativos. 


\begin{tabular}{|c|c|c|c|c|c|c|}
\cline { 2 - 7 } \multicolumn{1}{c|}{} & \multicolumn{3}{c|}{ Treinamento } & \multicolumn{3}{c|}{ Teste } \\
\hline Partição & Negativo & Positivo & Global & Negativo & Positivo & Global \\
\hline 1 & 92,7 & 84,3 & 88,5 & 84,5 & 71,1 & 73,5 \\
2 & 93,1 & 92,3 & 92,7 & 80,9 & 80,4 & 80,5 \\
3 & 92,7 & 88,3 & 92,7 & 88,1 & 74,6 & 77,1 \\
\hline Média & $92,8 \pm 0,2$ & $88,3 \pm 4,0$ & $91,3 \pm 2,4$ & $84,5 \pm 3,6$ & $75,4 \pm 4,7$ & $77,0 \pm 3,5$ \\
\hline \multicolumn{6}{c}{ Tabela 10: Desempenho alcançado pelo algoritmo C4.5 árvore. }
\end{tabular}

A Figura 33, a Figura 34, a Figura 35 e a Figura 36 mostram a Árvore de Decisão gerada pelo algoritmo C4.5 utilizando a terceira partição. Esta partição foi escolhida pelo fato de ser a partição que apresentou resultado intermediário entre as três partições do experimento. A árvore apresentada possui 30 nós, 63 folhas e altura 6. Para melhor visualização, a árvore original foi dividida em 4 sub árvores, originando assim as 4 figuras.

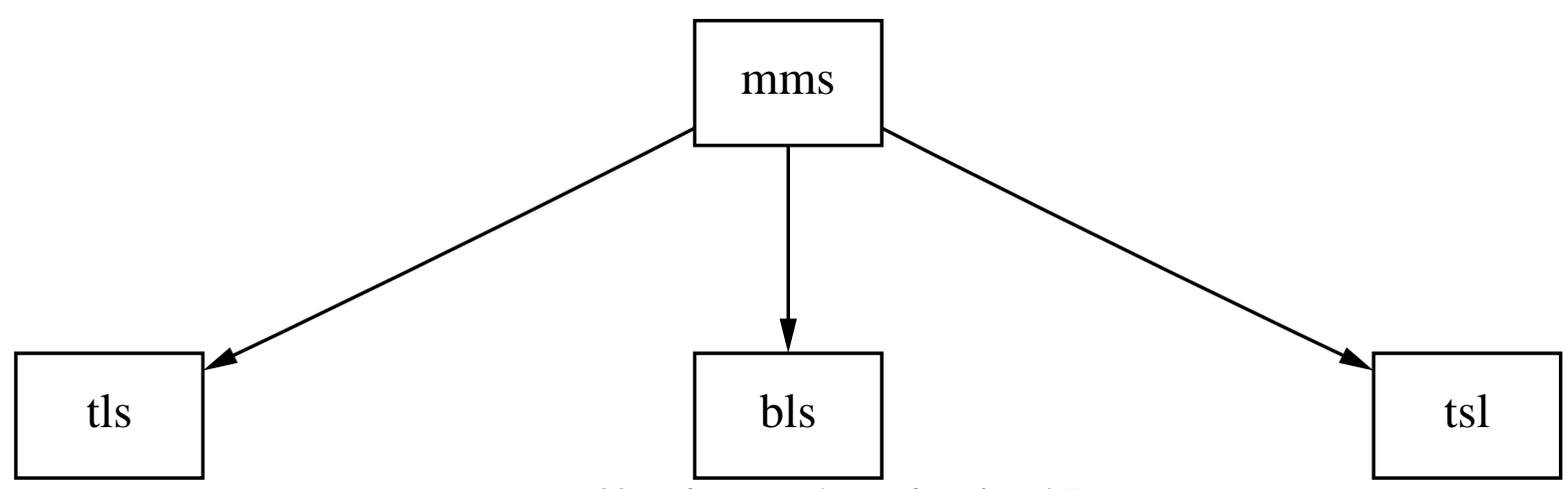

Figura 33: Sub árvore 1 gerada pelo C4.5. 


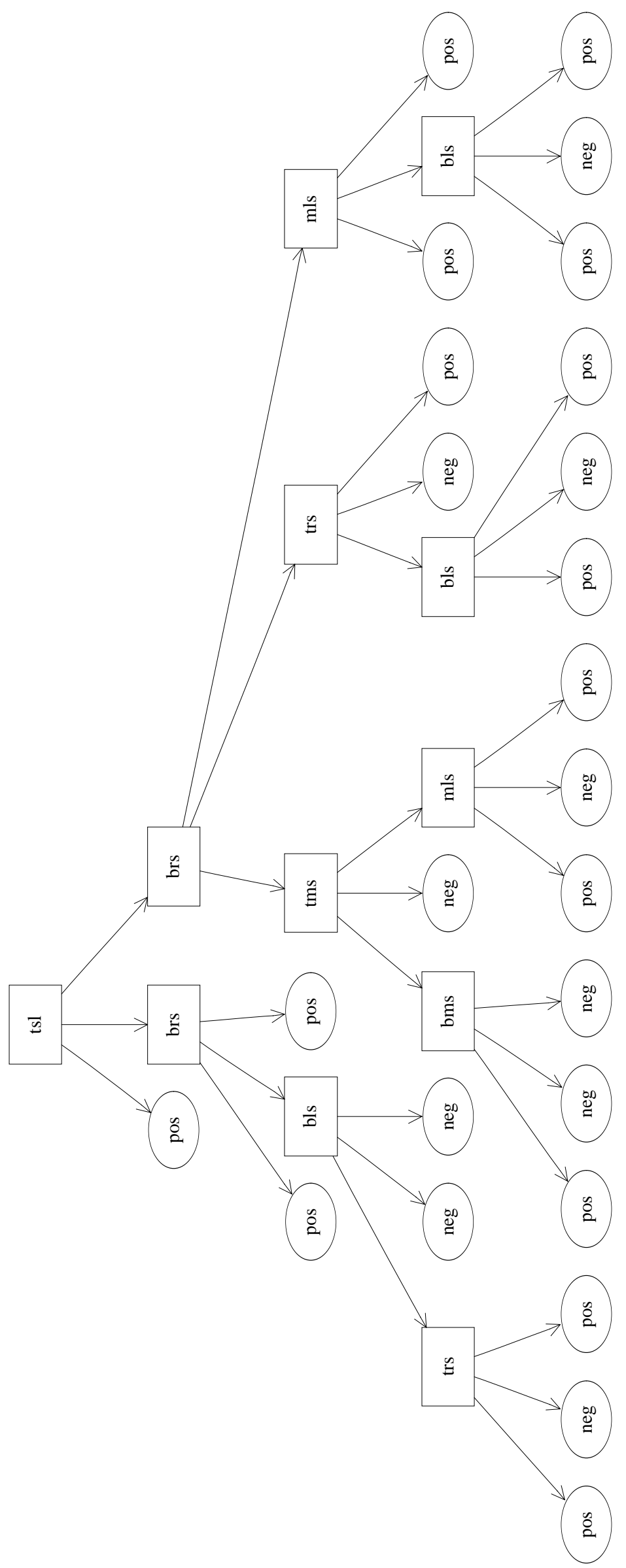

Figura 34: Sub árvore 2 gerada pelo C4.5. 


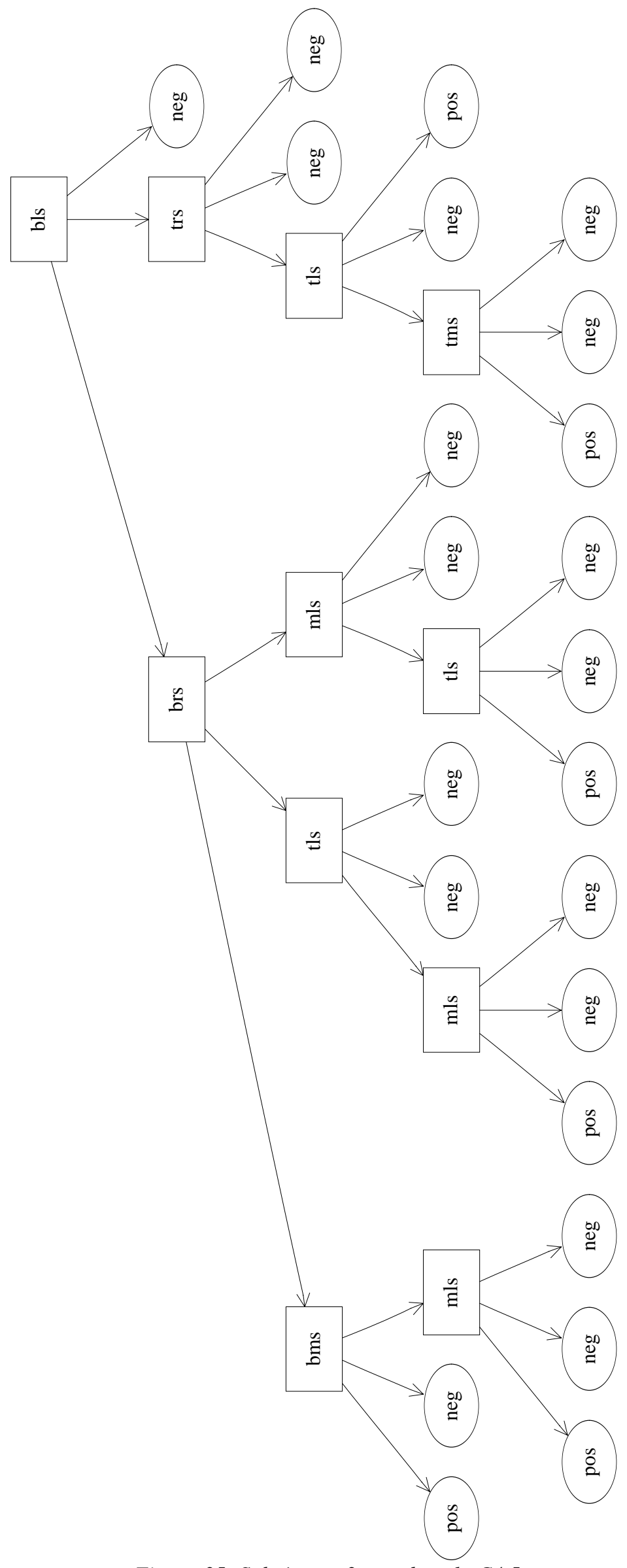

Figura 35: Sub árvore 3 gerada pelo C4.5. 


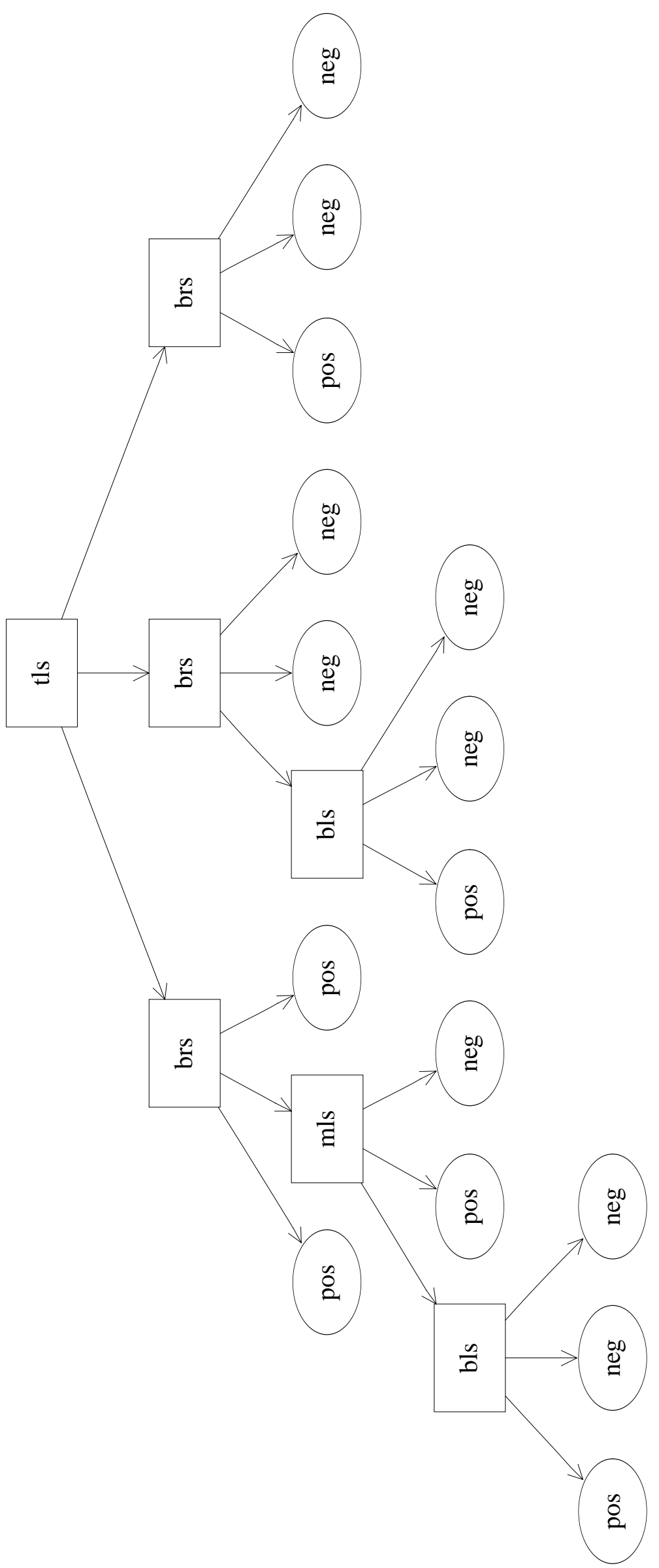

Figura 36: Sub árvore 4 gerada pelo C4.5. 
A Tabela 11 mostra as taxas de acertos alcançadas pelo algoritmo $\mathrm{C} 4.5$ regra. $\mathrm{O}$ desempenho alcançado pelos conjuntos de treinamento foram superiores ao desempenho dos mesmos conjuntos de dados com a utilização do C4.5 árvore. No entanto, a grande melhoria foi conseguida nos conjuntos de testes. Esta melhoria no conjunto de testes se deve ao fato de que o conhecimento armazenado na forma de regras conseguiu uma capacidade de generalização bem maior que a Árvore de Decisão.

\begin{tabular}{|c|c|c|c|c|c|c|}
\cline { 2 - 7 } \multicolumn{1}{c|}{} & \multicolumn{3}{c|}{ Treinamento } & \multicolumn{3}{c|}{ Teste } \\
\hline Partição & Negativo & Positivo & Global & Negativo & Positivo & Global \\
\hline 1 & 97,6 & 97,6 & 97,6 & 94,0 & 97,1 & 96,5 \\
2 & 94,7 & 97,9 & 96,4 & 88,1 & 92,1 & 91,3 \\
3 & 97,9 & 98,8 & 98,4 & 91,6 & 95,5 & 94,8 \\
\hline Média & $96,7 \pm 1,8$ & $98,1 \pm 0,6$ & $97,5 \pm 1,0$ & $91,2 \pm 3,0$ & $94,9 \pm 2,6$ & $94,2 \pm 2,7$ \\
\hline
\end{tabular}

A seguir, é mostrada na Figura 38 o conjunto de regras gerado pelo algoritmo C4.5 regra. No total são 23 regras incluindo a regra padrão (default).

\begin{tabular}{|c|c|c|}
\hline $\begin{array}{l}\text { Rule 1: } \\
\text { tls }=\mathrm{x}, \mathrm{mms}=\mathrm{x}, \text { brs }=\mathrm{x} \\
\text {-> class positivo }[96.7 \%]\end{array}$ & $\begin{array}{l}\text { Rule 59: } \\
\text { tms }=\mathrm{b}, \text { trs }=\mathrm{o}, \mathrm{bls}=\mathrm{x}, \mathrm{brs}=\mathrm{x} \\
\rightarrow>\text { class positivo }[84.1 \%]\end{array}$ & $\begin{array}{l}\text { Rule 28: } \\
\quad \text { tls }=0, \text { tms }=0, \operatorname{trs}=0 \\
->\text { class negativo }[95.0 \%]\end{array}$ \\
\hline $\begin{array}{l}\text { Rule 34: } \\
\text { trs }=x, m m s=x, b l s=x \\
\text {-> class positivo }[96.0 \%]\end{array}$ & $\begin{array}{l}\text { Rule 82: } \\
\text { tls }=\mathrm{x}, \mathrm{mls}=\mathrm{o}, \mathrm{mms}=\mathrm{b} \\
->\text { class positivo }[82.2 \%]\end{array}$ & $\begin{array}{l}\text { Rule } 36: \\
\quad \operatorname{trs}=0, m r s=o, b r s=0 \\
->\text { class negativo }[94.8 \%]\end{array}$ \\
\hline $\begin{array}{l}\text { Rule 10: } \\
\text { mls }=x, m m s=x, m r s=x \\
->\text { class positivo }[95.8 \%]\end{array}$ & $\begin{array}{l}\text { Rule 73: } \\
\text { tms }=x, \text { bls }=b, b m s=0 \\
->\text { class positivo }[77.7 \%]\end{array}$ & $\begin{array}{l}\text { Rule 51: } \\
\quad \text { tls }=0, m m s=0 \\
->\text { class negativo }[77.8 \%]\end{array}$ \\
\hline $\begin{array}{l}\text { Rule 2: } \\
\text { tms }=x, m m s=x, b m s=x \\
->\text { class positivo }[95.6 \%]\end{array}$ & $\begin{array}{l}\text { Rule } 63 \text { : } \\
\text { tms }=0, \text { trs }=b, b l s=x, b m s=x \\
\rightarrow>\text { class positivo }[75.6 \%]\end{array}$ & $\begin{array}{l}\text { Rule } 57: \\
\quad \operatorname{trs}=\mathrm{o}, \mathrm{mms}=\mathrm{o} \\
\quad>\text { class negativo }[76.5 \%]\end{array}$ \\
\hline $\begin{array}{l}\text { Rule 42: } \\
\text { trs }=x, m r s=x, \text { brs }=x \\
->\text { class positivo }[95.6 \%]\end{array}$ & $\begin{array}{l}\text { Rule 66: } \\
\text { tms }=b, \text { trs }=b, b l s=x \\
->\text { class positivo }[61.0 \%]\end{array}$ & $\begin{array}{l}\text { Rule } 65: \\
\text { tms }=0, m m s=0 \\
->\text { class negativo }[71.1 \%]\end{array}$ \\
\hline $\begin{array}{l}\text { Rule 45: } \\
\text { tls }=\mathrm{x}, \mathrm{mls}=\mathrm{x}, \mathrm{bls}=\mathrm{x} \\
->\text { class positivo }[95.3 \%]\end{array}$ & $\begin{array}{l}\text { Rule 16: } \\
\text { tls }=0, \text { mls }=o \text {, bls }=0 \\
\rightarrow>\text { class negativo }[95.5 \%]\end{array}$ & $\begin{array}{l}\text { Rule 11: } \\
\text { tls }=\mathrm{o}, \mathrm{mls}=\mathrm{x}, \mathrm{mms}=\mathrm{x} \\
\mathrm{mrs}=\mathrm{o}, \mathrm{brs}=\mathrm{x} \\
->\text { class negativo }[70.7 \%]\end{array}$ \\
\hline $\begin{array}{l}\text { Rule 86: } \\
\text { tls }=\mathrm{x}, \mathrm{mms}=\mathrm{b} \text {, brs }=\mathrm{b} \\
->\text { class positivo }[87.1 \%]\end{array}$ & $\begin{array}{l}\text { Rule 48: } \\
\text { mls }=\mathrm{o}, \mathrm{mms}=\mathrm{o}, \mathrm{mrs}=\mathrm{o} \\
\rightarrow>\text { class negativo }[95.2 \%]\end{array}$ & Default class: positivo \\
\hline $\begin{array}{l}\text { Rule } 9: \\
\text { tls }=\mathrm{x}, \mathrm{mms}=\mathrm{x}, \mathrm{brs}=\mathrm{b} \\
->\text { class positivo }[84.1 \%]\end{array}$ & $\begin{array}{l}\text { Rule 23: } \\
\text { bls }=0, \text { bms }=0 \text {, brs }=0 \\
\quad>\text { class negativo }[95.0 \%]\end{array}$ & \\
\hline
\end{tabular}

Figura 37: Conjunto de regras geradas pelo C4.5. 


\subsubsection{Resultados utilizando CN2}

A Tabela 12 mostra os desempenhos alcançados pelo algoritmo CN2. Nesta tabela pode ser observado que o CN2 obteve um desempenho muito bom, conseguindo taxas de acertos muito próximas de $100 \%$.

\begin{tabular}{|c|c|c|c|c|c|c|}
\cline { 2 - 7 } \multicolumn{1}{c|}{} & \multicolumn{3}{c|}{ Treinamento } & \multicolumn{3}{c|}{ Teste } \\
\hline Partição & Negativo & Positivo & Global & Negativo & Positivo & Global \\
\hline 1 & 99,6 & 100,0 & 99,8 & 96,4 & 99,5 & 98,9 \\
2 & 100,0 & 100,0 & 100,0 & 92,9 & 100,0 & 98,7 \\
3 & 100,0 & 100,0 & 100,0 & 98,8 & 100,0 & 99,8 \\
\hline Média & $99,9 \pm 0,2$ & $100,0 \pm 0,0$ & $99,9 \pm 0,1$ & $96,0 \pm 3,0$ & $99,8 \pm 0,3$ & $99,1 \pm 0,6$ \\
\hline
\end{tabular}

A Figura 38 mostra o conjunto de regras não ordenadas extraídas pelo CN2. Foram extraídas um total de 30 regras incluindo a regra padrão (default).

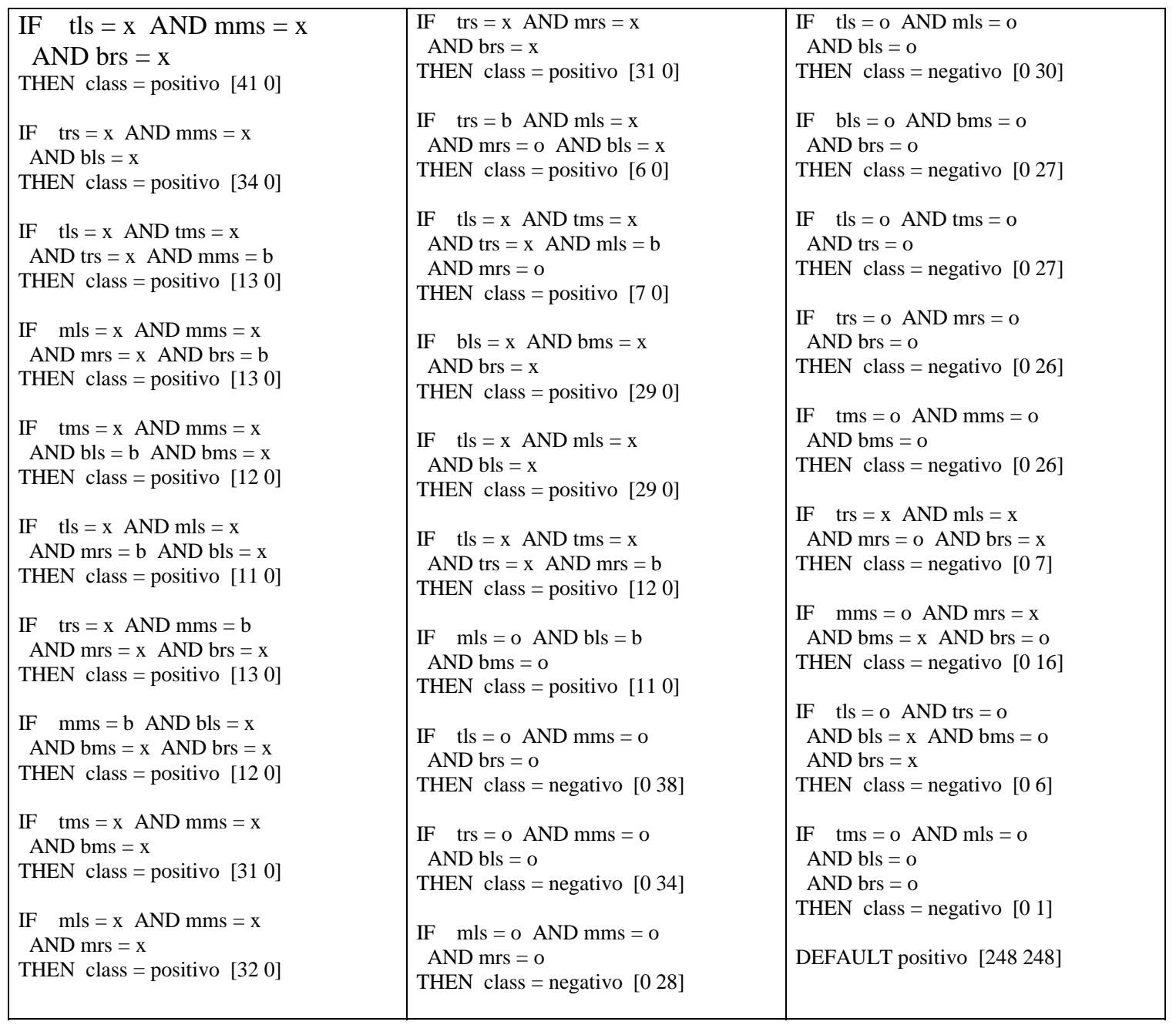

Figura 38: Conjunto de regras geradas pelo CN2. 


\subsubsection{Resultados utilizando RNAs}

Os experimentos utilizando dados do jogo da velha foram realizados com a utilização de RNAs do tipo MLP (Mult Layer Percepton)[HAY99] de arquitetura 27-20-2. Foi utilizado o algoritmo de atualização de pesos Rprop (Resilient Backpropagation)[RIE93] durante 100 ciclos na fase de treinamento. As RNAs foram implementadas no simulador de Redes Neurais SNNS (Sttutgart Neural Network Simulator) [ZEL95].

A Tabela 13 mostra os desempenhos alcançados pelas RNAs no problema do jogo da velha. Através desta tabela pode ser observado que as RNAs conseguiram uma boa taxa de acertos na fase de testes e uma taxa de acertos ainda melhor na fase de treinamento.

\begin{tabular}{|c|c|c|c|c|c|c|c|c|c|}
\cline { 2 - 9 } \multicolumn{1}{c|}{} & \multicolumn{3}{c|}{ Treinamento } & \multicolumn{3}{c|}{ Validação } & \multicolumn{3}{c|}{ Teste } \\
\hline Part. & Neg. & Pos. & Global & Neg. & Pos. & Global & Neg. & Pos. & Global \\
\hline 1 & 100,0 & 100,0 & 100,0 & 98,8 & 95,1 & 96,9 & 96,4 & 96,0 & 96,1 \\
2 & 100,0 & 100,0 & 100,0 & 97,6 & 97,6 & 97,6 & 91,7 & 98,7 & 97,4 \\
3 & 100,0 & 100,0 & 100,0 & 98,8 & 97,6 & 98,1 & 94,0 & 95,2 & 95,0 \\
\hline Média & $100 \pm 0,0$ & $100 \pm 0,0$ & $100 \pm 0,0$ & $98,4 \pm 0,7$ & $96,8 \pm 1,4$ & $97,5 \pm 0,6$ & $94,0 \pm 2,4$ & $96,6 \pm 1,8$ & $96,2 \pm 1,2$ \\
\hline
\end{tabular}

\subsubsection{Resultados utilizando o algoritmo TREPAN}

A Tabela 14 mostra os desempenhos alcançados pelo algoritmo TREPAN. Nesta tabela, pode-se observar que as taxas de acertos conseguidas pelo algoritmo TREPAN foram inferiores às taxas de acertos conseguidas pelas RNAs. Também pode ser observado que o melhor desempenho alcançado pelo TREPAN foi conseguido pelo método disjuntivo. 


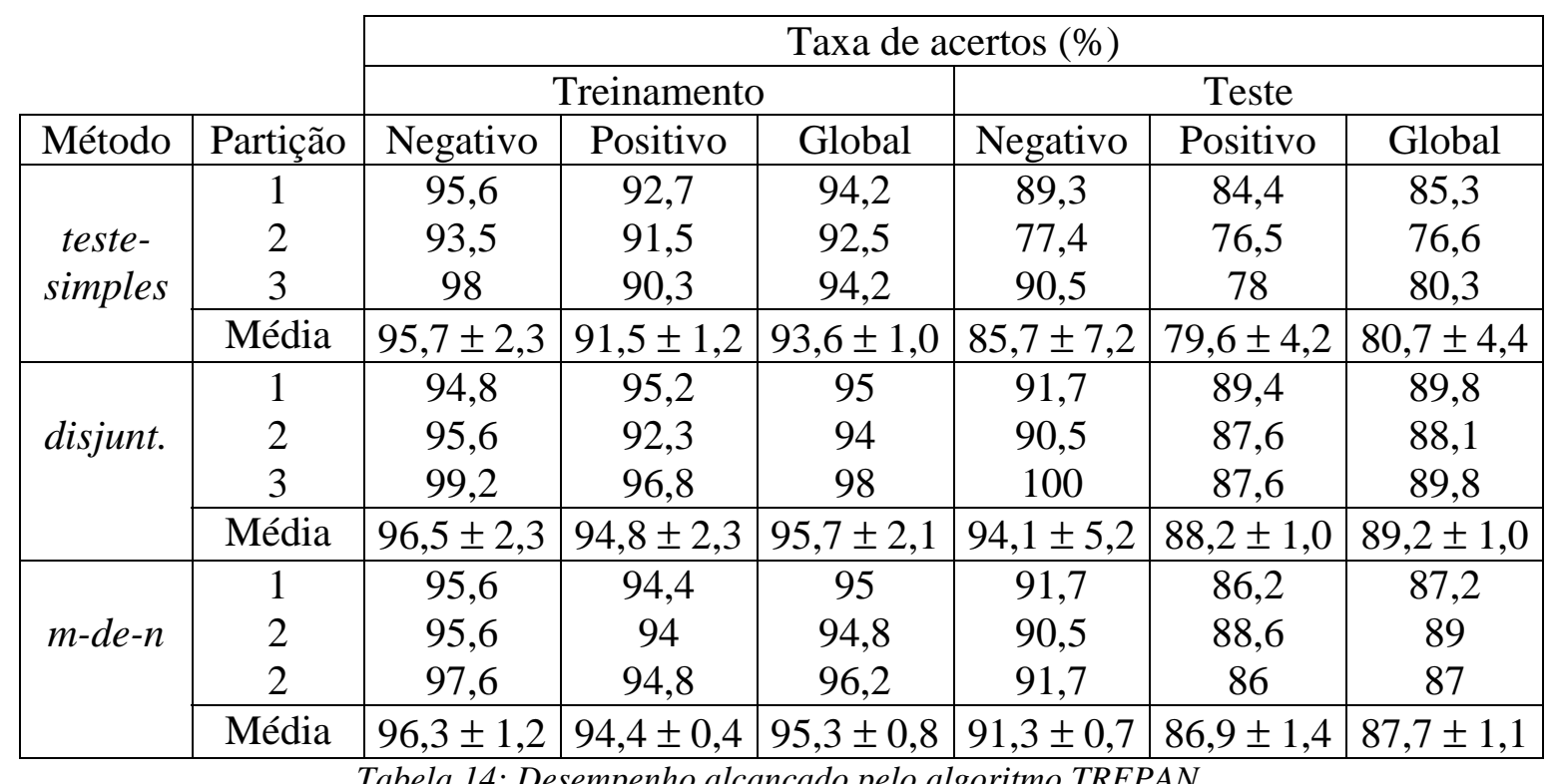

A seguir são mostradas as Árvores de Decisão extraídas pelo algoritmo TREPAN. A Figura 39, a Figura 40, a Figura 41 e a Figura 42 ilustram a árvore extraída através do método teste-simples, contendo 41 nós, 83 folhas e altura 7. A Figura 43 ilustra a árvore extraída pelo método disjuntivo, contendo 30 nós, 31 folhas e altura 12. A Figura 44 ilustra a árvore extraída pelo método $m$-de- $n$, contendo 14 nós, 15 folhas e altura 9.

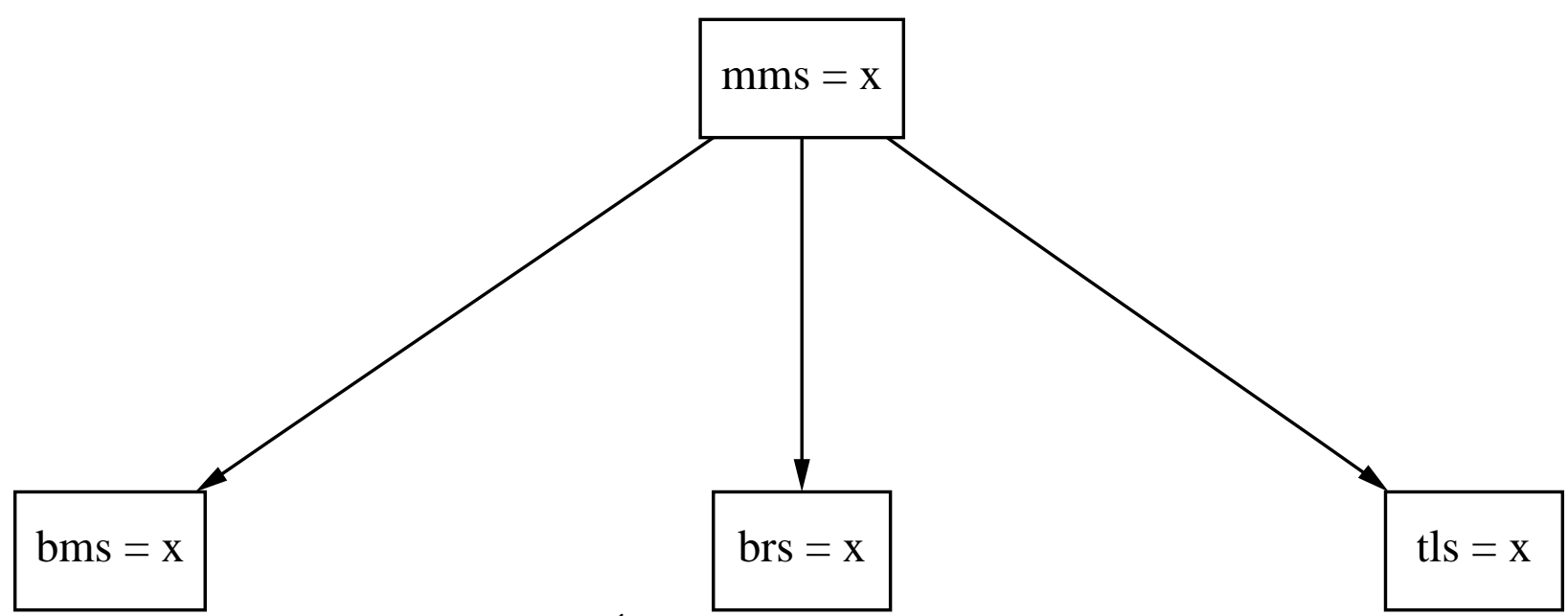

Figura 39: Sub Árvore de Decisão 1 gerada pelo método testesimples do TREPAN. 


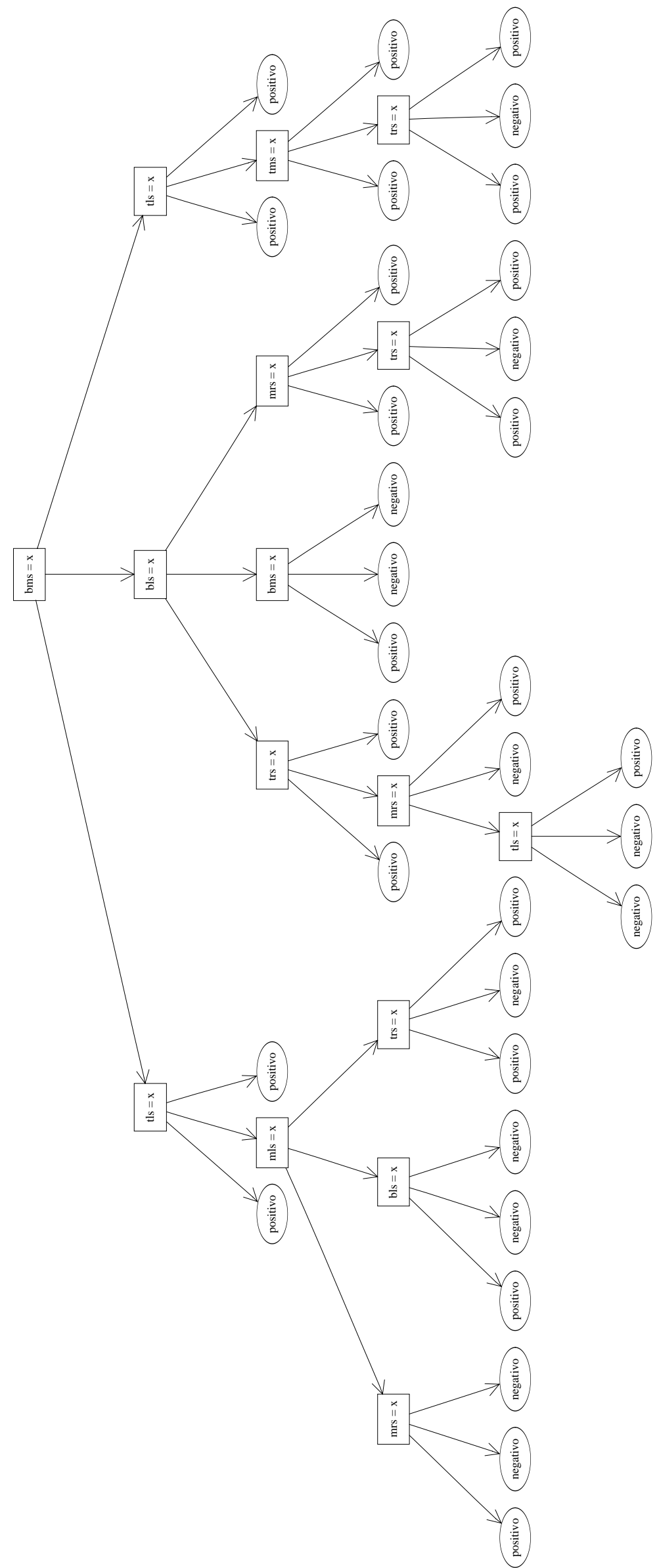

Figura 40: Sub Árvore de Decisão 2 gerada pelo método teste-simples do TREPAN. 


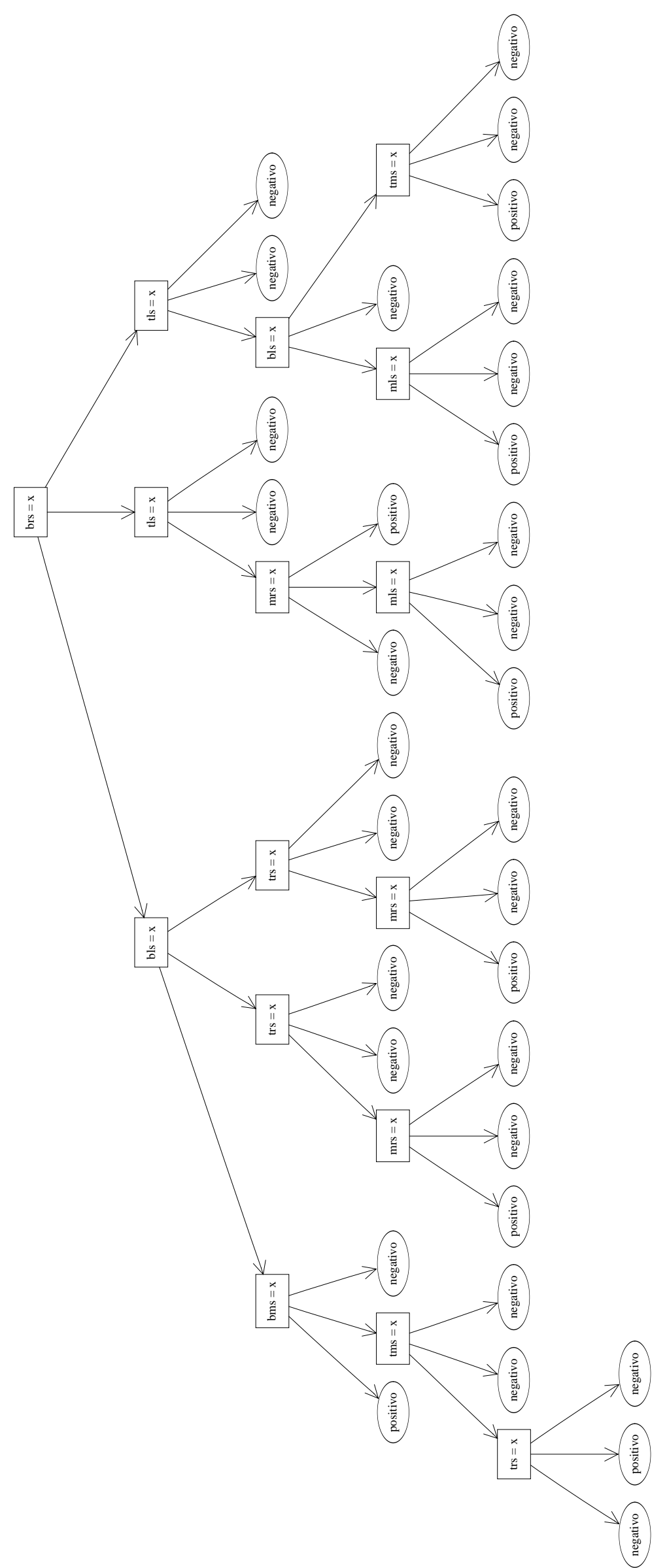

Figura 41: Sub Árvore de Decisão 3 gerada pelo método teste-simples do TREPAN. 


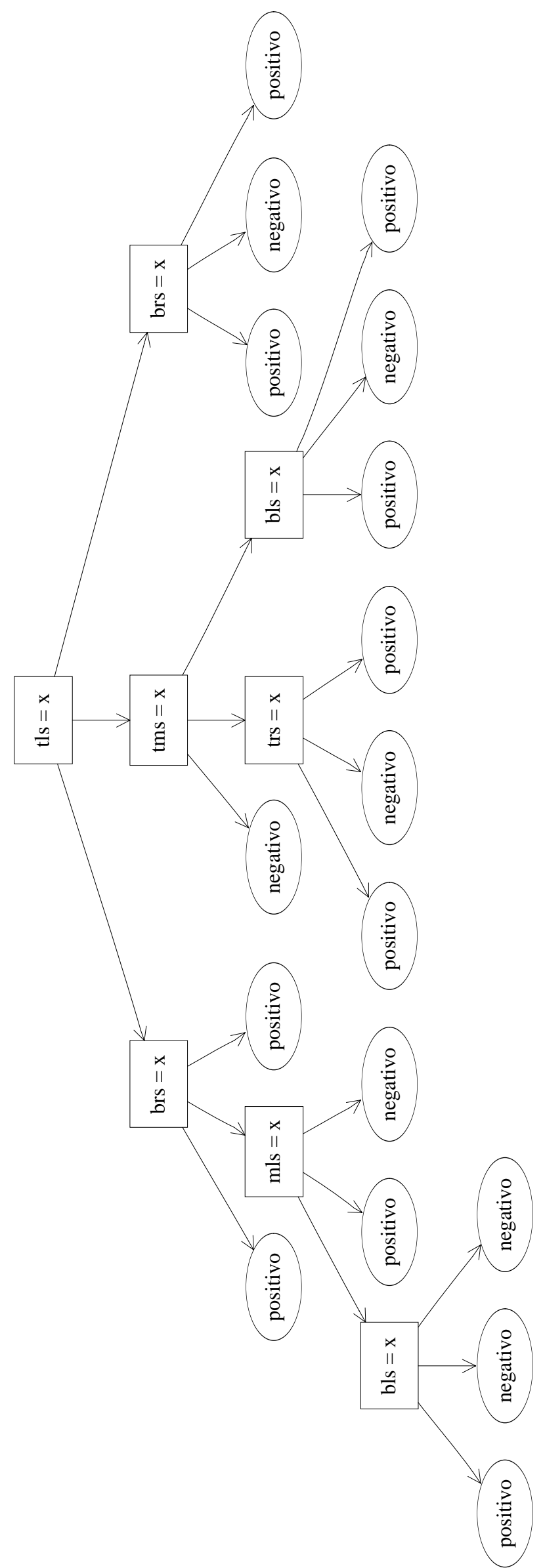

Figura 42: Sub Árvore de Decisão 4 gerada pelo método teste-simples do TREPAN. 


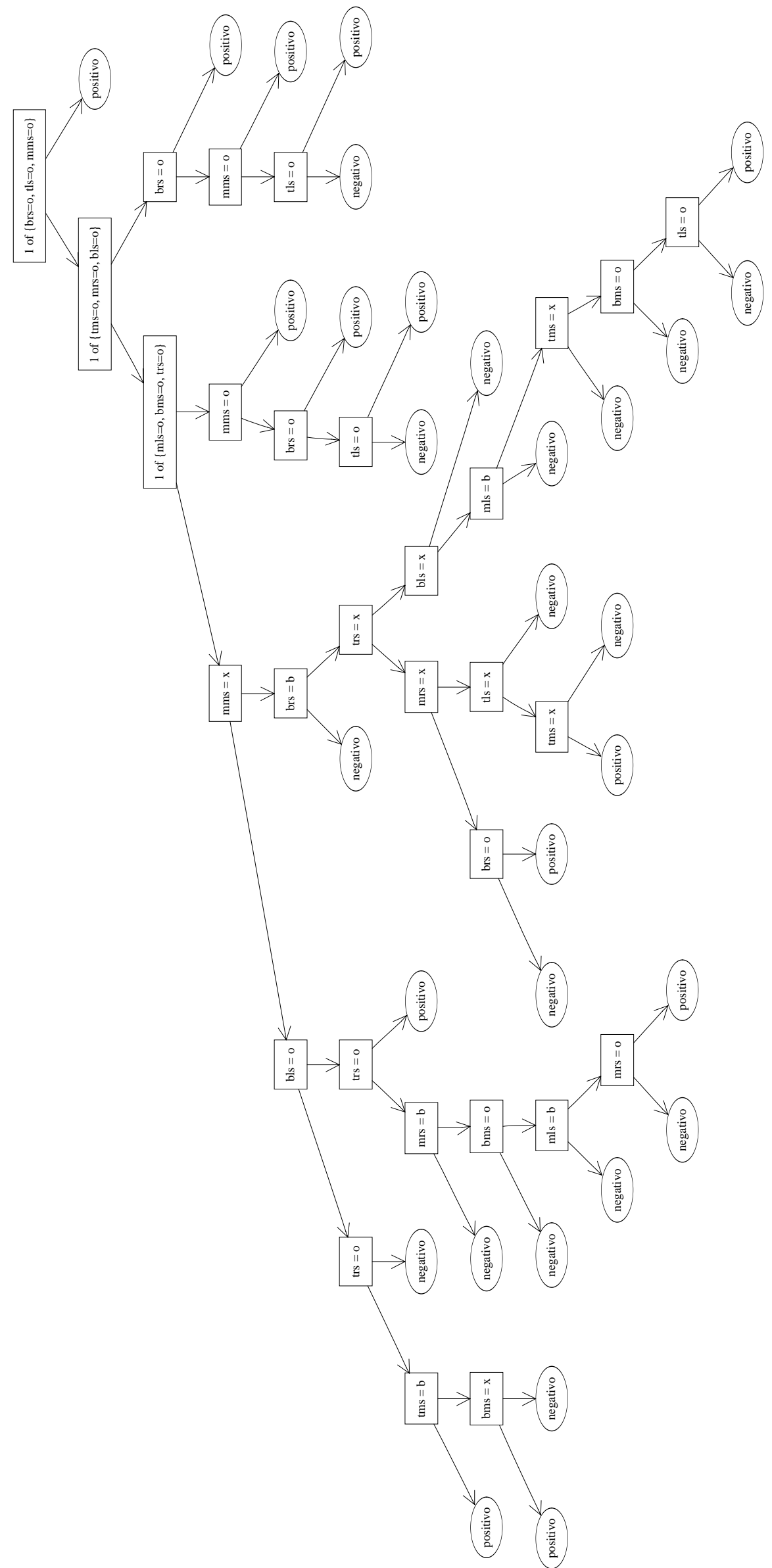

Figura 43: Árvore de Decisão gerada pelo método disjuntivo do TREPAN. 


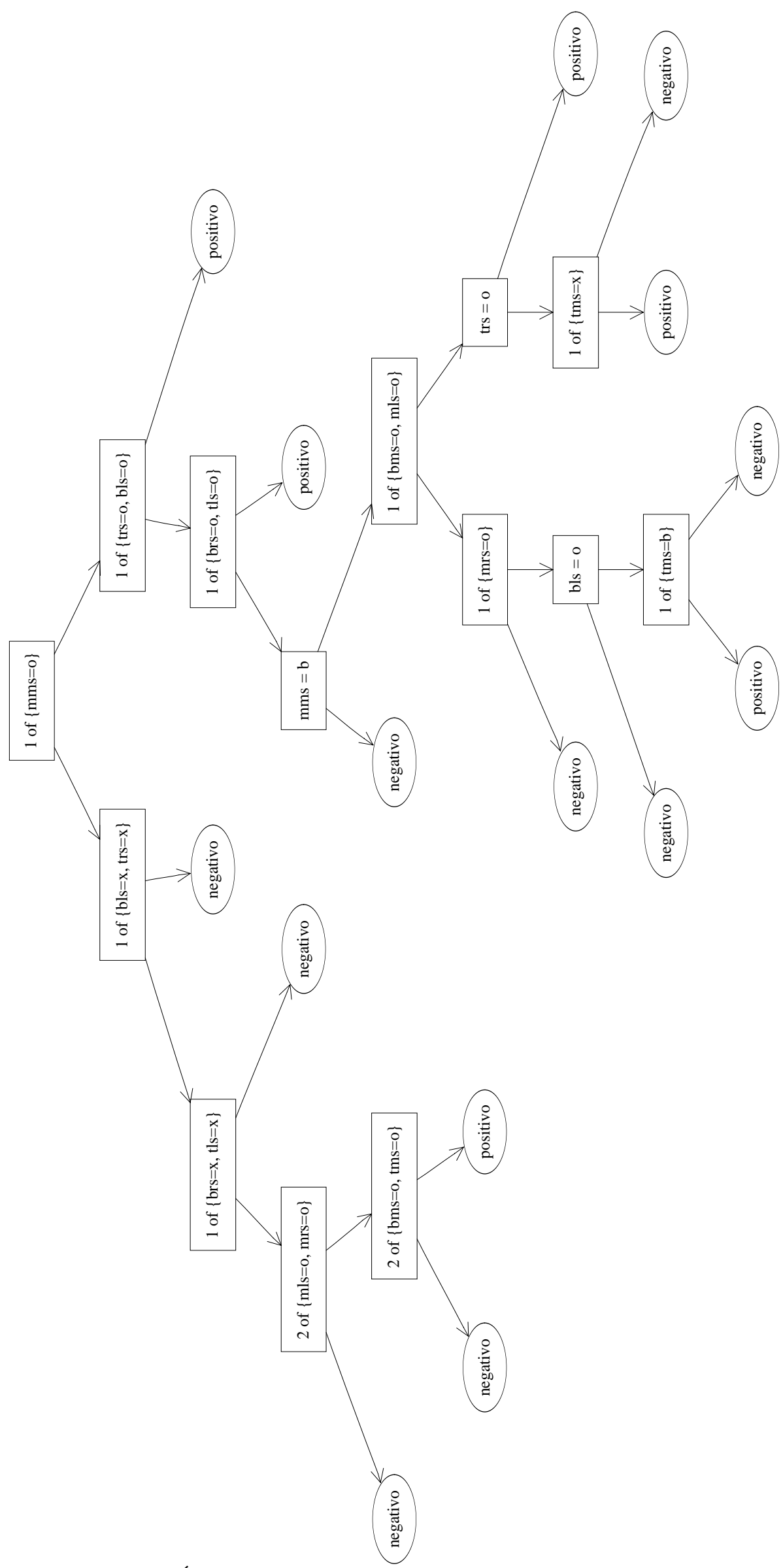

Figura 44: Árvore de Decisão gerada pelo método m-de-n do TREPAN. 


\subsubsection{Comparando os resultados}

A Tabela 15 mostra os desempenhos médios das RNAs e dos algoritmos C4.5, CN2 e TREPAN. Nesta tabela, pode ser observado que o melhor resultado foi obtido pelo algoritmo CN2, seguido pela RNA e C4.5 regra, respectivamente. Pode ser observado também que todos os algoritmos que armazenam o conhecimento na forma de Árvore de Decisão obtiveram desempenho abaixo de $90 \%$ de acertos.

\begin{tabular}{|c|c|c|}
\hline Algoritmo & Média do Treinamento & Média do Teste \\
\hline C4.5 árvore & $91,3 \pm 2,4$ & $77,0 \pm 3,5$ \\
\hline C4.5 regra & $97,5 \pm 1,0$ & $94,2 \pm 2,7$ \\
\hline CN2 & $99,9 \pm 0,1$ & $99,1 \pm 0,6$ \\
\hline RNA & $100,0 \pm 0,0$ & $96,2 \pm 1,2$ \\
\hline TREPAN (teste-simples) & $93,6 \pm 1,0$ & $80,7 \pm 4,4$ \\
\hline TREPAN (disjuntivo) & $95,7 \pm 2,1$ & $89,2 \pm 1,0$ \\
\hline TREPAN (m-de- $n)$ & $95,3 \pm 0,8$ & $87,7 \pm 1,1$ \\
\hline
\end{tabular}

Tabela 15: Desempenho alcançado pelas RNAs e pelos algoritmos C4.5, CN2 e TREPAN na fase de testes.

A Figura 45 mostra o desempenho médio por classes, obtido pelas RNAs e pelos algoritmos C4.5, CN2, TREPAN. Nesta figura, pode ser observado que a RNA e os algoritmos C4.5 regra e CN2 apresentaram comportamentos semelhantes nas taxas de acertos entre as classes de exemplos positivos e negativos. Também podem ser observados comportamentos semelhantes entre os algoritmos C4.5 e TREPAN.

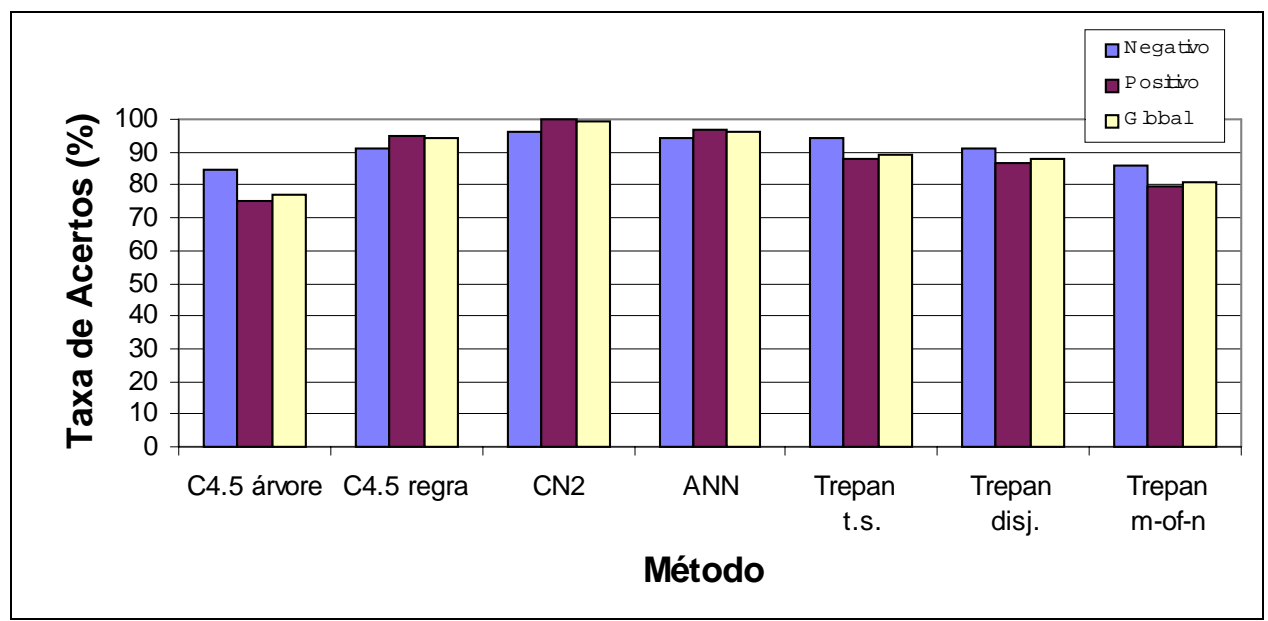

Figura 45: Desempenho por classes alcançado pelas RNAs e pelos algoritmos C4.5, CN2 e TREPAN na fase de testes. 
Para efeitos de compreensão das regras extraídas pelos algoritmos CN2 e C4.5, o algoritmo $\mathrm{C} 4.5$ foi melhor, por obter um conjunto menor de regras. $\mathrm{O}$ algoritmo $\mathrm{C} 4.5$, mostrado na Figura 37, extraiu um conjunto de 23 regras, enquanto que o algoritmo CN2, mostrado na Figura 38, extraiu um conjunto de 30 regras.

Quanto às Árvores de Decisão extraídas, é possível comparar somente as árvores extraídas pelos algoritmos C4.5 árvore e pelo método teste-simples do TREPAN, por serem árvores do mesmo tipo. Comparando estas duas árvores, Figura 36 e Figura 42, pode ser observado que o algoritmo C4.5 obteve uma árvore menor, por isso, mais fácil de ser analisada por um especialista. Enquanto a árvore extraída através do método teste-simples do TREPAN possui 41 nós, 83 folhas e altura 7, a árvore extraída pelo C4.5 possui 30 nós, 63 folhas e altura 6.

\subsection{Avaliação de Crédito}

O conjunto de dados para avaliação de crédito contém aplicações de crédito bancário do banco Banestado (Banco do Estado do Paraná). Esta base possui um histórico de aplicações de créditos de clientes, onde estes clientes são classificados em dois grupos: adimplentes e inadimplentes. Esses dados foram fornecidos pelo Centro de Pesquisas em Crédito e Banking da Faculdade de Economia e Administração da Universidade de São Paulo.

Esta base de dados possui os seguintes atributos: Profissional liberal, Valor do patrimônio, Limite da proposta, Limite do cartão, Pontos de crédito, Comprometimento da renda, Data de nascimento, Sexo, Estado civil, Atividade principal, Tempo de residência, Tipo de residência, Salário atual, Honorários, Pró-labore e Outros rendimentos.

Em [MEN97] também são apresentados experimentos realizados com RNAs para essa base de dados. 


\subsubsection{Divisão dos conjuntos de dados}

A base de dados de avaliação de crédito é constituída por 5635 registros divididos da seguinte forma: 5414 registros adimplentes $(96,1 \%)$ e 221 registros inadimplentes $(3,9 \%)$.

Este conjunto de dados foi dividido em subconjuntos de treinamento, validação e testes contendo 354, 563 e 563 exemplos, respectivamente. Para utilização pelos algoritmos C4.5, CN2 e TREPAN, foram unidos os conjuntos de treinamento e de validação.

O total de exemplos e a proporção de exemplos adimplentes e inadimplentes em cada subconjunto de dados foi definido como:

- treinamento: 177 adimplentes e 177 inadimplentes, total de 354 exemplos;

- validação: 22 adimplentes e 541 inadimplentes, total de 563 exemplos;

- teste: 22 adimplentes e 541 inadimplentes, total de 563 exemplos.

Como existe uma desigualdade entre o número de classes adimplentes e inadimplentes, foi realizado o particionamento pela menor classe, igualando assim, exemplos pertencentes à classe de exemplos adimplentes no conjunto de treinamento. No entanto, pode-se observar que os conjuntos de validação e teste estão desbalanceados. Esse particionamento foi realizado como em [MEN97]. O desbalanceamento nos conjuntos de validação e testes irá prejudicar a avaliação dos resultados obtidos, como pode ser visto mais adiante.

\subsubsection{Pré-processamento dos dados}

Para os algoritmos C4.5 e CN2, o único pré-processamento exigido foi a formatação dos dados de entrada necessária para cada um dos algoritmos.

Para as RNAs, foi necessária a normalização de atributos numéricos para o intervalo de 0 a 1, adotado também em [MEN97], e codificação de atributos nominais para atributos binários. Os atributos de saída foram codificados, como em [MEN97], da seguinte forma: 
- valor "adimplente": 10 ;

- valor "inadimplente": 01.

\subsubsection{Resultados dos Experimentos}

Os itens a seguir mostram tabelas e figuras ilustrativas dos experimentos realizados com o conjunto de dados de crédito utilizando RNAs e os algoritmos C4.5, CN2 e TREPAN.

\subsubsection{Resultados utilizando C4.5}

A Tabela 16 ilustra os resultados obtidos utilizando o algoritmo C4.5. Essa tabela mostra que a taxa de acertos de exemplos adimplentes foi muito boa nas fases de treinamento e teste. A taxa de acertos dos exemplos inadimplentes foi pior que a taxa de acertos obtida com os exemplos adimplentes. Também pode ser visto, observando o conjunto de testes, que o algoritmo não conseguiu uma generalização muito boa com relação à classe inadimplente. Pode ser observado também, que o desbalanceamento entre as classe no conjunto de testes fez com que as taxas de acentos globais ficassem muito próximas às taxas de acertos obtidas na classe adimplente.

\begin{tabular}{|c|c|c|c|c|c|c|}
\cline { 2 - 7 } \multicolumn{1}{c|}{} & \multicolumn{3}{c|}{ Treinamento } & Teste \\
\hline Partição & Adim. & Inadim. & Global & Adim. & Inadim. & Global \\
\hline 1 & 100,0 & 94,5 & 97,2 & 99,3 & 86,4 & 98,8 \\
2 & 100,0 & 94,0 & 97,0 & 100,0 & 86,4 & 99,5 \\
3 & 100,0 & 93,0 & 96,5 & 100,0 & 90,9 & 99,3 \\
\hline Média & $100,0 \pm 0,0$ & $93,8 \pm 0,8$ & $96,9 \pm 0,4$ & $99,8 \pm 0,4$ & $87,9 \pm 2,6$ & $99,2 \pm 0,4$ \\
\hline
\end{tabular}

A Figura 46 ilustra a Árvore de Decisão gerada pelo algoritmo C4.5 para a partição de desempenho médio. Esta figura mostra uma árvore de tamanho reduzido, e portanto, fácil de ser analisada por um especialista da área. Esta árvore possui 10 nós, 14 folhas e altura 7. 


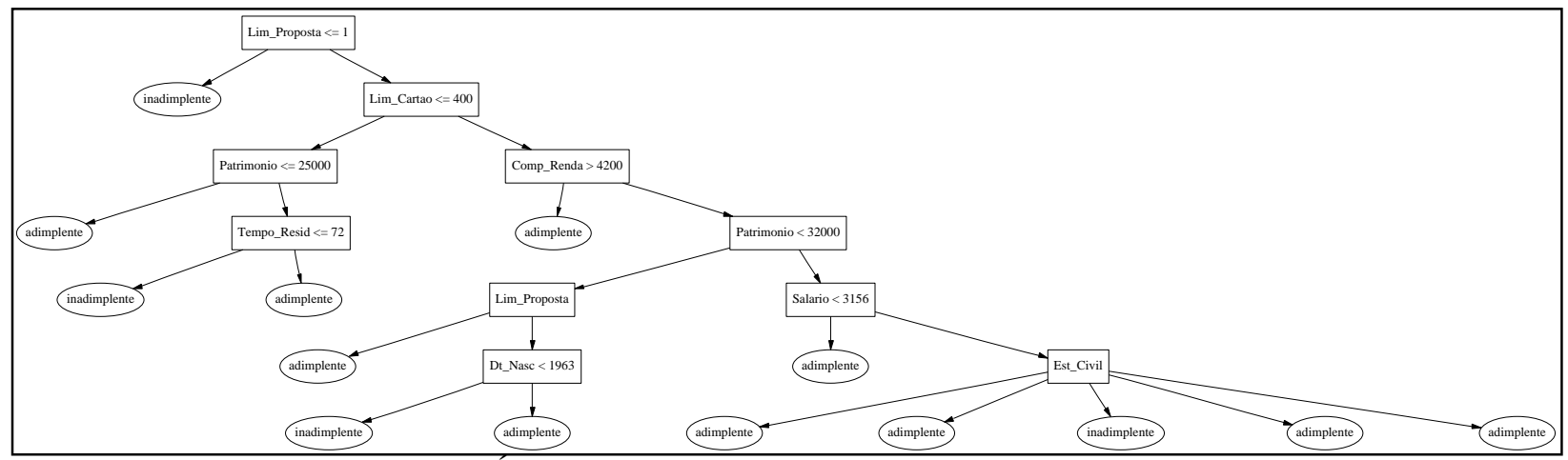

Figura 46: Árvore de Decisão extraída pelo algoritmo C4.5 árvore.

A Tabela 17 mostra os resultados obtidos com a utilização do algoritmo C4.5 regra. Os resultados obtidos foram muito parecidos com os obtidos com o $\mathrm{C} 4.5$ árvore.

\begin{tabular}{|c|c|c|c|c|c|c|}
\cline { 2 - 7 } \multicolumn{1}{c|}{} & \multicolumn{3}{c|}{ Treinamento } & \multicolumn{3}{c|}{ Teste } \\
\hline Partição & Adim. & Inadim. & Global & Adim. & Inadim. & Global \\
\hline 1 & 100,0 & 96,0 & 98,0 & 98,5 & 86,4 & 98,0 \\
2 & 100,0 & 96,0 & 98,0 & 98,5 & 86,4 & 98,0 \\
3 & 99,5 & 94,0 & 96,7 & 99,0 & 90,9 & 98,4 \\
\hline Média & $99,8 \pm 0,3$ & $95,3 \pm 1,2$ & $97,6 \pm 0,8$ & $98,7 \pm 0,3$ & $87,9 \pm 2,6$ & $98,1 \pm 0,2$ \\
\hline
\end{tabular}

Tabela 17: Taxa de acertos alcançada pelo algoritmo C4.5 regra.

A Figura 47 ilustra as regras extraídas pelo algoritmo C5.4 regras. Pode-se observar que estas regras são ainda mais fáceis de serem analisadas que a Árvore de Decisão mostrada na Figura 46. Esta maior facilidades se dá pelo fato de que o algoritmo C4.5 regra extraiu somente 4 regras, incluindo a regra padrão (default).

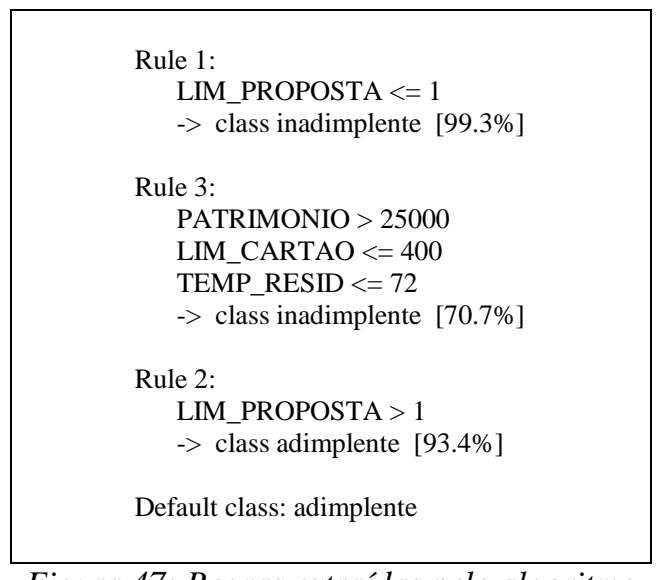

Figura 47: Regras extraídas pelo algoritmo C4.5 regra. 


\subsubsection{Resultados utilizando CN2}

A Tabela 18 mostra os resultados obtidos pelo algoritmo CN2 sobre o conjunto de dados de crédito. Nesta tabela pode ser observado que a taxa de erros, na fase de teste, da classe adimplente foi de aproximadamente 1,5\%. A taxa de erros, na fase de teste, da classe inadimplente foi de aproximadamente $7,5 \%$. Ou seja, a taxa de acertos da classe de adimplentes foi bem maior que a de inadimplentes.

\begin{tabular}{|c|c|c|c|c|c|c|}
\cline { 2 - 7 } \multicolumn{1}{c|}{} & \multicolumn{3}{c|}{ Treinamento } & \multicolumn{3}{c|}{ Teste } \\
\hline Partição & Adim. & Inadim. & Global & Adim. & Inadim. & Global \\
\hline 1 & 100,0 & 95,5 & 97,7 & 98,3 & 96,4 & 97,9 \\
2 & 100,0 & 98,0 & 99,0 & 98,5 & 90,9 & 98,2 \\
3 & 100,0 & 98,0 & 99,0 & 98,5 & 90,9 & 98,2 \\
\hline Média & $100,0 \pm 0,0$ & $97,2 \pm 1,4$ & $98,6 \pm 0,8$ & $98,4 \pm 0,1$ & $92,7 \pm 3,2$ & $98,1 \pm 0,2$ \\
\hline
\end{tabular}

Tabela 18: Taxa de acertos alcançada pelo algoritmo CN2.

A Figura 48 mostra as regras extraídas pelo algoritmo CN2. Nesta figura, pode-se observar que foram extraídas 11 regras, incluindo a regra padrão (default). Embora este seja conjunto de regras pequeno, é maior que o conjunto gerado pelo algoritmo C4.5 regra. Por esse motivo, possui um grau de dificuldade para análise um pouco maior que o conjunto de regras geradas pelo $\mathrm{C} 4.5$ regra.

\begin{tabular}{|c|c|}
\hline IF PT_CREDITOS $>57.50$ & IF PATRIMONIO $<250000.00$ \\
AND V_HONORARIOS $<1000.00$ & AND LIM_PROPOSTA $>150.50$ \\
AND OTROS_REND $<29150.00$ & AND ATIV_PRINC $=$ demais \\
THEN Classe $=$ adimplente [88 0] & THEN Classe $=$ adimplente [59 0] \\
IF LIM_PROPOSTA $>2250.00$ & IF ATIV_PRINC $=$ engenh \\
AND PT_CREDITOS $<73.50$ & THEN Classe $=$ adimplente [5 0] \\
THEN Classe $=$ adimplente [69 0] & IF LIM_PROPOSTA $<150.50$ \\
IF LIM_PROPOSTA $>750.00$ & THEN Classe $=$ inadimplente [0 188] \\
AND LIM_CARTAO $<2250.00$ & IF PATRIMONIO $>37500.00$ \\
AND COMP_RENDA $>4600.00$ & AND PT_CREDITOS $<41.50$ \\
THEN Classe $=$ adimplente [96 0] & THEN Classe $=$ inadimplente [0 42] \\
IF PATRIMONIO $<65000.00$ & IF ATIV_PRINC $=$ serv_est \\
AND LIM_CARTAO $<600.00$ & AND TEMP_RESID $<55.50$ \\
AND PT_CREDITOS $>48.00$ & THEN Classe $=$ inadimplente [0 7] \\
AND TEMP_RESID $>22.00$ & (DEFAULT) adimplente [200 199] \\
THEN Classe $=$ adimplente [23 0] & \\
IF LIM_PROPOSTA $>350.00$ & \\
AND PT_CREDITOS $<69.00$ & \\
AND OTROS_REND $>25000.00$ & \\
THEN Classe $=$ adimplente [39 0] & \\
\hline
\end{tabular}

Figura 48: Conjunto de regras extraídas pelo algoritmo CN2. 


\subsubsection{Resultados utilizando RNAs}

Os experimentos utilizando dados de crédito também foram realizados com a utilização de RNAs do tipo MLP (Mult Layer Percepton)[HAY99] de arquitetura 38-20-8-2. Para o treinamento das redes foi utilizado o algoritmo de atualização de pesos Rprop (Resilient Backpropagation)[RIE93] com 90 ciclos de treinamento. Os experimentos foram implementados no simulador de Redes Neurais SNNS (Sttutgart Neural Network Simulator) [ZEL95].

A Tabela 19 mostra os desempenhos alcançados com a aplicação de RNAs no conjunto de dados de crédito. Essa tabele ilustra que o desempenho conseguido foi praticamente o mesmo alcançado pelo algoritmo $\mathrm{C} 4.5$.

\begin{tabular}{|c|c|c|c|c|c|c|c|c|c|}
\cline { 2 - 9 } \multicolumn{1}{c|}{} & \multicolumn{3}{c|}{ Treinamento } & \multicolumn{3}{c|}{ Validação } & \multicolumn{3}{c|}{ Teste } \\
\hline Part. & Adim. & Inadim. & Global & Adim. & Inadim. & Global & Adim. & Inadim. & Global \\
\hline 1 & 99,4 & 93,2 & 96,3 & 99,2 & 100,0 & 99,3 & 99,8 & 86,3 & 99,2 \\
2 & 99,4 & 93,7 & 96,6 & 98,8 & 95,4 & 98,7 & 98,8 & 81,8 & 98,2 \\
3 & 100,0 & 94,3 & 97,1 & 96,8 & 86,3 & 96,4 & 96,5 & 95,4 & 96,5 \\
\hline Média & $99,6 \pm 0,3$ & $93,7 \pm 0,6$ & $96,7 \pm 0,4$ & $98,3 \pm 1,3$ & $93,9 \pm 7,0$ & $98,1 \pm 1,5$ & $98,4 \pm 1,7$ & $87,8 \pm 6,9$ & $98,0 \pm 1,4$ \\
\hline
\end{tabular}

\subsubsection{Resultados utilizando o algoritmo TREPAN.}

A Tabela 20 mostra o desempenho obtido com a utilização do algoritmo TREPAN no conjunto de dados de crédito. As RNAs utilizadas para a extração de conhecimento são as RNAs mostradas na Tabela 19. Pode-se observar que as taxas de acertos global de todos os algoritmos foram semelhantes. A análise da taxa de acertos em cada classe também mostra que não grandes as diferenças entre os três métodos. Pode ser observado que as médias das taxas de acertos no conjunto de testes das classes adimplentes e inadimplentes estão próximas a 100\% e 89\%, respectivamente. Pode ser observado também que as taxas de acertos globais estão próximas a $100 \%$. Isso se deve ao fato de haver mais exemplos adimplentes que inadimplentes no conjunto de testes. Tomando-se como taxa de acertos globais a média entre as taxas de acertos das classes adimplentes e inadimplentes, a taxa de acertos globais seria próxima de $94 \%$ e não próxima de $100 \%$. 


\begin{tabular}{|c|c|c|c|c|c|c|c|}
\cline { 3 - 7 } \multicolumn{2}{c|}{} & \multicolumn{6}{c|}{ Taxa de acertos (\%) } \\
\cline { 3 - 8 } \multicolumn{2}{c|}{} & \multicolumn{3}{c|}{ Treinamento } & \multicolumn{3}{c|}{ Teste } \\
\hline Método & Partição & Adim. & Inadim. & Global & Adim. & Inadim. & Global \\
\hline \multirow{3}{*}{ seste- } & 1 & 100,0 & 94,0 & 97,0 & 100,0 & 86,4 & 99,5 \\
simples & 2 & 100,0 & 94,0 & 97,0 & 100,0 & 86,4 & 99,5 \\
& 3 & 100,0 & 90,5 & 95,2 & 98,4 & 95,5 & 98,3 \\
\cline { 2 - 8 } & Média & $100,0 \pm 0,0$ & $92,8 \pm 2,0$ & $96,4 \pm 1,0$ & $99,5 \pm 0,9$ & $89,4 \pm 5,2$ & $99,1 \pm 0,7$ \\
\hline \multirow{4}{*}{ disjunt. } & 1 & 100,0 & 94,0 & 97,0 & 100,0 & 86,4 & 99,5 \\
& 2 & 100,0 & 93,0 & 96,5 & 100,0 & 86,4 & 99,5 \\
& 3 & 99,5 & 93,5 & 96,5 & 98,2 & 95,5 & 98,1 \\
\cline { 2 - 8 } m-de-n $n$ & Média & $99,8 \pm 0,3$ & $93,5 \pm 0,5$ & $96,7 \pm 0,3$ & $99,4 \pm 1,0$ & $89,4 \pm 5,2$ & $99,0 \pm 0,8$ \\
\hline & 1 & 100,0 & 93,0 & 96,5 & 100,0 & 86,4 & 99,5 \\
& 2 & 100,0 & 94,0 & 97,0 & 100,0 & 86,4 & 99,5 \\
& 3 & 100,0 & 91,0 & 95,5 & 98,4 & 95,5 & 98,3 \\
\cline { 2 - 7 } & Média & $100,0 \pm 0,0$ & $92,6 \pm 1,5$ & $96,3 \pm 0,0$ & $99,5 \pm 0,9$ & $89,4 \pm 5,2$ & $99,1 \pm 0,7$ \\
\hline
\end{tabular}

A Figura 49, a Figura 50 e a Figura 51 mostram as árvores geradas pelos métodos testesimples, disjuntivo e $m$-de- $n$ do algoritmo TREPAN para a partição de desempenho médio. A árvore gerada pelos métodos teste-simples e disjuntivo são iguais, possuindo 1 nós, 2 folhas e altura 2. A árvore gerada pelo método $m$-de-n possuem 2 nós, 3 folhas e altura 3 . Pode-se notar que as três árvores possuem tamanho reduzido, portanto fáceis de serem analisadas por um especialista. Pode também ser observado que estas árvores trabalham com no máximo 2 atributos, o que também facilita a análise.

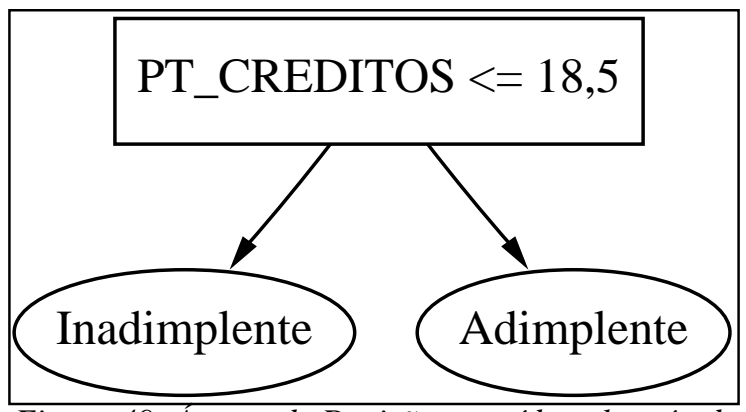

Figura 49: Árvore de Decisão extraída pelo método teste-simples do TREPAN. 


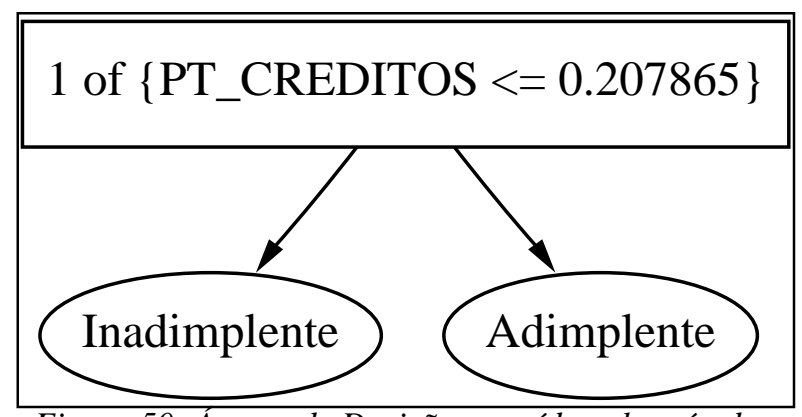

Figura 50: Árvore de Decisão extraída pelo método disjuntivo do TREPAN.

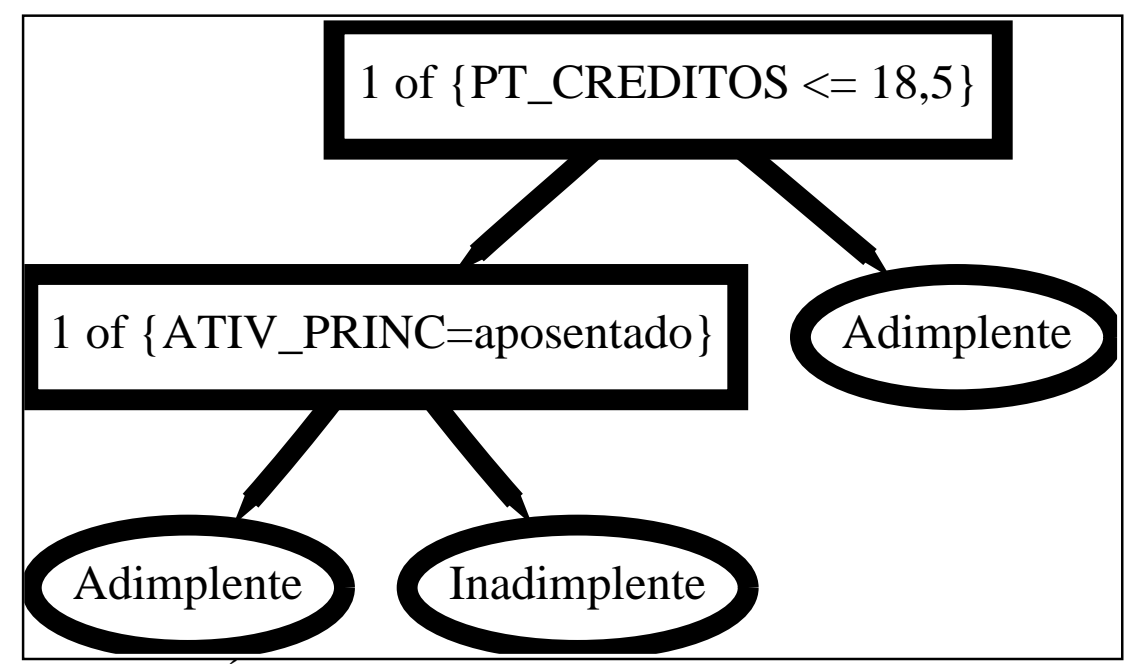

Figura 51: Árvore de Decisão extraída pelo método m-de-n do TREPAN.

\subsubsection{Comparando os resultados}

A Tabela 21 mostra o desempenho alcançado pelas RNAs e pelos algoritmos C4.5, CN2 e TREPAN. Nesta tabela, pode-se observar que todos os algoritmos obtiveram resultados semelhantes. As taxas de erros na fase de treinamento foram de no máximo 3,7\% e na fase de teste foram de no máximo $2 \%$.

\begin{tabular}{|c|c|c|}
\hline Algoritmo & Média do Treinamento & Média do Teste \\
\hline C4.5 árvore & $96,9 \pm 0,4$ & $99,2 \pm 0,4$ \\
\hline C4.5 regra & $97,6 \pm 0,8$ & $98,1 \pm 0,2$ \\
\hline CN2 & $98,6 \pm 0,8$ & $98,1 \pm 0,2$ \\
\hline RNA & $96,7 \pm 0,4$ & $98,0 \pm 1,4$ \\
\hline TREPAN (teste-simples) & $96,4 \pm 1,0$ & $99,1 \pm 0,7$ \\
\hline TREPAN (disjuntivo) & $96,7 \pm 0,3$ & $99,0 \pm 0,8$ \\
\hline TREPAN (m-de- $n$ ) & $96,3 \pm 0,8$ & $99,1 \pm 0,7$ \\
\hline
\end{tabular}

Tabela 21: Desempenho alcançado pelas RNAs e pelos algoritmos C4.5, CN2 e TREPAN. 
A Figura 52 mostra o desempenho por classes das RNAs e dos algoritmos CN2, C4.5 e TREPAN no conjunto de testes. Nesta figura, pode-se observar que o algoritmo CN2 obteve uma maior uniformidade nos dados e a maior taxa de acertos na classe de inadimplentes, apesar de outros métodos conseguirem desempenho global melhor. Pode ser observado também que o desbalanceamento entre classes no conjunto de teste fez com que o desempenho global ficasse bem próximo do desempenho conseguido pela classe adimplente.

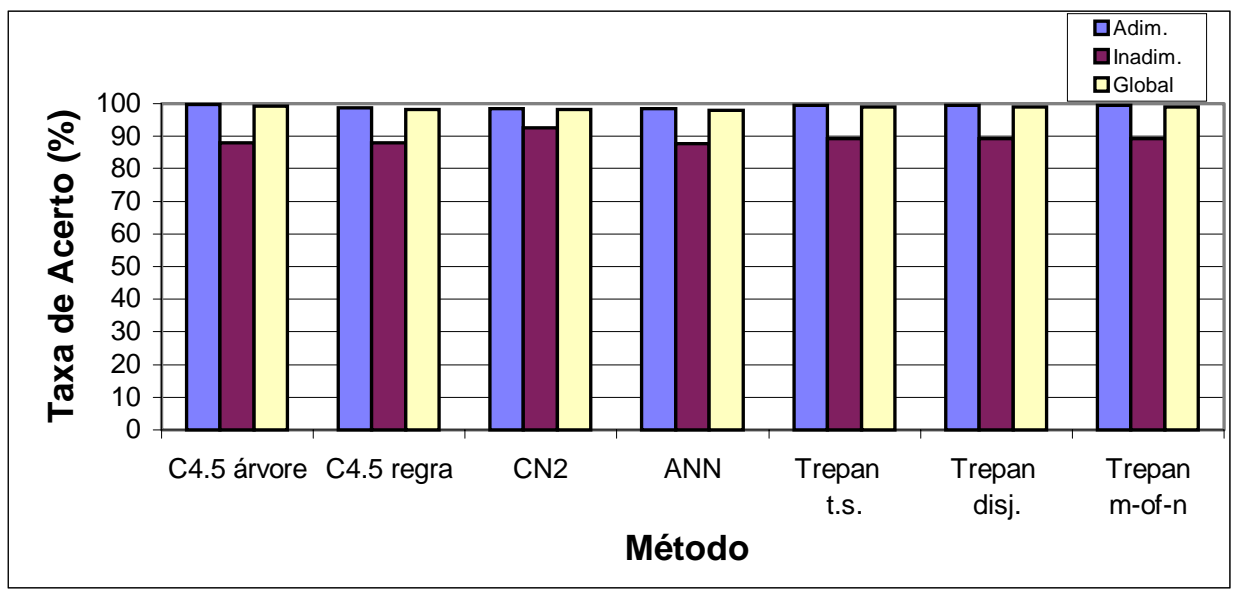

Figura 52: Resultado por classes para as RNAs e para os algoritmos C4.5, CN2, RNA e TREPAN.

Para efeitos de compreensão do conhecimento extraído, o algoritmo C4.5 regra foi muito bem. Como pode ser visto na Figura 47, o algoritmo C4.5 conseguiu um conjunto reduzido de regras, facilitando assim o trabalho de compreensão do conhecimento por um especialista.

Também merece destaque o algoritmo TREPAN, pelas árvores de tamanho reduzidas que foram obtidas. Estas árvores possuem um tamanho menor que a árvore conseguida pelo algoritmo C4.5 árvore e, por esse motivo, são ainda mais fáceis de serem analisadas. 


\subsection{Sumário do Capítulo}

Neste Capítulo foram apresentados experimentos reais envolvendo RNAs e os algoritmos C4.5, CN2 e TREPAN. Foram realizadas comparações entre os métodos de extração de conhecimento simbólicos e conexionistas aplicados à três bases de dados. As seguintes bases de dados foram utilizadas: dados sobre falência de instituições bancárias brasileiras, dados sobre o jogo da velha e dados sobre análise de crédito pessoal do Banco do Estado do Paraná. Foi observado que o algoritmo que obteve melhor desempenho em uma base de dados não foi necessariamente o que obteve o melhor desempenho em outra base de dados.

Neste Capítulo também foi investigada a facilidade de compreensão dos conhecimentos extraídos. Para isso, foi necessário a aplicação de um algoritmo de extração de conhecimento de RNAs, uma vez que o conhecimento armazenado por uma RNA é muito difícil de ser analisado em sua forma original. 


\section{Conclusão}

Neste trabalho foram investigados dois algoritmos para extração de conhecimento de RNAs e dois algoritmos de aprendizado simbólicos para extração de conhecimento. Os experimentos de um dos algoritmos de extração de conhecimento de RNAs, o algoritmo EN, são

apresentados no Apêndice A. É importante que se analise os algoritmos tradicionais de extração de conhecimento de dados, pois, processos similares podem ser aplicados com o objetivo de uma melhor extração de conhecimento de RNAs.

\subsection{Considerações}

O problema de extração de conhecimento de uma RNA treinada é o de interpretar, de uma forma compreensiva, o efeito coletivo dos parâmetros envolvidos na codificação do conhecimento aprendido durante a fase de treinamento. Com a extração de conhecimento de RNAs, é mais fácil mostrar que uma RNA se comporta de acordo com uma determinada especificação.

É cada vez mais claro que o potencial das RNAs não pode ser completamente explorado enquanto não for acrescentado a estes modelos um mecanismo que explique suas decisões.

Em situações de alto risco, como suporte à vôos, auxílio a cirurgias, diagnósticos médicos e processamento de alarmes em usinas hidrelétricas, é imprescindível que seja possível validar a saída de uma RNA sob todas as condições de entrada possíveis. A extração de conhecimento e rastreamento do funcionamento das RNAs poderão acarretar uma popularização de seu uso por ocasionar uma maior confiança e compressão dos resultados obtidos.

As regras extraídas da rede podem ainda ser utilizadas para verificar a adequação da arquitetura escolhida para a aplicação na qual a rede está sendo utilizada e ajudar na redefinição da Rede Neural, caso necessário. 


\subsection{Contribuições deste trabalho}

Nesta dissertação foi realizado um estudo de algumas técnicas de extração de conhecimento baseados em algoritmos simbólicos e extração de conhecimento de RNAs. Foi realizado um estudo comparativo destas técnicas e os resultado apresentados em forma de tabelas e gráficos. Foram investigadas formas alternativas de trabalho com conjuntos de dados contendo poucos casos e conjuntos de dados com grande desbalanceamento entre classes, mas um mínimo razoável de exemplos para a classe minoritária.

Visando melhoria dos resultados para conjuntos de dados contendo desbalanceamento entre classes, foi utilizada a técnica de eliminação de casos pertencentes à classe majoritária. Esta técnica visa o balanceamento entre classes para que o treinamento não se especialize em casos da classe majoritária.

As técnicas de melhoria dos resultados, em conjuntos de dados com poucos casos, utilizadas neste trabalho foram o acréscimo de dados com e sem ruído aos casos da classe minoritária e treinamento por mais alguns ciclos com junção do conjunto de treinamento e validação (no caso das RNAs). Estas duas técnicas foram utilizadas visando o aumento do número de exemplos vistos na fase de treinamento.

Foi observado que não somente o conjunto de treinamento deve ter um balanceamento no número de exemplos pertencente a cada classe. Um conjunto de testes desbalanceado leva a conclusões tomadas com base na classe com maior número de exemplos. Também foi observado que a ajuda de um especialista no trabalho de pré-processamento dos dados é de grande importância para que se consiga bons resultados.

Tornou-se evidente a importância do trabalho de extração de conhecimento de RNAs na obtenção de uma compreensão maior das RNAs. A compreensão do conhecimento armazenado em uma RNA em sua forma original é uma tarefa praticamente impossível de ser realizada. 


\subsection{Proposta para trabalhos futuros}

Neste trabalho foi verificada a existência de uma grande carência de métodos de extração de conhecimento de RNAs. Como proposta de trabalhos futuros, pedem ser citados a melhoria dos algoritmos TREPAN e EN, vistos nesta dissertação.

O algoritmo TREPAN trabalha somente com redes do tipo MLP compretamente conectadas. Este algoritmo pode ser modificado para que outros tipos de redes possam ser trabalhado. Esta inclusão da capacidade de trabalho com outros tipos de redes é uma tarefa perfeitamente possível, bastando para isso, a inclusão de métodos capazes de manipulação de redes com outras arquiteturas. Não é necessário realizar alterações em outras partes do algoritmo, uma vez que o TREPAN não olha a arquitetura interna da rede, somente utiliza a rede como um classificador.

Uma outra melhoria que pode ser feita no TREPAN é a inclusão de procedimentos que levem em conta a arquitetura da RNA. Para isso, é necessário que se faça um estudo da viabilidade do acréscimo destes métodos no TREPAN.

$\mathrm{O}$ algoritmo EN examina somente a arquitetura e as conexões de uma RNA. Uma proposta de melhoria no EN seria a de descobrir os neurônios e as conexões mais importantes através de uma análise envolvendo os dados utilizados durante o treinamento desta RNA. Para isso, a análise que o EN faz sobre os valores dos pesos das conexões deve ser alterada para a análise sobre os pesos das conexões e valores de ativação de cada neurônio.

Fica também como proposta para trabalhos futuros, a utilização de técnicas de limpezas de dados nos conjuntos de dados utilizados. Também seria de grande utilidade a aplicação de outras técnicas de extração de conhecimento de RNAs e aplicação de outros algoritmos simbólicos para extração de conhecimento. 


\section{Referências}

ALM97 ALMEIDA F. C.; SIQUEIRA J. O. Comparação entre Regressão Logística e Redes Neurais na Previsão de Falência de Bancos Brasileiros. Terceiro Congresso Brasileiro de Redes Neurais, Florianópolis, Brasil ,p. 27-32, 1997.

AND95a ANDREWS, R.; DIEDERICH, J.; TICKLE, A. B. A Survey and Critique of Technique for Extracting Rules Form Trained Artificial Neural Networks. Knowledge-Based Systems Journal, v. 8, n. 6, 1995.

AND95b ANDREWS, R.; GEVA, S. RULEX \& CEBP Networks As the Basis for a Rule Refinement System. In: Hybrid Problems Hybrid Solutions, Hallam J.(Ed), IOS Press, p. 1-12, 1995.

AND95c ANDREWS, R.; GEVA, S. Rules and Local Function Networks. Neurocomputing Research Center, Queensland University of Technology, Australia, 1995.

BAT97 BAtista, G. E. A. P. A.; MilarÉ, C. R.; MONARD, M. C. Descrição da Implementação Prolog de uma Ferramenta para Extração de Conhecimento de Redes Neurais. São Carlos ICMC, 1997. (Instituto de Ciências Matemáticas e de Computação - Universidade de São Paulo, Relatório técnico 54)

BEA92 BEALE, R; JACKSON, T. Neural Computing: An Introduction. IOP Publishing Ltd. Philadelphia, USA, 1992.

BLA98 BLAKE, E. K. C.; MERZ, C. UCI repository of machine learning databases, 1998.

BRE84 BREIMAN, L.; OLSHEN, R.; STONE, C. Classification and Regression Trees. Wadsworth and Brooks, Monterey, USA, 1984.

CLA87 CLARK, P.; NIBLET, T. Introduction in Noisy Domain. Proceedings of Second European Machine Learning Conference. Wilmslow, UK, p. 11-30, 1987.

CLA89 CLARK, P.; NIBLET, T. The CN2 Induction Algorithm. Machine Learning Journal. v. 3, n. 4, p. 261-283, 1989.

CLA91 CLARK, P.; BOSWELL, R. Rule Induction with CN2: Some Recent Improvements. Proceedings of Fifth European Conference Machine Learning, p. 151-163, 1991.

CRA94 CRAVEN, M. W.; SHAVLIK, J. W. Using Sampling and Queries to Extract Rules from Trained Neural Networks. Machine Learning: Proceedings of the Eleventh International Conference. San Francisco, USA, 1994. 
CRA96a CRAVEN, M. W. SHAVLIK, J. W. Extracting Tree-Structured Representations of Trained Networks. Advances in Neural Information Processing Systems. Cambridge, USA, v. 8, 1996.

CRA96b CRAVEN, M. W. Extracting Comprehensible Models from Trained Neural Networks. Madison, 1996. 199p. PhD thesis, University of Wisconsin.

FU94 FU, L. Rule Generation from Neural Networks. IEEE Transactions on Systems, Man, and Cybernetics, v. 24, n. 8, p. 1114-1123, August, 1994.

HAY99 HAYKIN, S. Neural Networks - A Comprehensive Foundation. Prentice Hall. Second edition. 1999.

HUN66 HUNT, E. B.; MARIN, J; STONE, P. J. Experiments in Induction. New York: Academic Press. 1966.

MAR97 MARTINELI, E; DINIZ, H; CARVALHO, A. C. P. L. F.; REZENDE, S. O. O problema de falência de bancos usando $\mathrm{CN} 2, \mathrm{C} 4.5$ e redes neurais artificiais. $I V$ Simpósio Brasileiro de Redes Neurais, Goiânia, Brasil, p. 86-88, 1997.

MAR98 MARTINELI, E; DINIZ, H; CARVAlHO, A. C. P. L. F.; REZENDE, S. O. Bankruptcy Prediction Using Connectionist and Symbolic Learning Algorithms. IEEE World Congress on Computational Intelligence, Anchorage, Alaska, USA, p. 271-276, 1998.

MAR99 MARTINELI, E; DINIZ, H; CARVALHO, A. C. P. L. F.; REZENDE, S. O. Comparing connectionist and symbolic models for bankruptcy prediction. Computational Finance, USA, 1999.

MEN97 MENDES FILHO, E. F. Projeto Evolucionário de Redes Neurais Artificiais para Avaliação de Crédito Financeiro. São Paulo, 1997. 85p. Dissertação (Mestrado), Instituto de Ciências Matemáticas de São Carlos, Universidade de São Paulo.

MIC69 MICHALSKI, R. S. On the quasi-minimal solution of the general covering problem. In Proceedings of the $5^{\text {th }}$ international symposium on Information Processing, v. A3 (Switching circuits), Bled, Yugoslavia, p. 125-128, 1969.

MIL90 MILLER, I. FREUND, J.; JOHNSON, R. Probability and Statistics for Engineers. Prentice-Hall Editions. 1990.

MUR91 MURPHY, P. M.; PAZZANI, M. J. ID2-of-3: Constructive induction of M-of-N concepts for discriminators in decision trees. In Proc. Of de $8^{\text {th }}$ International Machine Learning Workshop, p. 183-187, Evanston, IL, Morgan Kaufmann, 1991. 
NOB98 NOBRE, C.; BRAGA, A. P. Extração de conhecimento: uma comparação entre os métodos clássico e conexionista. V Simpósio Brasileiro de Redes Neurais, Belo Horizonte, Brasil, p. 126-131, 1998.

NOB99 NOBRE, C. et al. Knowledge extraction: a comparison between symbolic and connectionist methods. International Journal of Neural Systems, USA, 1999.

PAU92 PAU, L. F.; GÖTZCHE, T. Explanation Facility for Neural Networks. Journal of Intelligent and Robotic Systems, v. 5, p. 193-206, 1992.

PRE94 PRECHELT, L. PROBEN1 - A set of Neural Network Benchmark Problems and Benchmarking Rules. Germany, 1994. (University of Karlsruhe, Technical Report 21)

QUI83 QUINLAN, J. R. Learning efficient classification procedures and their application to chess end games. In J. G. Carbonell, R. S. Michalski, and T. M. Mitchell, editors, Machine Learning, v. 1, Tioga, Palo Alto, USA, 1983.

QUI93 QUINLAND, J. R. C4.5: Programs for Machine Learning. Morgan Kaufmann Publishers. San Mateo, USA, 1993.

RIE93 RIEDMILLER, M.; BRAUN,H. A direct adaptive method for faster backpropagation learning: the rprop algorithm. Proccedings of the IEEE International Conference on Neural Networks, p. 586-591, 1993.

SAC84 SACHS, L. Applied Statistics: A Hardbook of Techniques. Springer-Verlag, New York, $2^{\text {nd }}$ edition, 1984.

SIL86 SILVERMAN, B. Density estimation for statistics and data analysis. Clapman and Hall, New York, 1986.

TOW93 TOWELL, G. G.; SHAVLIK, J. W. Extracting Refined Rules from KnowledgeBased Neural Networks. Machine Learning, v. 13, p. 71-101, 1993.

ZEL95 ZELL, A.; MAMIER, G.; MACHE, M. V. N.; et al. SNNS: Sttutgart Neural Network Simulator User Manual. Version 4.1, Germany, 1995. (Universidade de Sttutgart, Technical Report 6) 


\section{Apêndice A}

\section{Aplicação prática do algoritmo EN}

Este apêndice apresenta uma série de tabelas e figuras ilustrando a aplicação do algoritmo EN à base de dados de falência de bancos brasileiros. As tabelas mostram a sequiência de pesos e neurônios ativados, listados em ordem de importância, para cada critério de seleção de pesos do algoritmo EN. As figuras ilustram graficamente a rede com a seqüência de pesos e neurônios ativados para cada critério de seleção de pesos do algoritmo EN.

A base de dados de falência de bancos brasileiros foi escolhida para ilustrar a aplicação do algoritmo EN pelo fato de apresentar RNAs com arquiteturas menores. Por esse motivo, a análise dos resultados obtidos ficam mais fáceis de serem feitas. Também fica facilitada a apresentação dos neurônios e conexões mais significativos na forma de tabelas e figuras.

Em RNAs do tipo MLP, cada neurônio possui uma conexão independente contendo um peso chamado de bias, como ilustra a Figura 53(a). Para que o bias também seja levado em conta pelo algoritmo EN é necessário que se faça uma operação de eliminação do bias de um neurônio. Essa operação pode ser realizada através da inclusão deste bias nos pesos que chegam ao neurônio. O bias é dividido pelo número de pesos que chegam ao neurônio e o resultado é somado a cada um destes pesos. A eliminação de bias é ilustrada na Figura 53(b).

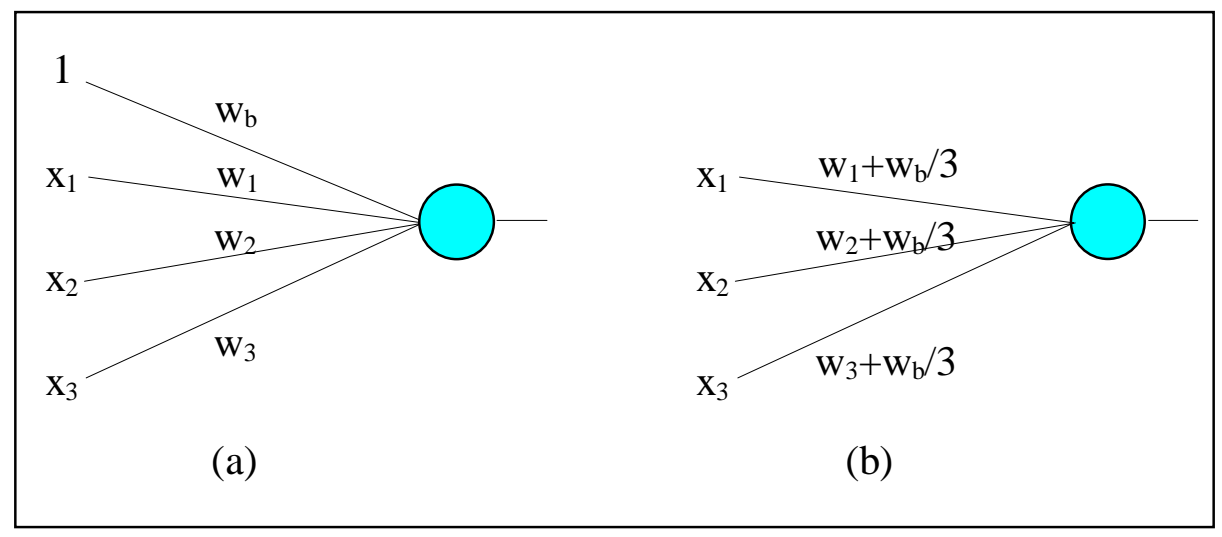

Figura 53: Eliminação do bias de um neurônio. 
A Tabela 22, a Tabela 23, a Figura 54 e a Figura 55 ilustram a aplicação do critério de seleção de pesos soma do EN com o mecanismo de explicação Por que e Com grau de explicação de 0,4. Neste método, é escolhido um neurônio de saída e o método seleciona os neurônios mais significativos nas camadas anteriores até a camada de entrada.

Pode ser observado através da Tabela 22 e Figura 54, que ao ser selecionado o neurônio da camada de saída correspondente à classe de bancos insolventes, foram apontados como neurônios mais significativos na camada de entrada os neurônios correspondentes aos atributos: ativo, capital de giro, custo de intermediação e capitações totais.

Pode ser observado através da Tabela 23 e Figura 55, que ao ser selecionado o neurônio da camada de saída correspondente à classe de bancos solventes, foram apontados como neurônios mais significativos na camada de entrada os neurônios correspondentes aos atributos: ativo, capital de giro, alavancagem e capitações totais.

Conclui-se que os atributos da camada de entrada mais importantes são: ativo, capital de giro, alavancagem, custo de intermediação e capitações totais. Ficam de fora os atributos: comprometimento, custo de pessoal, custo administrativo, geração de rendas e rentabilidade do patrimônio líquido.

\begin{tabular}{|c|c|c|}
\hline Camada & $\begin{array}{c}\text { Soma dos Pesos } \\
\text { (Neurônio, Soma) }\end{array}$ & $\begin{array}{c}\text { Neurônios } \\
\text { Selecionados }\end{array}$ \\
\hline 4 & & 1 \\
\hline 3 & $(2,22.2)$ & 2 \\
\hline 2 & $(3,16.0)(1,5.2)(5,4.7)(2,2.3)$ & $1,5,2,3$ \\
\hline 1 & $(5,8.5)(10,6.7)(2,4.3)(1,3.8)$ & $1,2,10,5$ \\
\hline
\end{tabular}

Tabela 22: Método Por que soma do EN aplicado à classe de bancos insolventes.

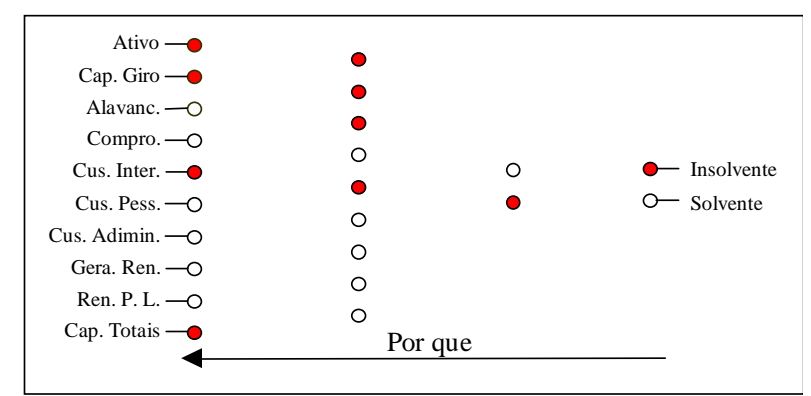

Figura 54: Neurônios selecionados pelo método Por que soma do EN aplicado à classe de bancos insolventes. 


\begin{tabular}{|c|c|c|}
\hline Camada & $\begin{array}{c}\text { Soma dos Pesos } \\
\text { (Neurônio, Soma) }\end{array}$ & $\begin{array}{c}\text { Neurônios } \\
\text { Selecionados }\end{array}$ \\
\hline 4 & & 2 \\
\hline 3 & $(1,16.9)$ & 1 \\
\hline 2 & $(5,74.1)(7,12.3)(9,1.5)(4,0.7)$ & $4,9,7,5$ \\
\hline 1 & $(2,3.5)(3,3.1)(10,1.8)(1,1.3)$ & $1,10,3,2$ \\
\hline
\end{tabular}

Tabela 23: Método Por que soma do EN aplicado à classe de bancos solventes.

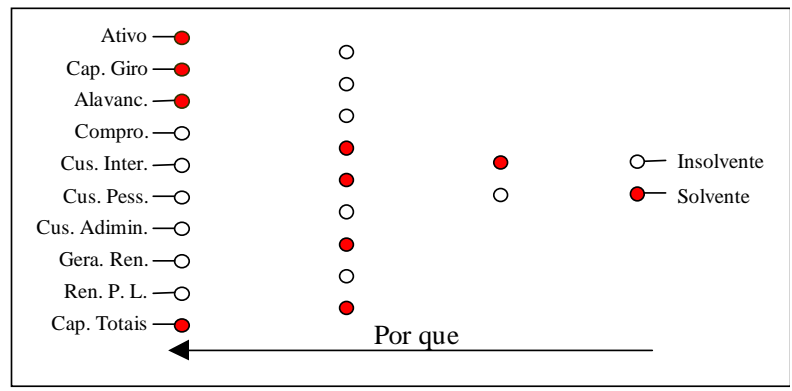

Figura 55: Neurônios selecionados pelo método Por que soma do EN aplicado à classe de bancos solventes.

A Tabela 24, a Tabela 25, a Figura 56 e a Figura 57 apresentam a aplicação do método ccg do EN com o mecanismo de explicação porque e com grau de explicação de 0,4 . Neste método, é escolhido um neurônio de saída e o método seleciona as conexões e neurônios mais significativos nas camadas anteriores até a camada de entrada.

Pode ser observado que os mesmos atributos de entrada foram apontados como mais significativos em ambas as seleções na camada de saída. Primeiro na seleção do neurônio correspondente à classe de bancos insolventes e posteriormente na seleção do neurônio correspondente à classe de bancos solventes. A diferença existente entre estas duas seleções realizadas foi a sequiência de ativação de pesos e neurônios intermediários. Foram apontados como atributos mais significativos na camada de entrada: ativo, capital de giro, alavancagem., custo de intermediação, custo de pessoal, custo administrativo, rentabilidade do patrimônio líquido, captações totais. Ficam de fora os atributos: geração de rendas e capitações totais.

\begin{tabular}{|c|c|c|}
\hline Camada & $\begin{array}{c}\text { Pesos Selecionados } \\
\text { (Orig., Dest., Peso) }\end{array}$ & $\begin{array}{c}\text { Neurônios } \\
\text { Selecionados }\end{array}$ \\
\hline 4 & & 1 \\
\hline 3 & $(2,1,22.2)$ & 2 \\
\hline 2 & $(3,2,16.0)(1,2,5.2)(5,2,4.7)(2,2,2.3)$ & $2,5,1,3$ \\
\hline 1 & $(10,2,7.2)(1,5,5.2)(2,5,3.8)(5,1,3.1)(5,3,2.7)(5,5,2.1)$ & $5,1,6,3,7,9,2,10$ \\
& $(3,1,1.4)(2,1,1.3)(9,3,0.9)(7,5,0.9)(7,2,0.8)(7,3,0.8)$ & \\
& $(3,3,0.7)(6,5,0.6)(1,3,0.5)(5,2,0.5)$ & \\
\hline
\end{tabular}

Tabela 24: Método Por que ccg do EN aplicado à classe de bancos insolventes. 


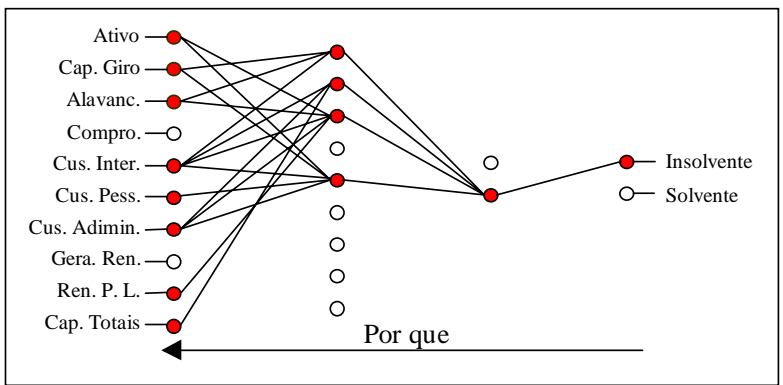

Figura 56: Neurônios e conexões selecionados pelo método

Por que ccg do EN aplicado à classe de bancos insolventes.

\begin{tabular}{|c|c|c|}
\hline Camada & $\begin{array}{c}\text { Pesos Selecionados } \\
\text { (Orig., Dest., Peso) }\end{array}$ & $\begin{array}{c}\text { Neurônios } \\
\text { Selecionados }\end{array}$ \\
\hline 4 & $(1,2,16.9)$ & 2 \\
\hline 3 & $(5,1,74.1)(7,1,12.3)(9,1,1.6)(4,1,0.7)$ & 1 \\
\hline 2 & $(1,5,5.2)(1,7,4.8)(2,5,3.8)(2,4,2.8)(3,4,2.4)(5,5,2.1)$ & $4,9,7,5$ \\
\hline 1 & $(10,4,1.2)(2,9,0.9)(7,5,0.9)(3,7,0.6)(6,5,0.6)(6,7,0.4)$ & $10,8,6,3,7,2,5,1$ \\
& $(10,9,0.4)(8,4,0.4)(8,5,0.3)(10,5,0.3)$ & \\
\hline
\end{tabular}

Tabela 25: Método Por que ccg do EN aplicado à classe de bancos solventes.

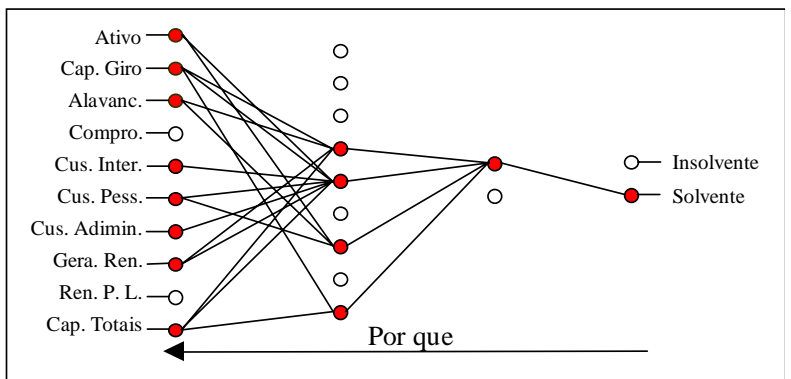

Figura 57: Neurônios e conexões selecionados pelo método

Por que ccg do EN aplicado à classe de bancos solventes.

A Tabela 26, a Tabela 27, a Figura 58 e a Figura 59 ilustram a aplicação do método pau do EN com o mecanismo de explicação porque e com grau de explicação de 0,4. Neste método, é escolhido um neurônio de saída e o método seleciona as conexões e neurônios mais significativos nas camadas anteriores até a camada de entrada.

Pode ser observado que ambas as seleções de neurônios na camada de saída resultaram na mesma seqüência de ativação de neurônios e conexões, mudando somente as conexões existentes na ultima camada. Foram apontados como atributos mais significativos: ativo, capital de giro, alavancagem., comprometimento, custo de intermediação, custo de pessoal, custo administrativo, geração de rendas e rentabilidade do patrimônio líquido. Somente captações totais não foi escolhido. 


\begin{tabular}{|c|c|c|}
\hline Camada & $\begin{array}{c}\text { Pesos Selecionados } \\
\text { (Orig., Dest., Peso) }\end{array}$ & $\begin{array}{c}\text { Neurônios } \\
\text { Selecionados }\end{array}$ \\
\hline 4 & $(2,1,22.2)$ & 1 \\
\hline 3 & $(3,2,16.0)(6,2,-8.5)(7,2,-6.6)(1,2,5.2)$ & 2 \\
\hline 2 & $(5,6,5.2)(1,7,4.8)(2,7,-4.1)(8,6,-3.2)(5,1,3.1)(7,6,3.1)$ & $2,6,9,3,1,4,5,7,8$ \\
& $(5,3,2.7)(4,7,-2.7)(4,1,-1.8)(2,6,1.7)(1,1,-1.7)$ & \\
& $(6,1,-1.5)(3,1,1.4)(9,6,1.4)(6,6,1.3)(2,1,1.3)$ & \\
\hline
\end{tabular}

Tabela 26: Método Por que pau do EN aplicado à classe de bancos insolventes.

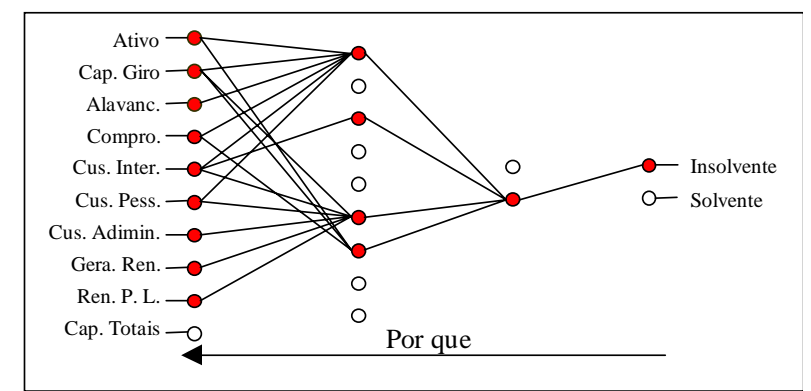

Figura 58: Neurônios e conexões selecionados pelo método

Por que pau do EN aplicado à classe de bancos insolventes.

\begin{tabular}{|c|c|c|}
\hline Camada & $\begin{array}{c}\text { Pesos Selecionados } \\
\text { (Orig., Dest., Peso) }\end{array}$ & $\begin{array}{c}\text { Neurônios } \\
\text { Selecionados }\end{array}$ \\
\hline 4 & $(2,2,-22.2)$ & 2 \\
\hline 3 & $(3,2,16.0)(6,2,-8.5)(7,2,-6.6)(1,2,5.2)$ & 2 \\
\hline 2 & $(5,6,5.2)(1,7,4.8)(2,7,-4.1)(8,6,-3.2)(5,1,3.1)(7,6,3.1)$ & $2,6,9,3,1,4,5,7,8$ \\
& $(5,3,2.7)(4,7,-2.7)(4,1,-1.8)(2,6,1.7)(1,1,-1.7)$ & \\
\hline 1 & $(6,1,-1.5)(3,1,1.4)(9,6,1.4)(6,6,1.3)(2,1,1.3)$ & \\
\hline
\end{tabular}

Tabela 27: Método Por que pau do EN aplicado à classe de bancos solventes.

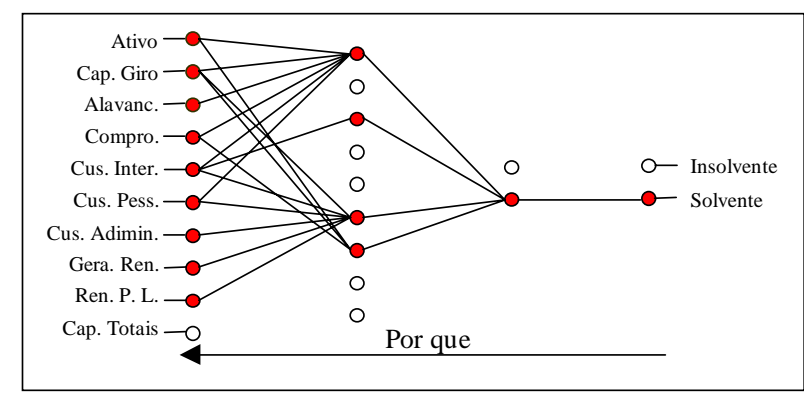

Figura 59: Neurônios e conexões selecionados pelo método

Por que pau do EN aplicado à classe de bancos solventes.

A Tabela 28 e a Figura 60 ilustram a aplicação do método soma do EN com o mecanismo de explicação como e com grau de explicação de 0,4 . Neste método, são escolhidos um conjunto de neurônios de entrada e o método seleciona os neurônios mais significativos nas camadas posteriores até a camada de saída. Simulando-se a ativação de todos os neurônios de entrada foi apontado como neurônio ativo na saída o neurônio correspondente à classe de bancos insolventes. 


\begin{tabular}{|c|c|c|}
\hline Camada & $\begin{array}{c}\text { Soma dos Pesos } \\
\text { (Neurônio, Soma) }\end{array}$ & $\begin{array}{c}\text { Neurônios } \\
\text { Selecionados }\end{array}$ \\
\hline 1 & & $1,2,3,4,5,6,7,8,9,10$ \\
\hline 2 & $(8,11.3)(6,9.7)(2,8.5)(3,3.6)$ & $3,2,6,8$ \\
\hline 3 & $(2,10.7)$ & 2 \\
\hline 4 & $(1,22.2)$ & 1 \\
\hline
\end{tabular}

Tabela 28: Método Como soma do EN aplicado às entradas.

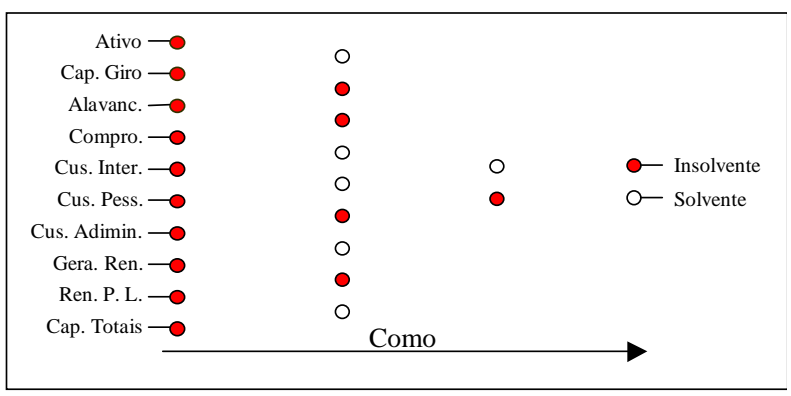

Figura 60: Neurônios selecionados pelo método Como soma do EN aplicado às entradas.

A Tabela 29 e a Figura 61 mostram a aplicação do método $c c g$ do EN com o mecanismo de explicação como e com grau de explicação de 0,4 . Neste método, são escolhidos um conjunto de neurônios de entrada e o método seleciona as conexões e neurônios mais significativos nas camadas posteriores até a camada de saída. Simulando-se a ativação de todos os neurônios de entrada foi apontado como neurônio ativo na saída o neurônio correspondente à classe de bancos insolventes.

\begin{tabular}{|c|c|c|}
\hline Camada & $\begin{array}{c}\text { Pesos Selecionados } \\
\text { (Orig., Dest., Peso) }\end{array}$ & $\begin{array}{c}\text { Neurônios } \\
\text { Selecionados }\end{array}$ \\
\hline 1 & & $1,2,3,4,5,6,7,8,9,10$ \\
\hline 2 & $(10,2,7.2)(5,6,5.2)(1,5,5.2)(1,7,4.8)(9,8,4.2)(2,5,3.8)$ & $5,3,9,6,8,4,1,7,2$ \\
& $(1,8,3.6)(5,1,3.1)(7,6,3.1)(5,8,2.9)(2,4,2.8)(5,3,2.7)$ & \\
& $(3,4,2.4)(5,5,2.1)(2,6,1.7)(4,8,1.6)(3,1,1.4)(9,6,1.3)$ & \\
& $(6,6,1.3)(2,1,1.3)(10,4,1.2)(7,8,1.2)(6,8,1.1)(3,6,0.9)$ & \\
\hline 3 & $(2,9,0.9)(9,3,0.9)(7,5,0.9)$ & 2,1 \\
\hline 4 & $(5,1,74.1)(3,2,16.0)(7,1,12.3)(1,2,5.2)(5,2,4.7)$ & 1 \\
\hline
\end{tabular}

Tabela 29: Método Como ccg do EN aplicado às entradas. 


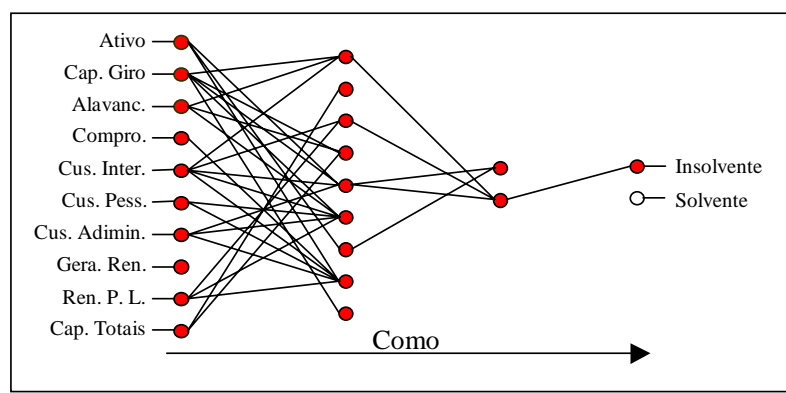

Figura 61: Neurônios selecionados pelo método Como ccg do EN aplicado às entradas.

A Tabela 30 e a Figura 62 mostram a aplicação do método pau do EN com o mecanismo de explicação como e com grau de explicação de 0,4 . Neste método, são escolhidos um conjunto de neurônios de entrada e o método seleciona as conexões e neurônios mais significativos nas camadas posteriores até a camada de saída. Simulando-se a ativação de todos os neurônios de entrada foi apontado como neurônio ativo na saída o neurônio correspondente à classe de bancos solventes.

\begin{tabular}{|c|c|c|}
\hline Camada & $\begin{array}{c}\text { Pesos Selecionados } \\
\text { (Orig., Dest., Peso) }\end{array}$ & $\begin{array}{c}\text { Neurônios } \\
\text { Selecionados }\end{array}$ \\
\hline 1 & & $1,2,3,4,5,6,7,8,9,10$ \\
\hline 2 & $(4,5,-12.8)(10,2,7.1)(1,4,-5.8)(5,6,5.2)(1,5,5.1)$ & $4,8,1,6,5,7,3,9,2$ \\
& $(1,7,4.8)(9,8,4.2)(2,7,-4.1)(2,5,3.8)(1,8,3.6)(8,6,-3.1)$ & \\
& $(5,1,3.1)(7,6,3.1)(5,8,2.9)(1,9,-2.8)(2,4,2.8)(5,3,2.7)$ & \\
& $(4,7,-2.7)(5,4,-2.5)(3,4,2.4)(2,8,-2.2)(5,5,2.1)(4,1,-1.7)$ & \\
\hline 3 & $(2,6,1.7)(1,1,-1.6)(4,8,1.5)(6,4,-1.5)$ & 2,1 \\
\hline 4 & $(5,1,74.1)(3,2,16.0)(7,1,12.3)(6,2,-8.5)(7,2,-6.5)$ & 2 \\
\hline
\end{tabular}

Tabela 30: Método Como pau do EN aplicado às entradas.

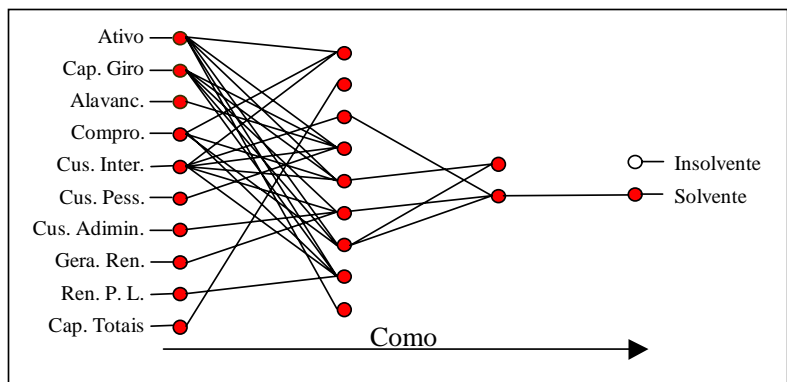

Figura 62: Neurônios selecionados pelo método Como pau do EN aplicado às entradas. 